Florida International University FIU Digital Commons

$12-7-2016$

\title{
Design and synthesis of novel Azasteroids and Pseudoazulenyl nitrones
}

Nagaraju Birudukota

nbiru001@fiu.edu

DOI: $10.25148 /$ etd.FIDC001734

Follow this and additional works at: https://digitalcommons.fiu.edu/etd

Part of the Biochemistry Commons, and the Organic Chemistry Commons

\section{Recommended Citation}

Birudukota, Nagaraju, "Design and synthesis of novel Azasteroids and Pseudoazulenyl nitrones" (2016). FIU Electronic Theses and Dissertations. 3262.

https://digitalcommons.fiu.edu/etd/3262 


\section{FLORIDA INTERNATIONAL UNIVERSITY}

Miami, Florida

\section{DESIGN AND SYNTHESIS OF NOVEL AZASTEROIDS AND PSEUDOAZULENYL NITRONES}

A dissertation submitted in partial fulfillment of

the requirements for the degree of

DOCTOR OF PHILOSOPHY

in

CHEMISTRY

by

Nagaraju Birudukota 
To: Dean Michael R. Heithaus

College of Arts, Sciences and Education

This dissertation, written by Nagaraju Birudukota, and entitled Design and Synthesis of Novel Azasteroids and Pseudoazulenyl Nitrones, having been approved in respect to style and intellectual content, is referred to you for judgment.

We have read this dissertation and recommend that it be approved.

$\begin{array}{r}\hline \text { Stanislaw F. Wnuk } \\ \hline \text { Kevin O'Shea } \\ \hline \text { Anthony P. DeCaprio } \\ \hline \text { Richard A. Bone } \\ \hline \text { David A. Becker, Major Professor }\end{array}$

Date of Defense: December 7, 2016

The dissertation of Nagaraju Birudukota is approved.

Dean Michael R. Heithaus College of Arts, Sciences and Education

Andrés G. Gil Vice President for Research and Economic Development and Dean of the University Graduate School

Florida International University, 2017 


\section{DEDICATION}

This study is dedicated, with love and affection, to my beloved parents, brothers and my wife whose love and prayers have always been a great source of inspiration. 


\section{ACKNOWLEDGMENT}

I would like to thank my mentor Dr. David A. Becker for his direction, advice and freedom throughout these past five years. I would also like to thank my dissertation committee members for their guidance, service and support. I am greatly thankful to Dr. Stanislaw Wnuk, Dr. Kevin O'Shea for providing support as committee members and for teaching chemistry as teachers in my course work. You have been some of the most challenging and effective teachers I have known. I would also like to extend my gratitude to the professors who taught me chemistry, all other people in the department and Dr. Watson Lees for providing me valuable information as graduate program director. I also want to thank Department of Chemistry and Biochemistry at Florida International University for providing me teaching assistantship throughout my doctoral studies.

I would like to give special thanks to Dr. Wnuk's former and present group members Ramanjaneyulu Rayala, Mukesh Mudgal, Jessica Zayas, Yong Liang, Cesar Gonzalez and my lab mate Gloria Perez for their unconditional help at any time. I would like to use this opportunity to thank my friends who gave me moral support to reach this position: Nagaraju Dodla, Kishore Thalluri, Subhramanyam Kalaga, Revanth Redla and a special thanks to my cousin Vanaja Birudukota for being with me when I needed most.

Most importantly, I would like to thank my parents for their unconditional love and hard work to support throughout my life. There is nothing to compare in this world for your love and scarifies you made in your life for your children. Finally, I would love to thank

my lovable wife Divya Prasanna Barnikalla for being with me all the time and eagerly waiting for my $\mathrm{PhD}$ without any intolerance. 


\title{
ABSTRACT OF THE DISSERTATION \\ DESIGN AND SYNTHESIS OF NOVEL AZASTEROIDS AND PSEUDOAZULENYL NITRONES
}

\author{
by \\ Nagaraju Birudukota \\ Florida International University, 2016 \\ Miami, Florida \\ Professor David A. Becker, Major Professor
}

Steroids are one of the essential classes of bioactive compounds and are involved in many biological functions which include their role as signaling compounds, the alteration of membrane fluidity and the regulation of a variety of metabolic processes. In order to identify novel compounds with beneficial pharmacological action, the synthesis of modified steroids is gaining much attention in recent years. Among those analogs, azasteroids are one of the most important classes which display a variety of biological activities, often free from undesirable side effects. The challenges in the synthesis of steroids, particularly azasteroids, and the potential of azasteroids as novel drugs has prompted numerous investigations in this field. The synthetic methods leading to steroidal derivatives (azasteroids) with one or more nitrogen atoms are very limited. Generally, oxidative cleavage of the steroidal rings is needed to introduce nitrogen atom(s) in order to synthesize azasteroids.

In the first part of this dissertation, explorations into the synthetic methods needed for making a new steroidal A-ring or seco A-ring on a tricyclic benz[ $e$ ]indenedione (a dimer 
compound obtained in connection with continued work on the study of anhydrobases of the isoxazole series) were pursued. In this process, a series of three tricyclic hydrazone compounds have been designed and synthesized to mimic the tetracyclic rigid core structure of azasteroids. We are eager to ascertain if these compounds possesses any interesting biological properties.

In continued research on the synthesis of azulenyl and pseudoazulenyl nitrones, (to target ROS generation at the site of mitochondria), the second part of this research was aimed at the synthesis of cationic pseudoazulenyl nitrones with mitochondriotropic properties. Several pseudoazulenyl nitrone derivatives were synthesized using the natural compound valtrate, obtained from the roots of Centranthus ruber. Unfortunately, the attempts made to convert these compounds into the corresponding cationic pseudoazulenyl nitrones failed. However, an interesting pseudoazulenyl dinitrone molecule bearing an imidazole group was prepared. Also, a pseudoazulenyl mono nitrone compound with an electron donating group was synthesized by leaving a highly reactive aldehyde functionality intact for further use in synthetic study. 


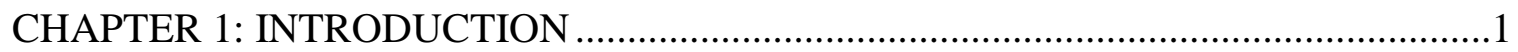

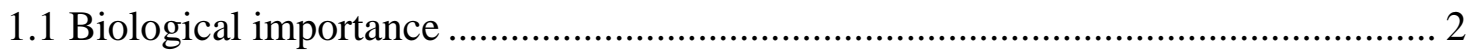

1.1.1 Benign prostatic hyperplasia (BPH) and $5 \alpha$-reductase inhibitors ........................ 3

1.1.2 Azasteroids as Selective androgen receptor modulators (SARMs) ....................... 5

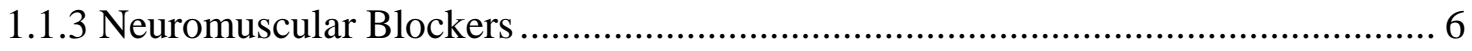

1.1.4 Aminosteroid or Azasteroid neuromuscular blockers ........................................... 9

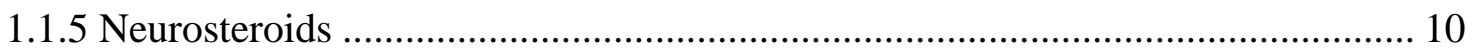

1.1.6 Anticancer and some biologically active heterosteroids ..................................... 13

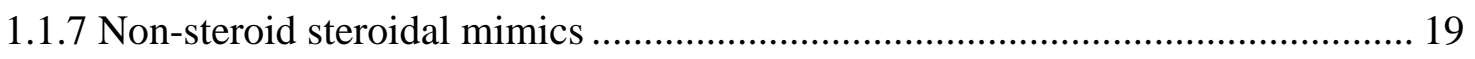

1.2 Previous synthetic efforts reported on azasteroids ............................................... 21

1.2.1 Ring contraction-expansion strategy by using Beckmann rearrangement ........... 21

1.2.2 Ring opening and closing strategy by using oxidative cleavage......................... 22

1.2.3 A combinatorial one step approach............................................................... 23

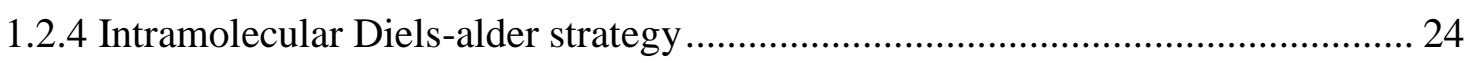

1.2.5 Electrocylization involving Stille and Heck coupling ……................................ 25

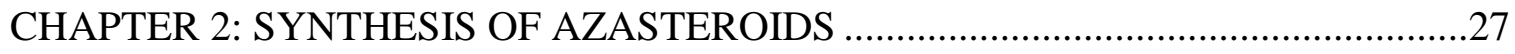

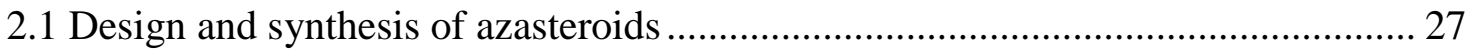

2.1.1 One-pot pyridazinone formation method from ketones ....................................... 29

2.1.2 Hydrazone formation methods .................................................................... 31

2.1.3 Attempts to activate the benzylic ketone moiety ................................................. 32

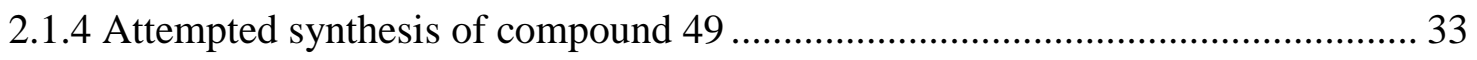

2.1.5 Hydrazone formation using 4-amino-4H-1,2,4-triazole...................................... 35

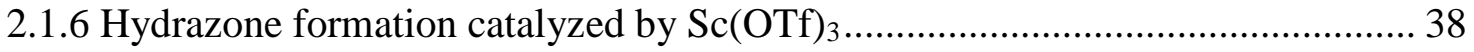

2.2 Conclusion regarding azasteroidal synthesis..................................................... 41 


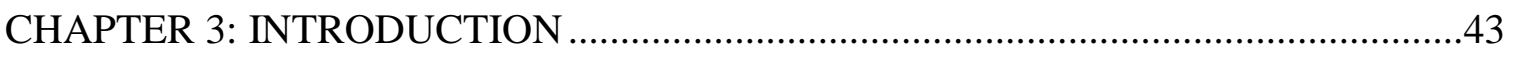

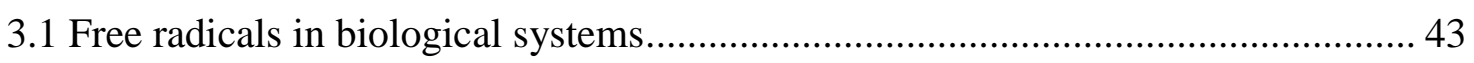

3.1.1 Generation of reactive oxygen species (ROS) in the human body ...................... 44

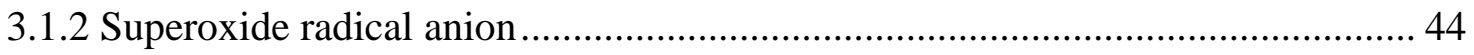

3.1.3 Secondary free radicals ............................................................................. 47

3.1.4 Reactive nitrogen species (RNS) ................................................................. 48

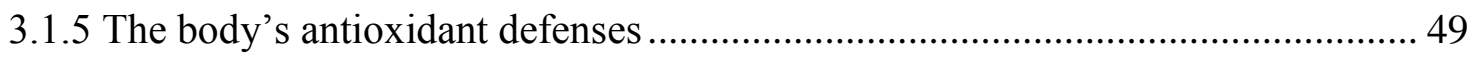

3.1.6 Pathological conditions caused by free radicals ................................................ 50

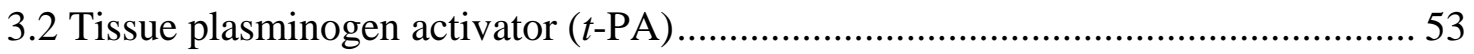

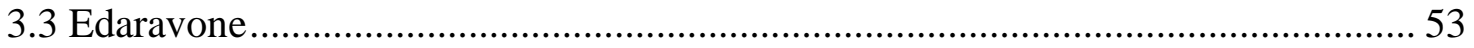

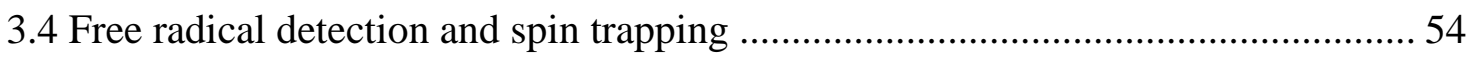

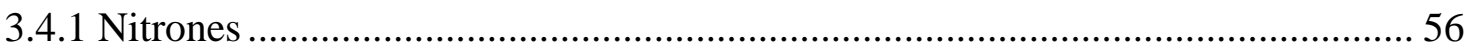

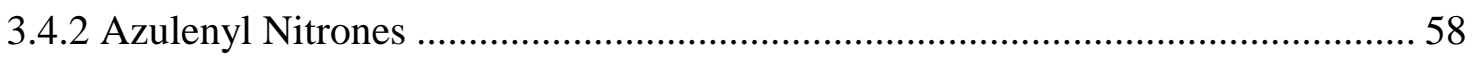

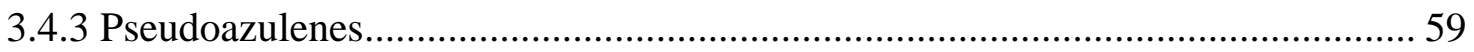

CHAPTER 4: SYNTHESIS OF PSEUDOAZULENYL NITRONES ...............................61

4.1 Design and synthetic efforts of pseudoazulenyl nitrones......................................... 61

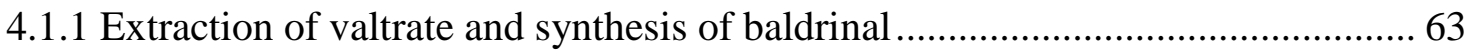

4.1.2 Synthesis of pseudoazulenyl dicarbaldehyde with imidazole side chain ............. 64

4.1.3 Synthesis of pseudoazulenyl mono and dinitrones ............................................. 65

4.1.4 Attempts at making pseudoazulenyl dinitrone salts and Girard's reagent

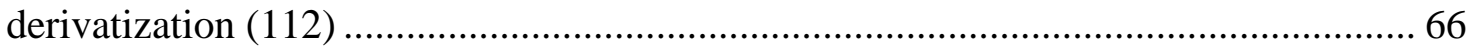

4.2 Conclusion regarding pseudoazulenyl nitrones synthesis ...................................... 67

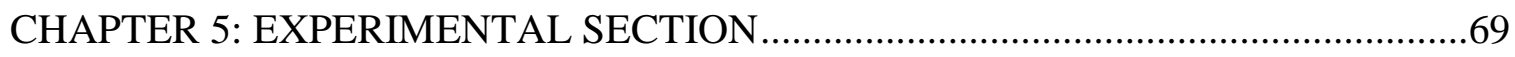

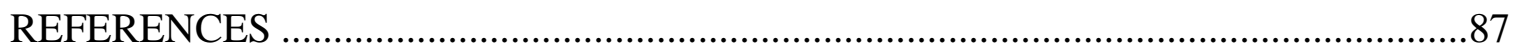

VITA 103 


\section{LIST OF FIGURES}

FIGURE

PAGE

Figure 1. Examples of biologically active azasteroids........................................... 1

Figure 2. Conversion of testosterone to DHT.............................................................. 4

Figure 3. Selective androgen receptor modulators (SARMs) of azasteroids.................... 6

Figure 4. Structures of acetylcholine and Succinylcholine............................................. 7

Figure 5. Non-depolarizing neuromuscular blocking agent, Tubocurarine. ..................... 8

Figure 6. Azasteroidal neuromuscular blockers.................................................. 9

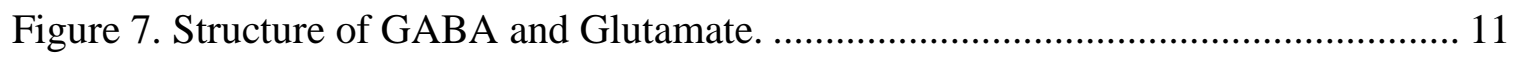

Figure 8. GABA and glutamatergic neurotransmitters/ neurosteroids. ........................ 11

Figure 9. Benz[e]indenes and selective antagonists of neurosteroids........................... 12

Figure 10. Anticancer and some of the biologically active azasteroids........................ 13

Figure 11. Structure of danazol and stanozolol. ................................................... 14

Figure 12. Structures of Abiraterone and cardinolides. .......................................... 15

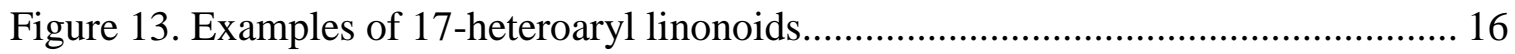

Figure 14. Structures of triterpenoids, KHF16 and cucurbitacin E. .............................. 17

Figure 15. Anticancer compounds isolated from Cimicifuga..................................... 17

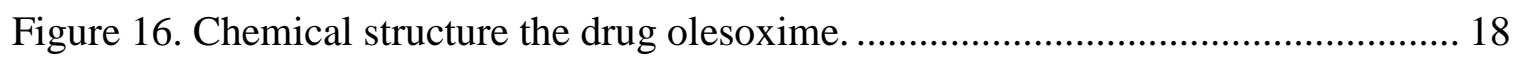

Figure 17. Structures of antitumor cephalostatin series.......................................... 19

Figure 18. Non-steroidal selective androgen receptor modulators. .............................. 20

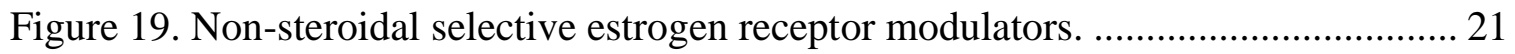


Figure 20. Structures of novel azasteroid and azasteroidal mimics

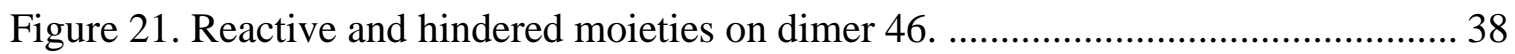

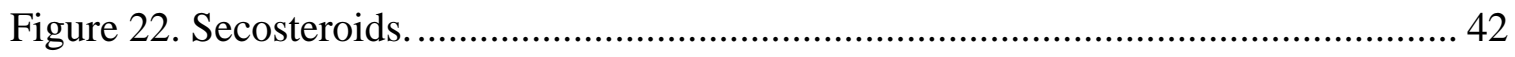

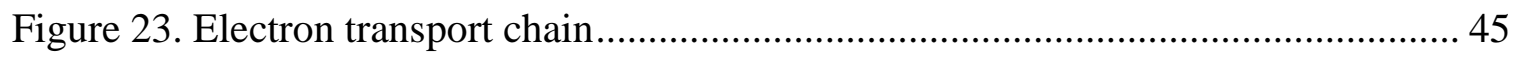

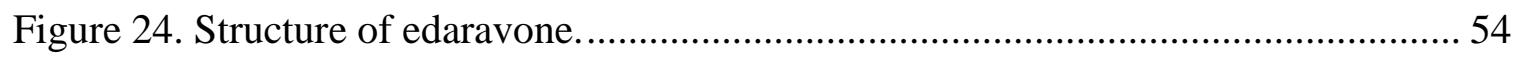

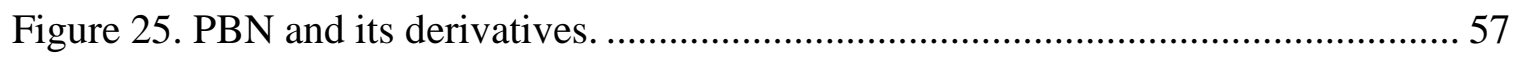

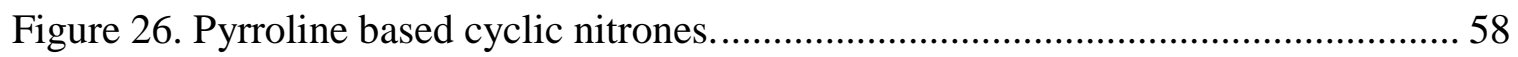

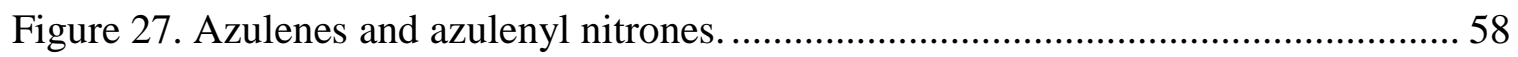

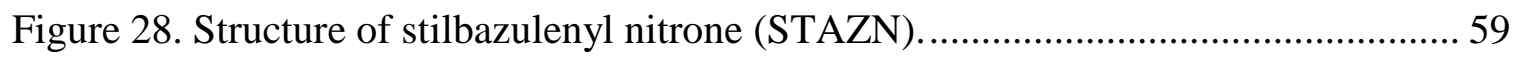

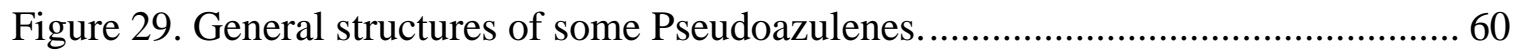

Figure 30. Structures of designed pseudoazulenyl nitrones..................................... 61

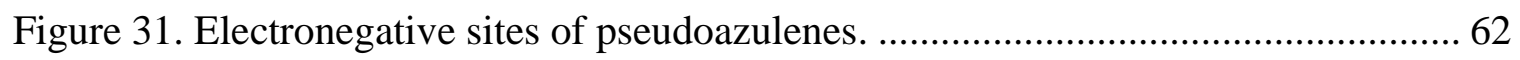




\section{LIST OF SCHEMES}

SCHEME

PAGE

Scheme 1: Ring contraction and expansion strategy in azasteroidal synthesis. 22

Scheme 2: Ring opening and closing strategy in azasteroidal synthesis. 23

Scheme 3: One step approach in azasteroidal synthesis. 23

Scheme 4: Intramolecular Diels-alder strategy-1 in azasteroidal synthesis. 24

Scheme 5: Intramolecular Diels-alder strategy-2 in azasteroidal synthesis. 25

Scheme 6: Electrocyclization strategy in azasteroidal synthesis. 26

Scheme 7: Synthesis of tricyclic benz[e]indenedione (Dimer, 46).............................. 27

Scheme 8: Pyridazinone formation reaction on 1-tetralone and dimer........................... 30

Scheme 9: Second attempt of making Pyridazinone on dimer. ................................... 30

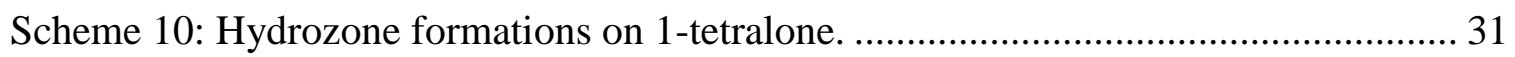

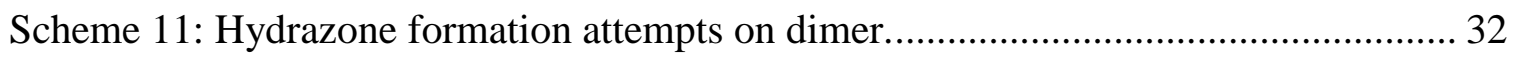

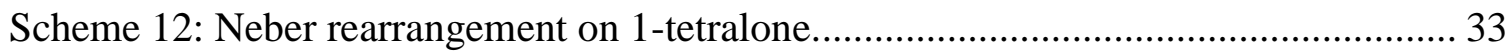

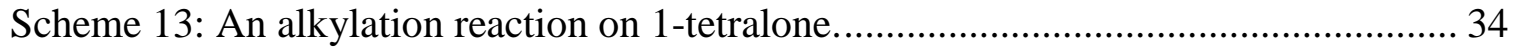

Scheme 14: Horner-Wadsworth-Emmons reaction on 1-tetralone............................... 34

Scheme 15: Enolization reaction of 1-tetralone......................................................... 35

Scheme 16: Hydrazone formation employing 4-amino-4H-1,2,4-triazole moiety on 1tetralone. 35

Scheme 17: Hydrazone formation attempts using 4-amino-4H-1,2,4-triazole on dimer.. 37

Scheme 18: Attempted hydrazone formation between 5,8-dimethyl-1-tetralone \& 4amino-4H-1,2,4-triazole. 
Scheme 19: Scandium triflate catalyzed hydrazonation of 5,8-dimethyl-1-tetralone....... 39

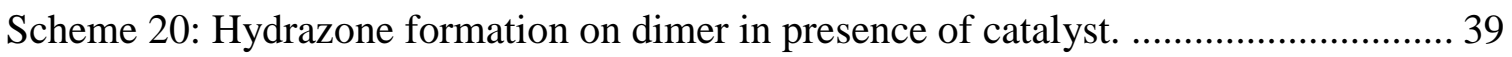

Scheme 21: Hydrazone formation (two steps) on dimer in presence of catalyst............. 40

Scheme 22: Selective dehydrazone reaction on Bishydrazone compound 76................ 41

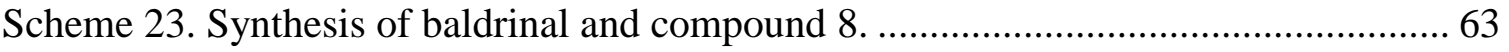

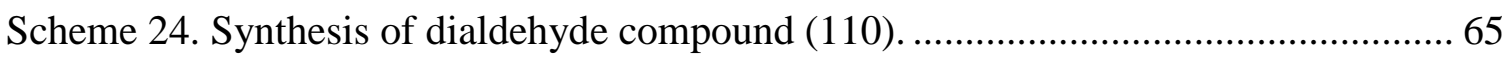

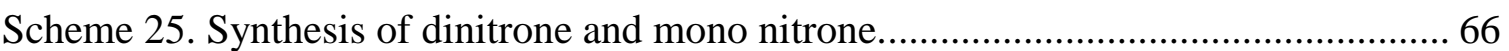

Scheme 26: Reaction attempts to form quaternary salts and Girard's reagent derivative. 67 


\section{LIST OF ABBREVIATIONS}

\begin{tabular}{|c|c|}
\hline AAS & anabolic androgenic steroids \\
\hline Ac & acetyl \\
\hline $\mathrm{ACh}$ & acetylcholine \\
\hline ATP & adenosine triphosphate \\
\hline $\mathrm{AZN}$ & azulenyl nitrone \\
\hline$\alpha$ & alpha \\
\hline$\beta$ & beta \\
\hline $\mathrm{Bn}$ & benzyl \\
\hline $\mathrm{BPH}$ & benign prostatic hyperplasia \\
\hline$t$-But & tert-butyl \\
\hline $\mathrm{CNS}$ & central nervous system \\
\hline${ }^{\circ} \mathrm{C}$ & degrees Celsius \\
\hline$\delta$ & delta \\
\hline $\mathrm{d}$ & doublet (NMR) \\
\hline DCM & dichloromethane \\
\hline DHT & dihydrotestosterone \\
\hline DMF & $N, N$-dimethylformamide \\
\hline DMSO & dimethylsulfoxide \\
\hline DNA & deoxyribonucleic acid \\
\hline EPR & electron paramagnetic resonance \\
\hline ESI & electrospray ionization \\
\hline ESR & electron spin resonance \\
\hline
\end{tabular}




\begin{tabular}{|c|c|}
\hline Et & ethyl \\
\hline g & $\operatorname{gram}(\mathrm{s})$ \\
\hline GABA & gamma aminobutyric acid \\
\hline GAD & glutamic acid decarboxylase \\
\hline h or hr or hrs & hour(s) \\
\hline $\mathrm{Hz}$ & hertz \\
\hline HRMS & high resolution mass spectroscopy \\
\hline $\mathrm{IC}_{50}$ & half maximal inhibitory concentration \\
\hline IMM & inner mitochondrial membrane \\
\hline$J$ & coupling constant in $\mathrm{Hz}$ (NMR) \\
\hline $\mathrm{L}$ & liter(s) \\
\hline LDA & lithium diisopropylamide \\
\hline LDL & low density lipoproteins \\
\hline LRMS & low resolution mass spectroscopy \\
\hline $\mathrm{m}$ & milli; multiplet (NMR) \\
\hline$\mu$ & micro \\
\hline M & moles per liter \\
\hline $\min$ & minute(s) \\
\hline mol & mole(s) \\
\hline MS & mass spectrometry \\
\hline$m / z$ & mass to charge ratio (MS) \\
\hline NADPH & nicotinamide adenine dinucleotide phosphate \\
\hline NMDA & $N$-methyl-D-aspartic acid \\
\hline
\end{tabular}




\begin{tabular}{|c|c|}
\hline NMR & nuclear magnetic resonance \\
\hline$p$ & para \\
\hline PAM & positive allosteric modulators \\
\hline PET & positron Emission Tomography \\
\hline py & pyridine \\
\hline$\%$ & percentage \\
\hline $\mathrm{q}$ & quartet (NMR) \\
\hline RNA & ribonucleic acid \\
\hline RNR & ribonucleotide reductase \\
\hline RNS & reactive nitrogen species \\
\hline ROS & reactive oxygen species \\
\hline RPE & retinal pigment epithelial \\
\hline $\mathrm{rt}$ & room temperature \\
\hline $\mathrm{s}$ & second(s); singlet (NMR) \\
\hline SARMs & selective androgen receptor modulators \\
\hline $\mathrm{SCh}$ & succinylcholine \\
\hline SOD & superoxide dismutase \\
\hline STAZN & stilbazulenyl nitrone \\
\hline $\mathrm{t}$ & triplet (NMR) \\
\hline TBDMS & tert-butyldimethylsilyl \\
\hline tert or $t$ & tertiary \\
\hline THF & tetrahydrofuran \\
\hline TLC & thin layer chromatography \\
\hline
\end{tabular}


Ts

t-PA

UV

VIS

$v S$ tosyl

tissue plasminogen activator

ultraviolet

visible

versus 


\section{AZASTEROIDS}

\section{CHAPTER 1: INTRODUCTION}

Azasteroids are steroid mimics, a class of natural or synthetic compounds, containing nitrogen in a cyclopentenophenanthrene steroidal nucleus. The replacement of one or more carbon atoms of a steroidal molecule with a heteroatom affects chemical properties and can produce useful alterations in its biological activities. ${ }^{1}$ Heterosteroids and specifically azasteroids, have received much attention among structurally modified natural steroids because of their wide variety of biological activities, often free from undesirable or harmful side effects. ${ }^{1-3}$ One could divide azasteroids into two categories, nuclear and exonuclear, determined by the position of heteroatoms. The compounds in which replacement of carbon atom in the steroidal skeleton at positons 1-17 are nuclear, whereas in the side chain or in extra rings are exonuclear. Nuclear azasteroids are further classified by the position (1-17) of heteroatom or by the ring (A-D) of the steroidal skeleton. For example, Finasteride and Dutasteride (Avodart) are synthetic, A-ring 4- azasteroids used as 5 $\alpha$-reductase inhibitors. The series of A25822 (A, B, D, L, M, N), natural, homo-D-ring 15-azasteroids was isolated from the mold Geotriclzum flavor-brunneum in $1975 .^{4}$

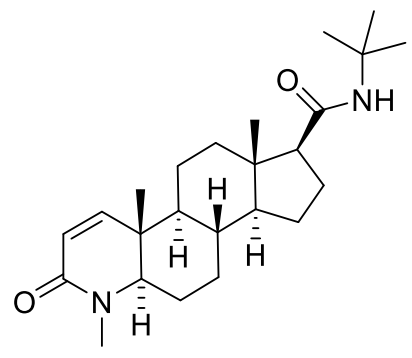

Finasteride

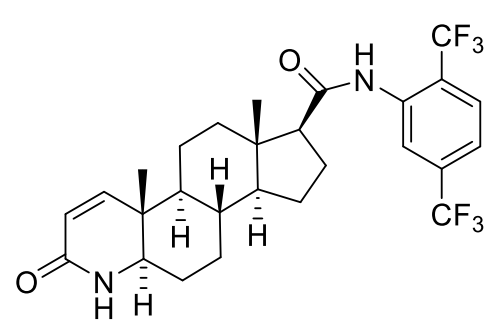

Dutasteride

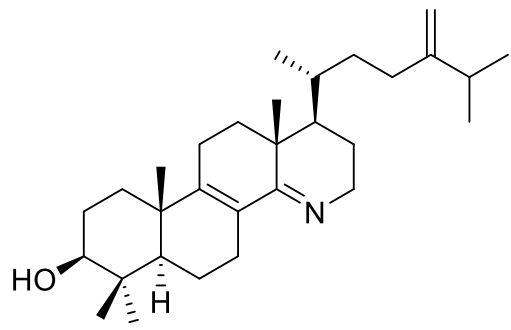

A25822A

Figure 1. Examples of biologically active azasteroids. 


\subsection{Biological importance}

Steroids are one of the most important classes of molecules and perform a number of fundamental biological functions. These natural and synthetic drugs get great attention in research because of such interesting biological properties ${ }^{3}$ and many have an ability to cross cell membranes readily. ${ }^{3,5}$ In order to find new steroidal molecules with desirable biological effects, natural steroids are often modified at several positions, especially in the cyclopentenophenanthrene ring system with heteroatoms or rings. ${ }^{6}$ Replacement of one or more atoms in steroids with heteroatoms (nitrogen) generates new molecules called azasteroids with such diverse biological properties as cytotoxicity, anti-atherogenicity, anti-carcinogenicity, antifungal, antilipemic, local anaesthetic, neuromuscular blocking activity, inhibition of steroidal reductases, and more. ${ }^{7-12}$ Certain azasteroidal pills are well known contraceptive drugs, because of their binding with steroid receptors, thereby blocking the binding of the actual steroids. ${ }^{13-14}$ Enzymes that normally transform steroids may bind with substrates and form undesirable steroids. Certain azasteroids have an ability to block the biosynthesis of physiologically undesirable steroids.

Finasteride is a synthetic azasteroid derived from progesterone. It is a specific inhibitor of steroid $5 \alpha$-reductase type-II, an intracellular enzyme that converts the androgen testosterone into 5a-dihydrotestosterone (DHT) ${ }^{15}$ The DHT is responsible for the development and enlargement of the prostate gland called Benign Prostatic Hyperplasia (BPH). Dutasteride (Avodart) is also a synthetic drug used to treat hair loss and prostate enlargement in men. Avodart is considered to be a dual $5 \alpha$-reductase inhibitor because it suppresses both isomers of the enzyme (type-I and type-II) ${ }^{16-17}$ The activity of inhibition 
of the generation of DHT is called antiandrogenic activity. Another azasteroid, RU-5135, contains nitrogen in the steroid D ring and it acts as a GABA receptor antagonist. ${ }^{18}$

\subsubsection{Benign prostatic hyperplasia $(\mathrm{BPH})$ and $5 \alpha$-reductase inhibitors}

Benign prostatic hyperplasia known as $\mathrm{BPH}$ is a condition of prostate gland enlargement and which is not malignant prostate cancer. The unwanted enlargement of the prostate gland may start during its second phase of natural growth in almost all men at the age of 25 and continues rest of the life. After several years of enlargement, the gland presses against the urethra, makes the urethra bladder walls weaker and unable to empty completely by leaving some urine unextruded. Ultimately this leads to many other BPH related problems such as urinary related infections (Lower Urinary Tract Symptoms, LUTS), kidney damage, kidney stones, bladder damage and more. ${ }^{17}$

Generation of androgens at normal levels plays an important role in the necessary growth and development of the prostate gland. In other cases, abnormal androgen levels may lead to prostate cancer, BPH, acne and other diseases. ${ }^{17}$ Dihydrotestosterone (DHT) is one type of androgen sex steroid, generated from testosterone in the presence of $5 \alpha-$ reductase enzyme and NADPH. Dihydrotestosterone is involved in the growth of the prostate gland which is necessary for the development of male secondary sex characteristics. Accumulation of DHT can lead to BPH in older men as they continue to produce it even at the age of 70 . Scientists found that there is no $\mathrm{BPH}$ in men who are unable to produce DHT. ${ }^{15-17}$

The enzyme, $5 \alpha$-reductase, is responsible for the conversion of testosterone to $5 \alpha$ -

dihydrotestosterone. The physical appearance of genetic males with deficiency in $5 \alpha$ reductase is feminine. After a certain age in normal males, $5 \alpha$-reductase creates urinary 
problems by continuous production of DHT, which is responsible for prostate development as well as the pathogenesis of BPH and male-pattern baldness. There are three types of $5 \alpha-$ reductase enzymes and type- 2 is the one that is mainly responsible for the generation of DHT. $^{16}$

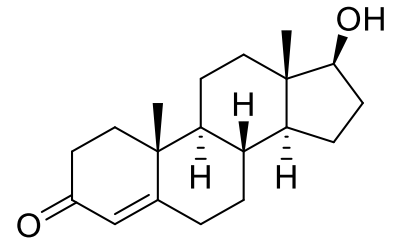

Testosterone

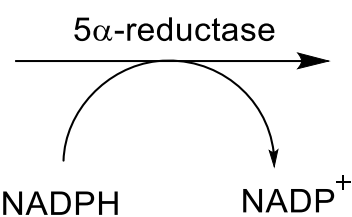

NADPH

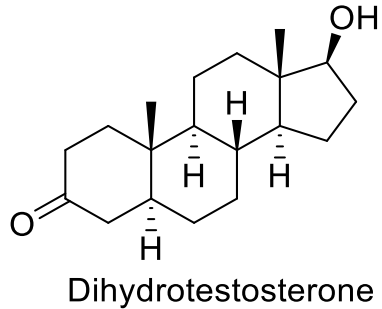

Dihydrotestosterone

Figure 2. Conversion of testosterone to DHT.

The inhibitors of the 5 $\alpha$-reductase, especially the steroidal type, quench the generation of DHT by blocking the enzyme $5 \alpha$-reductase and it leads to a reduction in the size of the prostate gland ${ }^{17}$ The activity of $5 \alpha$-reductase inhibitors engender the increased levels of testosterone and decreased levels of DHT. By inhibiting DHT, $5 \alpha$-reductase inhibitors reduce the effects of androgens such as DHT on the prostate. These inhibitors are used to treat $\mathrm{BPH}$, prostate cancer, and baldness. Much research focused on these $5 \alpha-$ reductase inhibitors for the identification of a potential drug to treat androgen related complications. In this process of identification of potential drug, several diverse compounds were synthesized but the azasteroids drew more attention than steroidal/nonsteroidal compounds because of their relatively facile and attractive biological properties.

Two drugs currently available in this steroidal class are Finasteride and Dutasteride. These two medications differ because of their levels of inhibition of the conversion from testosterone to dihydrotestosterone. ${ }^{16}$ Dutasteride has a greater ability in suppression of 
DHT than Finasteride by inhibiting both type-1 and type-2 $5 \alpha$-reductases while Finasteride inhibits type-2 alone. Also Dutasteride is superior to Finasteride in estimated half-life with approximately five weeks as that of the latter is only five to eight hours. ${ }^{17}$

Finasteride is used to treat men with $\mathrm{BPH}$, alone or in combination with other medicines such as alpha-blockers. Finasteride is also used to treat male pattern hair loss, the gradual thinning of men's hair which leads to the balding on the top of the scalp. Finasteride will increase the growth of scalp hair but not the body hair by blocking only the production of a male hormone in the scalp that stops hair growth. The effect of Finasteride will stay as long as the medicine is taken. When it is stopped, the prostate begins to grow and hair loss increases.

\subsubsection{Azasteroids as Selective androgen receptor modulators (SARMs)}

Selective androgen receptor modulators (non-steroidal) are a novel class of therapeutic compounds having properties similar to anabolic-androgenic steroids (AAS) but more selective in their action. ${ }^{19}$ Such selectivity includes androgen receptor specificity, tissue selectivity, fewer steroid-related side effects and, most importantly, an ability to differentiate between anabolic and androgenic activities. ${ }^{20}$ These exceptional properties make SARMs unique in the treatment of androgen related complications although they do have the potential for misusage as performance enhancement drugs in sports because of their anabolic properties and an ability to stimulate androgen receptors. ${ }^{21}$

In the process of finding new SARMs, several azasteroidal androgen receptor agonists were designed and synthesized from DHT. ${ }^{22-24}$ These new azasteroidal selective androgen receptor modulators $\mathbf{1 - 3}$ showed potent hAR binding, low virilizing potential and

a favorable pharmacokinetic profile in $\operatorname{dogs} .{ }^{22}$ Several other patented compounds were also 
reported by virtue of their clinical properties that were useful for the enhancement of weakened muscle tone and amelioration of complications generated by androgen deficiency such as osteoporosis, atherosclerosis, obesity, BPH, prostate cancer, etc. ${ }^{23-24}$

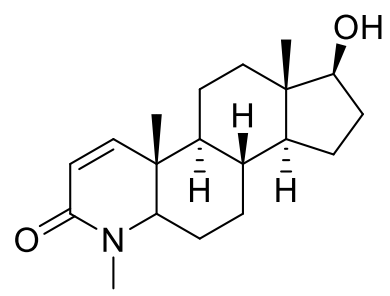

1

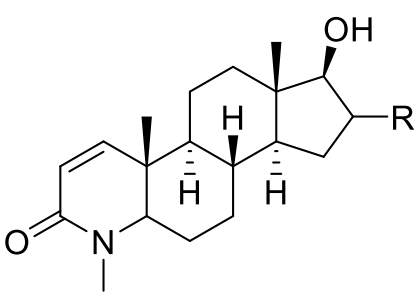

2

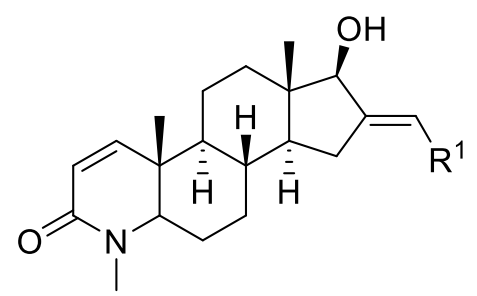

$\mathrm{R}=\mathrm{Me}, \mathrm{CH} 2 \mathrm{OMe}$ etc $\mathrm{R} 1=\mathrm{Me}, \mathrm{Ph}$, Pyridyl, Pyrimidyl etc

Figure 3. Selective androgen receptor modulators (SARMs) of azasteroids.

\subsubsection{Neuromuscular Blockers}

Neuromuscular blockers are used clinically as an adjunct to anesthesia to provide muscle relaxation during surgery. Before introduction of neuromuscular blockers, anesthesia was used to maintain muscle relaxation bearing the risk of respiratory or cardiac depression. During surgical operations, it is necessary to control spontaneous movement of muscles. Compounds with quaternary ammonium groups (usually two) in their structure are common muscle relaxant drugs. These relaxant drugs mimic the action of acetylcholine and prevent the transmission of signaling muscle neurons by blocking the nicotinic acetylcholine (ACh) receptors. ${ }^{25}$

A revolution took place in the field of anesthesia after isolation of $d$-tubocurarine, a mono quaternary alkaloid extracted from a native plant of Central and South America, Chondodendron tomentosum, in 1942. The compound $d$-tubocurarine is historically known as an arrow poison and it has paralyzing activity. Neuromuscular blockers are classified 
into two categories: Depolarizing and Non-depolarizing, defined by their mechanism of action. $^{25-28}$

Depolarizing neuromuscular blockers: This type of neuromuscular blockers blockade of ACh receptors create by occupying and activating the nicotinic receptors for a prolonged period of time. The structures of the depolarizing neuromuscular blockers resemble that of Ach. Succinylcholine (SCh) is the only drug available in this class of neuromuscular blockers. Succinylcholine has two acetylcholine molecules connected at their acetyl groups. Succinylcholine is also called Suxamethonium chloride and it is used in emergency medicine to cause quick and short term muscle relaxation. It has a rapid onset of action about 30 seconds with a duration of action of about five to eight minutes. ${ }^{25-28}$<smiles>CC(=O)OCC[N+](C)(C)C</smiles>

Acetylcholine (ACh)

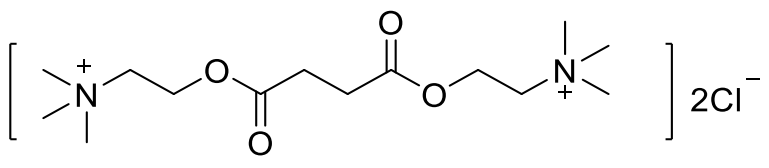

Succinylcholine (SCh)

Figure 4. Structures of acetylcholine and Succinylcholine.

Succinylcholine mimics the action of acetylcholine by binding to acetylcholine receptors in the neuromuscular junction. ${ }^{25}$ These receptors open their channel allowing sodium ions to flow into the muscle cells and potassium ions to rush out. The ion flow causes depolarization in muscle cells and it leads to the initial muscle contraction called fasciculation, and subsequently, to paralysis. Succinylcholine has a prolonged depolarization effect under the influence of acetylcholinesterase inhibitors. Because of this prolonged endplate depolarization, normal neuron transmission to muscle cannot produce muscle contraction. Succinylcholine can cause many side effects, such as hyperthermia and 
hyperkalemia. The latter one occurs as a result of increased potassium levels in serum which leads to nerve damage and then subsequently to cardiac arrest.

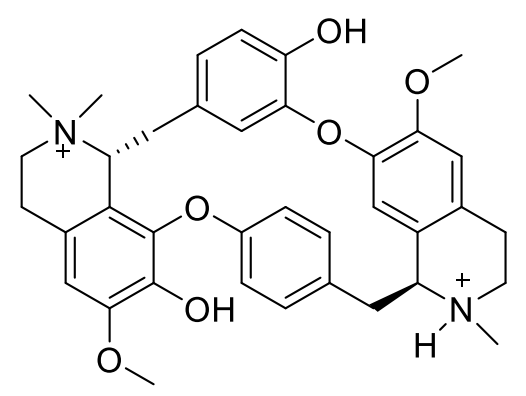

Tubocurarine

Figure 5. Non-depolarizing neuromuscular blocking agent, Tubocurarine.

Non-depolarizing neuromuscular blockers: These neuromuscular blockers bind to the same nicotinic $\mathrm{ACh}$ receptor, but do not open up the sodium channel, and thus, do not polarize the motor endplate. ${ }^{25}$ These non-depolarizing agents simply antagonize the actions of ACh at nicotinic acetylcholine receptors by blocking them, so there is no muscle contraction and depolarization because ACh cannot transmit the nerve impulses. The blockage can be reversed by increasing the concentration of ACh. The structures of these blockers are bulky and rigid, and most of them have quaternary ammonium moieties. The drugs of this category of agents is further divided into two groups, aminosteroids and benzylisoquinolinium derivatives. Tubocurarine is a natural benzylisoquinolinium compound and was the first neuromuscular blocking agent isolated from plants by South Americans, who used it to paralyze their prey. Later on, several related synthetic agents were developed. ${ }^{25-33}$ 


\subsubsection{Aminosteroid or Azasteroid neuromuscular blockers}

Neuromuscular blockers are further divided by their structure; steroidal (azasteroidal) or non-steroidal. Aminosteroids are non-depolarizing agents and constitute most of the neuromuscular blockers. ${ }^{25}$ These agents have a common steroidal rigid structure with two quaternary ammonium moieties. ${ }^{29}$ Aminosteroids block neuromuscular activity either by binding Ach receptors or by blocking ionotropic activity of Ach. A range of aminosteroids, with positive neuromuscular blocking activity, have been synthesized with a varying degree of flexibility in their steroidal structures. Some of them have been used as successful drugs and commercialized as curariforms, such as Pancuronium, Pipecuronium, Rocuronium and Vecuronium. ${ }^{30-33}$
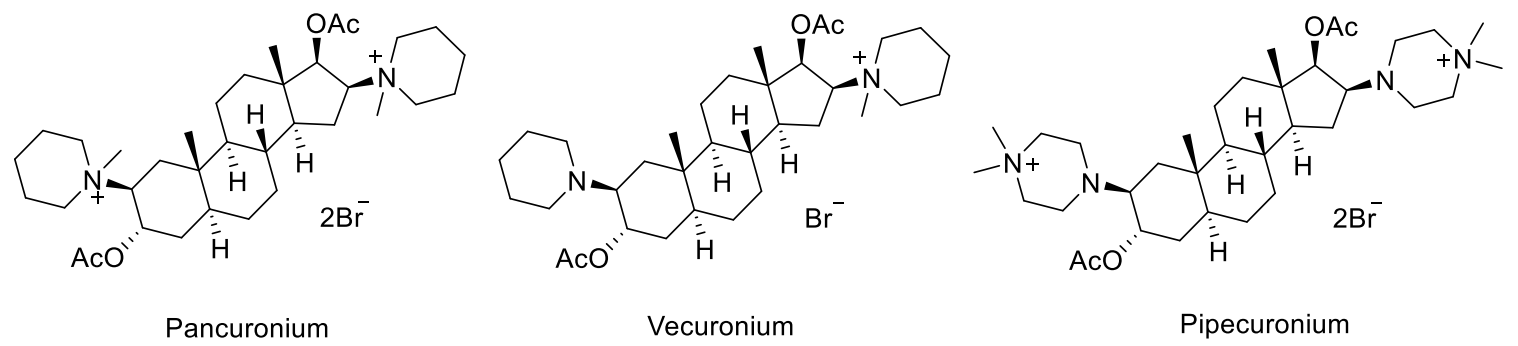

Figure 6. Azasteroidal neuromuscular blockers.

Pancuronium or Pancuronium bromide is a non-depolarizing neuromuscular blocking agent that acts by blocking cholinergic receptors at the motor end-plate. It is more potent and possesses a longer duration of neuromuscular blockage than Tubocurarine. Rapacuronium and Rocuronium are analogues of Pancuronium. Other neuromuscular blocking agents such as Vecuronium, Atracurium and Pipecuronium have a similar clinical activity as that of Pancuronium. Animal experiments exploring the activity of Pipecuronium have shown that the activity of Pipecuronium is four times that of 
Pancuronium and the duration of action is twice that of Pancuronium. Several other azasteroid neuromuscular blockers with promising clinical activities have been discovered. ${ }^{29}$

\subsubsection{Neurosteroids}

In the mammalian brain, gamma-Aminobutyric acid (GABA) and glutamate (Glu) are the most abundant inhibitory and excitatory neurotransmitters. ${ }^{34}$ Over half of all the brain's neurotransmitters are glutamergic, and 30-40 \% are GABAergic. ${ }^{34-36}$ Glutamate is actually a metabolic precursor of GABA, and the conversion from glutamate to GABA is controlled by an enzyme called glutamic acid decarboxylase (GAD). The fundamental function of GAD is that of keeping GABA and Glu properly balanced in order to maintain regular functioning of the CNS. Brain disorders such as anxiety, depression and schizophrenia are the result of an imbalance between excitation and inhibition activities. ${ }^{37}$ Gamma-Aminobutyric acid plays a crucial role in neurons. Changes in GABA metabolism such as a decrease in GABA or GABAergic neurons leads to the generation of most of the brain's neuron related disorders. ${ }^{38}$

Several synthetic and natural medications are available for the treatment of GABAGlu balance disorders and they are categorized based on their action on GABA-Glu receptors. Most importantly, GABA $(\mathrm{A} \& \mathrm{~B})$ receptor agonists are the major class of therapeutic compounds (which includes PAMs-positive allosteric modulators- such as alcohols, barbiturates and benzodiazepines) which indirectly influence or enhance the activity of GABA receptors. The GABA receptor antagonist, and $N$-methyl-D-aspartic acid (NMDA) receptor (a glutamate receptor) antagonists are some of the other classes of medications. ${ }^{35-40}$ 
<smiles>NCCCC(=O)O</smiles>

GABA<smiles>[NH3+]C(CCC(=O)[O-])C(=O)[O-]</smiles>

Glutamate

Figure 7. Structure of GABA and Glutamate.

Neurosteroids are the natural/synthetic steroids that modulate GABA and glutamatergic neural communications. These have received wide attention recently as they are produced endogenously in the brain and affect the activity of GABA-Glu receptors. ${ }^{40}$ Synthetic analogues of these endogenous steroids are also useful as anticonvulsants, neuroprotectants and as anesthetics. ${ }^{39}$ Althesin, alphaxalone (one of the constituent of althesis) and endogenously produced anesthetics such as allopregnanolone and pregnanolone are shown to be GABAergic neurotransmitters. Some endogenous steroidal precursors, pregnenolone sulfate (PREGS) and dehydroepiandrosterone sulfate (DHEAS), were shown to suppress neural activity by diminishing GABAergic neurotransmission. ${ }^{40}$ The PREGS also showed enhancement of NMDA receptor function. It has been clear that neurosteroids show activity at both types of receptors, but GABAergic agonists and blockers of NMDA receptor neurotransmissions are associated with anticonvulsant, neuroprotectant and anesthetic properties. ${ }^{40}$

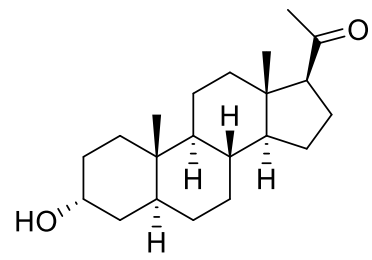

Allopregnanolone

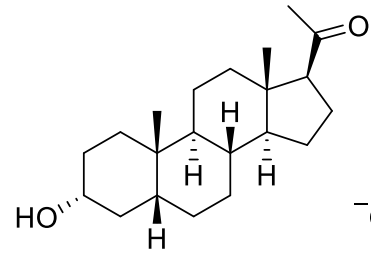

Pregnanolone

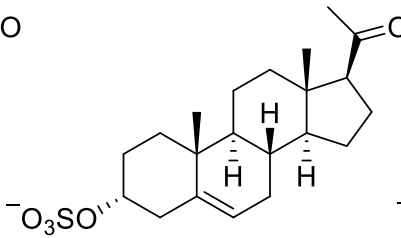

PREGS

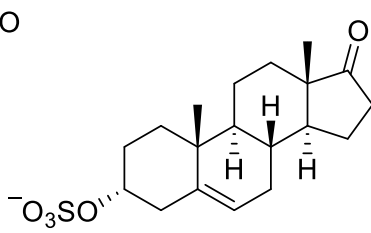

DHEAS

Figure 8. GABA and glutamatergic neurotransmitters/ neurosteroids. 
Benz $[e]$ indenes, tricyclic non-steroidal compounds having a structural framework similar to steroids such as pregnanolone and allopregnanolone, showed enhanced GABAergic transmissions by mimicking the structural properties of steroids with a side chain having a hydroxyl group similar to the $3 \alpha-\mathrm{OH}$ in steroids. ${ }^{40}$ Steven Mennerick et al.

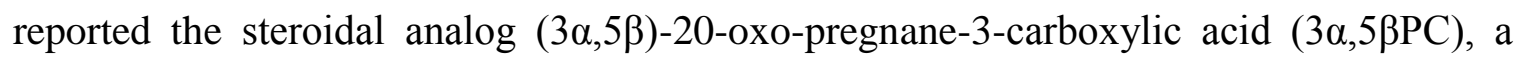
neuroactive steroid that positively modulates the $\mathrm{GABA}_{\mathrm{A}}$ receptor at low concentrations and negatively modulates NMDA receptors. ${ }^{39}$
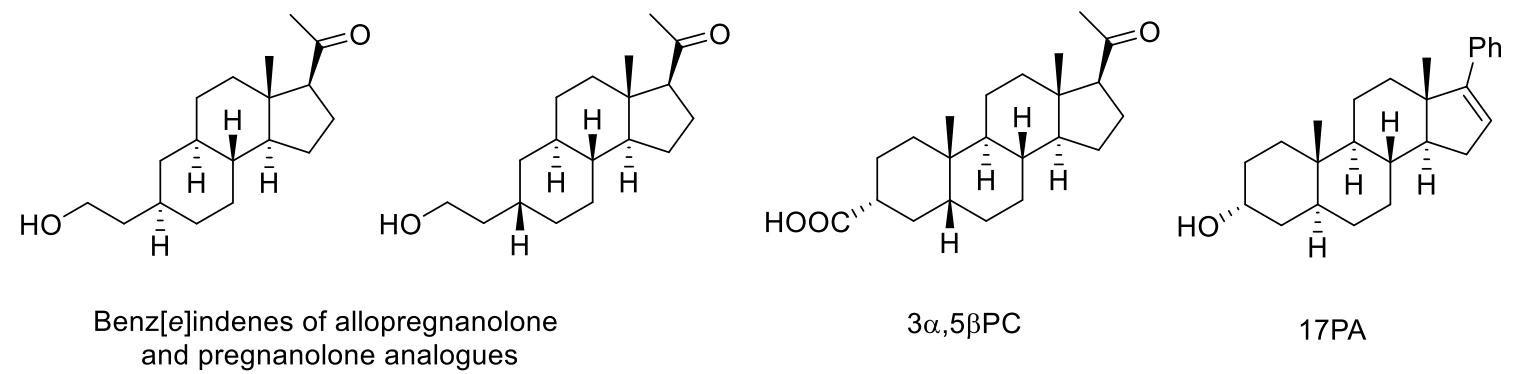

Figure 9. Benz[e]indenes and selective antagonists of neurosteroids.

The number of binding sites and their positions in $\mathrm{GABA}_{\mathrm{A}}$ receptors is unclear. Thus, it is hard to understand the mechanism of action of neurosteroids at GABA receptors without any knowledge of their binding sites. Evidence of multiple distinct neurosteroid binding sites at GABA receptors was reported recently. ${ }^{41-42}$ The action of neurosteroids at GABA receptors by using steroidal antagonists has been studied. These examinations showed that $3 \beta$-hydroxysteroids competitively (non-competitively in electrophysiological studies) antagonize the activities of both of the potentiating steroids allopregnanolone (5areduced) and pregnanolone (5 $\beta$-reduced). Mennerick et al also reported the synthesis and actions of $(3 \alpha, 5 \alpha)$-17-phenylandrost-16-en-3-ol (17PA), a selective antagonist of neurosteroid potentiation at GABA receptors. Studies on 17PA provided further evidence 
for the presence of multiple neurosteroid binding sites. ${ }^{41}$ The compound 17PA antagonized anesthetic actions and direct gating of $\mathrm{GABA}_{\mathrm{A}}$ receptor channels by $5 \alpha$-reduced steroids, but showed little or no effect on $5 \beta$-reduced steroids as well as little effect on barbiturate and benzodiazepine potentiation. Also 17PA showed a competitive interaction with steroids by decreasing inhibition of $5 \alpha$-reduced steroid potentiation when steroid concentration increased. ${ }^{42}$

\subsubsection{Anticancer and some biologically active heterosteroids}

Cortistatins are a group of natural steroids, isolated from the marine sponge Corticium simplex in $2006 .{ }^{43}$ Cortistatin A is the most potent compound that inhibits proliferation of human umbilical vein endothelial cells (HUVECs) and displays selective inhibition of CDK8 and CDK19 kinases, which is key for angiogenesis and wet macular degeneration. ${ }^{44-45}$ In 2006 , E. J. Corey et al. synthesized structurally simple but biologically active analogs of cortistatin A (Figure 10) ${ }^{45}$ On the basis of the biological data reported on various cortistatins, they synthesized analogs $1 \& 2$ which show greater inhibitory activity in the process related to angiogenesis than natural Cortistatins. They also made many changes in cortistatin analogs by varying the heterocycle at the $\mathrm{C}-17$ position and some of them showed greater activity than Cortistatin.

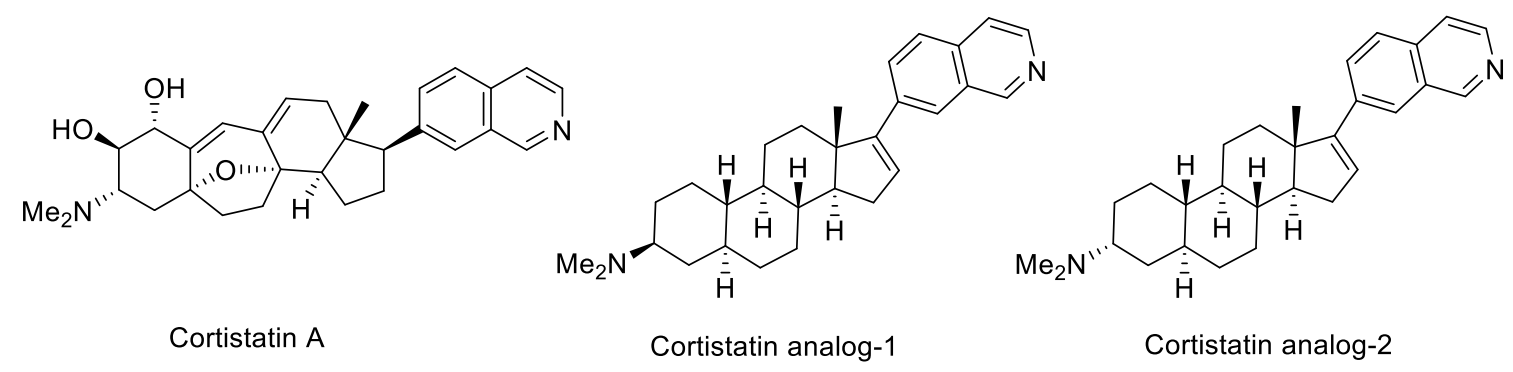

Figure 10. Anticancer and some of the biologically active azasteroids. 
Danazol and Stanozolol are synthetic steroidal compounds similar to testosterone in their structures (Figure 11). Danazol is a derivative of ethisterone where the keto group is replaced with an isoxozol moiety. Synthesized in 1963, and it is used for the treatment of endometriosis and some other congenital diseases. ${ }^{46-47}$ Danazol has complex pharmacology which includes inhibition of enzymes involved in steroidogenesis and activation of sex hormone receptors. ${ }^{47}$ Stanozolol is an anabolic steroid synthesized from dihydrotestosterone by replacing the keto group with a pyrazole ring. ${ }^{48}$ Stanazolol is used in the treatment of anemia in humans and for the promotion of muscle growth in other animals. ${ }^{49}$ Besides its legitimate medical usage, stanozolol is one of the widely used performance enhancing drugs. ${ }^{50}$

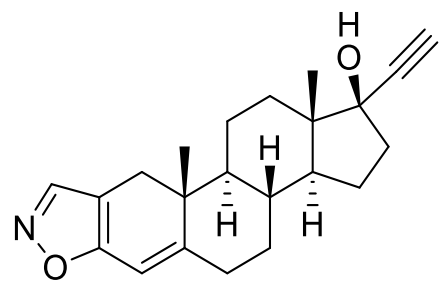

Danazol

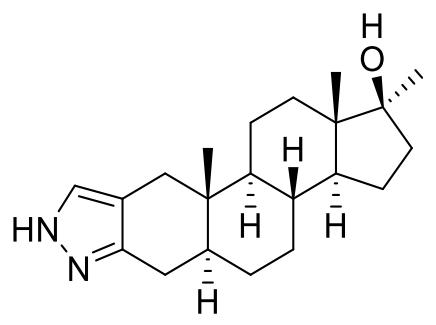

Stanozolol

Figure 11. Structure of danazol and stanozolol.

Abiraterone and Cardenolides are also similar to Cortistatin analogs in their structures (Figure 12). Abiraterone is a steroidal anti-androgen and it is a successful drug which is used in the treatment of prostate cancer. ${ }^{51-52}$ It has also been tested in the treatment of advanced estrogen-dependent breast cancer. ${ }^{53}$ Abiraterone inhibits the synthesis of testosterone by blocking an enzyme called cytochrome P17. Cardenolides are unique 
steroidal toxins produced by many plants such as those in the family Apocynaceae. These are heart arresting natural steroids that act by inhibiting the enzyme Na/K -ATPase. ${ }^{54-55}$

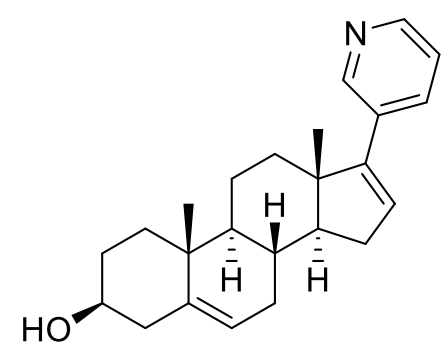

Abiraterone

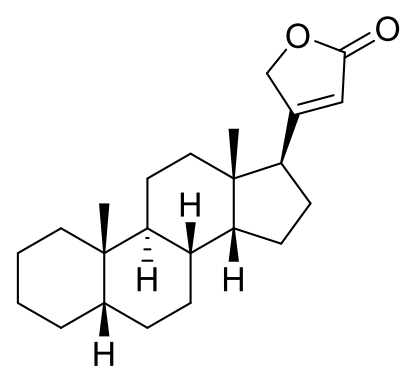

Cardenolide

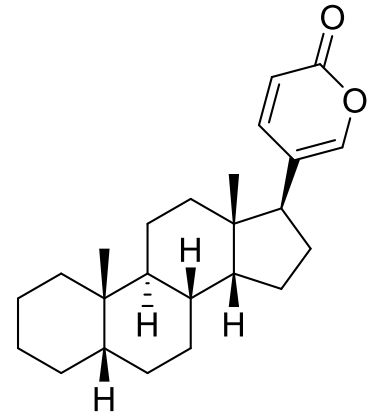

Bufadienolide

Figure 12. Structures of Abiraterone and cardinolides.

Bufadienolides are toxic natural steroidal compounds homologues to Cardenolides (Figure 12). In addition to their occurrence in certain toads, the plant families Crassulaceae and Hyacinthaceae are also rich sources of bufadienolides. This class of compounds is generally used in traditional remedies for the treatment of infections, inflammation, and disorders associated with the central nervous system. ${ }^{56}$

Several other biologically effective 17-heteroaryl limonoids (such as azadirone, azadiradione, and gedunin), are structurally related to Abiraterone, isolated from the neem tree, Azadirachta indicia, a native Indian subcontinent tree that is cultivated throughout the tropics (Figure 13). ${ }^{57-58}$ Azadirachta indicia belongs to the Meliaceae family, which is known for triterpene derivatives having several pharmacological activities including antifeedant, antibacterial, antifungal, antimalarial, antipyretic and growth regulatory properties. Cytotoxicity and anti HIV properties of limonoid constituents of Meliaceae were also reported recently. ${ }^{59}$ These tree species are well known for their tremendous 
therapeutic properties and used to treat more than 40 maladies. Various parts of the tree (stem, oil, seed, bark, leaf) have been used in ayurveda, unani, and homeopathic medicine..$^{57-61}$

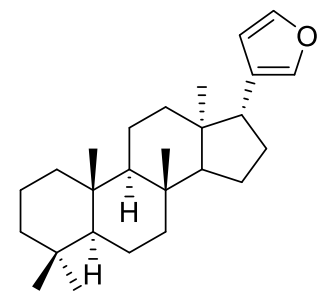

Limonoid skeleton

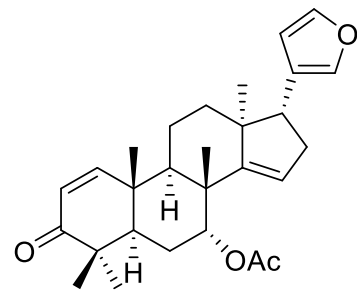

Azadirone

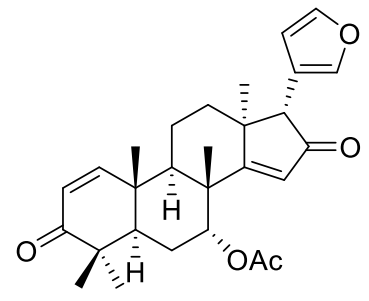

Azadiradione

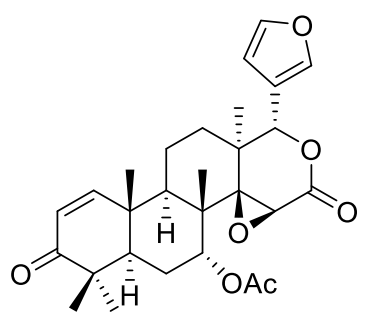

Gedunin

Figure 13. Examples of 17-heteroaryl linonoids.

The studies in vitro and in vivo of azadirone and its derivatives, isolated from neem flowers, identified such compounds as cytotoxic agents and it is concluded that the furan moiety present in azadirone is one of the structural requirements for its cytotoxic activity. ${ }^{59}$ Another study on azadirone revealed its anti-cancer/anti-tumor properties and its mechanism of action on human tumor cells that are resistant to tumor necrosis factorrelated apoptosis-inducing ligand (TRAIL). The combination of TRAIL and azadirone is may be an effective in anticancer treatment. ${ }^{57-58}$ Azadiradione is another potential therapeutic compound isolated and studied in vivo in various ulcer models which showed strong antiulcer activity by inhibiting the proton pump with its cytoprotective and antisecretory effects. ${ }^{60}$ Azadiradione and its companion, gedunin, are effective as (HPA) human pancreatic $\alpha$-amylase inhibitors (anti-diabetic). ${ }^{57}$

Various compounds of another class of triterpenoids, including KHF16 (24acetylisodahurinol-3-O- $\beta$-D-xylopyranoside), extracted from the medicinal plant Cimicifuga foetida, have been reported to possess anticancer properties by inducing cell 
cycle arrest and apoptosis (Figure 14). ${ }^{62}$ Triple-negative breast cancer (TNBC) is one subtype of breast cancer that is promoted by HER2 protein. Apoptosis inhibits the development of cancer, but unfortunately, the drugs used for TNBC cancer indirectly stimulate the generation of anti-apoptotic proteins by improper regulation and activation of $\mathrm{NF}_{\mathrm{K}} \mathrm{B}$, a protein that controls cell survival. ${ }^{62-64}$ Natural compounds obtained from plants including Cimicifuga recemosa are another option for cancer treatment. The compounds cucurbitacin E and KHF16 showed inhibition of higher levels of anti-apoptotic proteins such as Mcl-1 and, promoted survival by regulating NF- $\mathrm{KB}$ activation. ${ }^{62-64}$

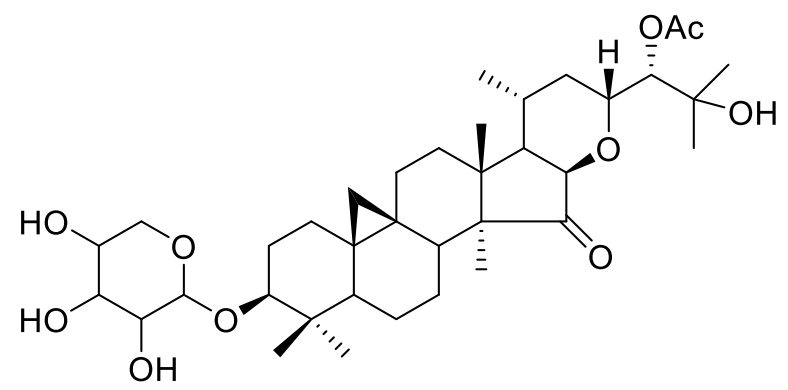

KHF16

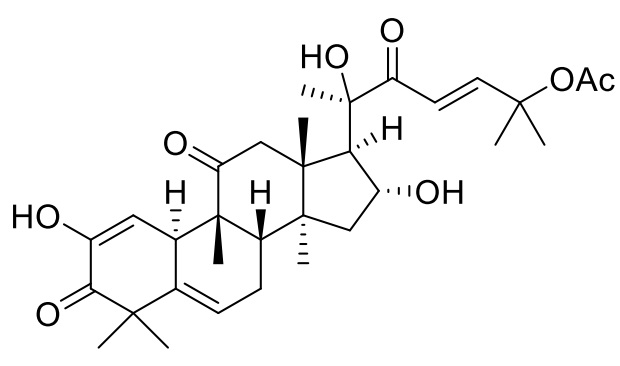

Cucurbitacin E

Figure 14. Structures of triterpenoids, KHF16 and cucurbitacin E.

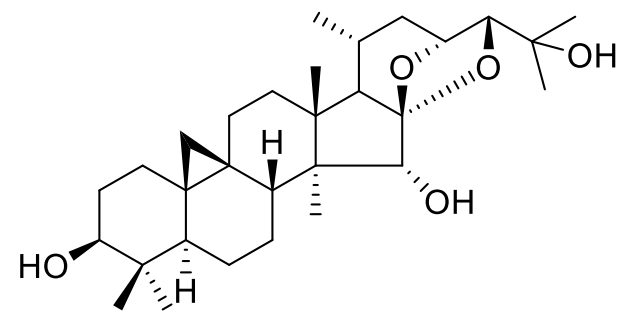

Cimigenol

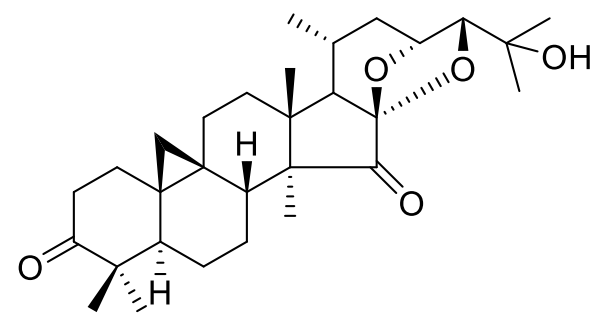

Cimigenol-3,15-dione

Figure 15. Anticancer compounds isolated from Cimicifuga.

Previously, many triterpenoid glycosides similar to KHF16 (including cimigenol and its derivatives) (Figure 15) were isolated from the aforementioned herb Cimicifuga 
recemosa. These compounds were tested for cancer chemoprevention in vitro. ${ }^{65}$ Cimigenol and its derivative cimigenol-3,15-dione showed significant antitumor activity in an animal model of two stage skin tumor carcinogenesis.

Olesoxime (cholest-4-ene-3-one oxime) is a cholesterol-oxime with neuroprotective and neuroregenerative properties (Figure 16). It was first identified for promoting motor neuron survival in cultured rat neurons in the absence of neurotrophic factors. ${ }^{66}$ Olesoxime binds to the outer mitochondrial membrane proteins and hinders oxidative stress-mediated permeability transition pore (mptp) opening. It is a potential therapeutic drug (development started in 2015) for treating neurodegenerative/motor neuron diseases involving trophic factor deprivation and mitochondrial dysfunction such as amyotrophic lateral sclerosis (ALS) and spinal muscular atrophy (SMA). ${ }^{67}$ It is hypothesized that olesoxime may be clinically useful in treating autism because this disease is also related to mitochondrial dysfunction and mptp opening mediated by oxidative stress. ${ }^{68}$ Huntington's disease (HD) is another neurodegenerative condition involving mitochondrial dysfunction. Recent research with olesoxime in animal models show promising results and support its further study in the treatment of HD. ${ }^{69-70}$

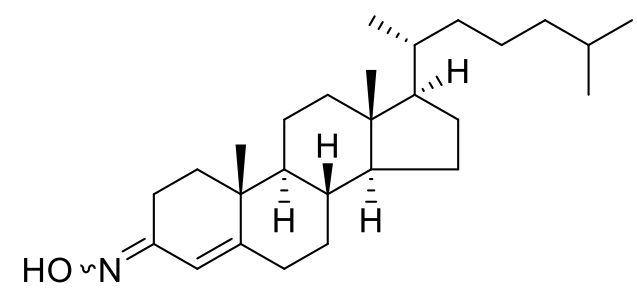

Olesoxime

Figure 16. Chemical structure the drug olesoxime. 
Cephalostatins are disteroidal pyrazines which show cytotoxicity against human tumors ( $\sim 1 \mathrm{nM}$ in the 2-day NCI 60 cell panel) (Figure 17). They are among the most potent anticancer agents known by oncologists. ${ }^{71}$ Isolation of Cephalostatins was reported in 1988 from the marine tubeworm Cephalodiscus gilchristi..$^{72}$ To date Cephalostatin 1 is the most powerful anticancer agents ever tested. All Cephalostatins have two steroidal skeletal units linked by a pyrazine ring. Cephalostatin 5 and 6 are unusual among all others in this family in that they bear aromatic C-rings while retaining significant cell growth inhibition.

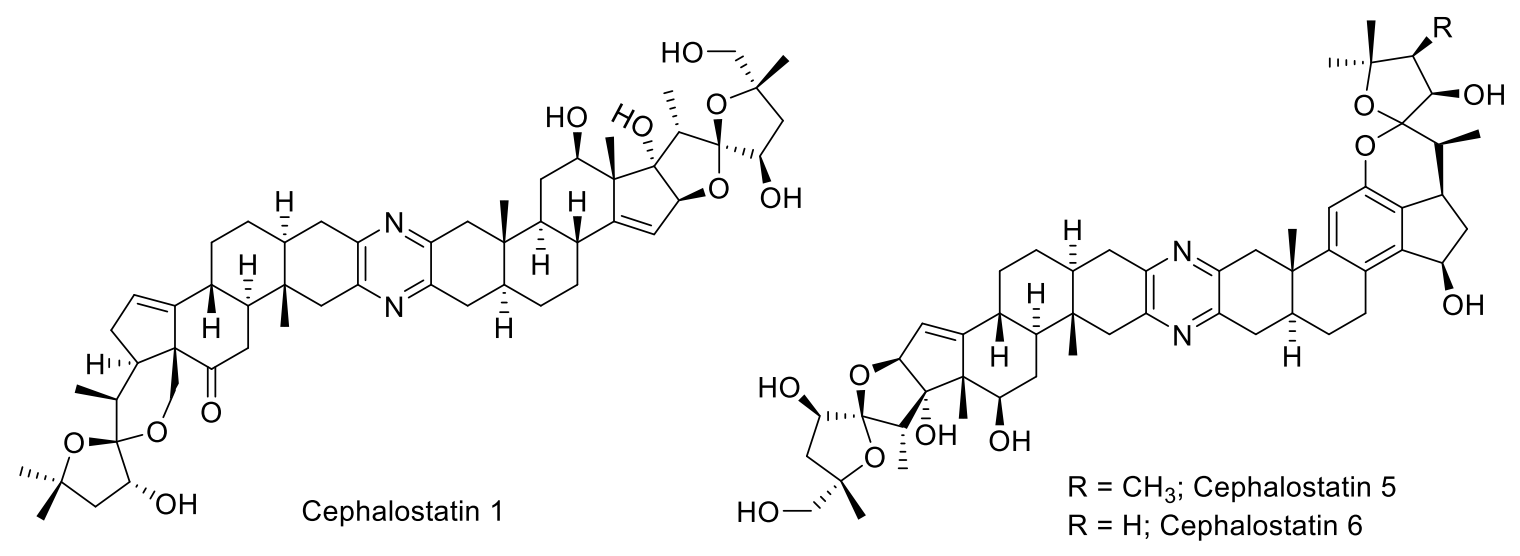

Figure 17. Structures of antitumor cephalostatin series.

\subsubsection{Non-steroid steroidal mimics}

Anabolic steroids are compounds that are similar to androgens (such as testosterone) in structural and biological properties. The mechanism of action of anabolic steroids begins when the compound binds to an androgen receptor. A novel class of androgen receptor drugs called Selective Androgen Receptor Modulators (SARMs) has been developed to minimize adverse effects of anabolic steroids on such targets as the prostate and heart. ${ }^{20}$ Among all SARMs, the non-steroidal SARMs are drawing tremendous 
attention since the first report of such compounds in 1998, as the use of anabolic steroids is limited by lack of tissue selectivity and prostate impairment. ${ }^{73}$ Many of the in vivo clinical properties of non-steroidal SARMs have been reported. ${ }^{20,73-75}$ These compounds show therapeutic activities such as the counteracting of muscle wasting associated with burns, cancer, end-stage renal disease, osteoporosis, frailty, or hypogonadism. Certain SARMs are aryl-propionamide (Ostarine, Enobosarm or GTx-024), bicyclic hydantoin (BMS-564,929), quinolinones (LGD-4033), tetrahydroquinoline analogs (S-40503) and some other imidazole, indole, and pyrazoline derivaties.

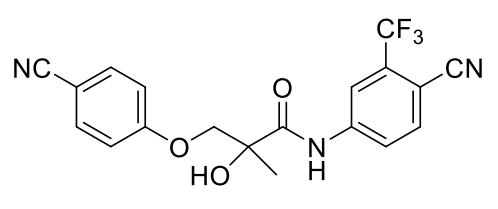

Ostarine

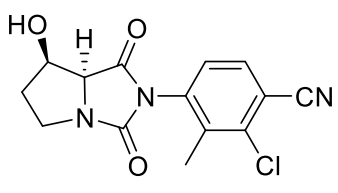

BMS-564929

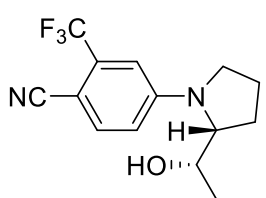

LGD-4033

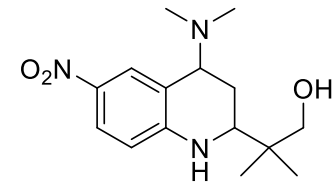

S-40503

Figure 18. Non-steroidal selective androgen receptor modulators.

Apart from the androgens and SARMs, there are several other therapeutic nonsteroid steroidal mimics such as non-steroidal estrogens and Selective Estrogen Receptor Modulators (SERMs) that have been using as drugs for hormone related complications. ${ }^{75}$ These compounds interact with estrogen receptors selectively in target cells as estrogen receptors vary in their structure within different tissues such as breast, bones, and uterus. Selective androgen receptor modulators are the most well-studied and most used drugs for the treatment of postmenopausal related issues including breast cancer and osteoporosis. Non-steroidal estrogens like Stilbestrol and its derivatives are used for the treatment of estrogen deficiency, menopausal symptoms, and prostate cancer. ${ }^{76}$ The drugs such as those with a triphenylethylene group (Clomifene, Tamoxifen, Toremifene and Ospemifene), 
Raloxifene, and newly discovered SERMs such as lasofoxifene, bazedoxifene and arzoxifene, are the examples in this class.

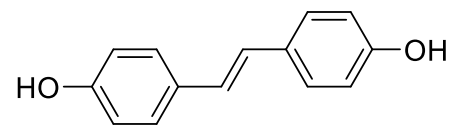

Stilbestrol

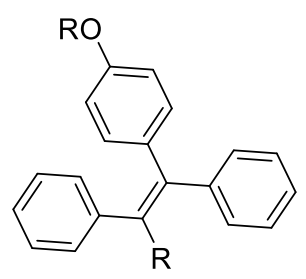

Triphenylethylene group

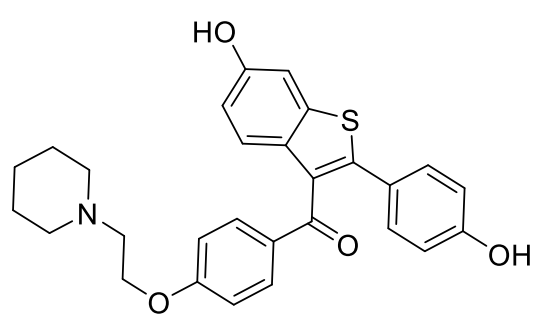

Raloxifene

Figure 19. Non-steroidal selective estrogen receptor modulators.

\subsection{Previous synthetic efforts reported on azasteroids}

Heterosteroids, particularly azasteroids, are of interest as novel drugs and the challenges in their synthesis prompted synthetic chemists to initiate studies in the total or partial synthesis of these compounds. Most of the synthetic approaches performed on azasteroids followed ring contraction and expansion strategies by using oxidative cleavages or Beckmann rearrangements. ${ }^{22-24,77-81}$ The direct synthetic methods leading to the azasteroids are very limited. Mentioned here are some of the previous partial/total synthetic methods leading to azasteroids including ring opening strategies in order to introduce nitrogen atoms.

\subsubsection{Ring contraction-expansion strategy by using Beckmann rearrangement}

In order to develop a route for the synthesis of 2-azasteroid $\mathbf{9}$, Robinson et al. ${ }^{23}$ used a ring contraction-expansion strategy starting from epiandrosterone 4 (Scheme 1). Initially, the A-ring was cleaved using chromium trioxide in acetic acid to get dicarboxylic acid compound 5. The seven-membered anhydride compound $\mathbf{6}$ was obtained from the corresponding dicarboxylic acid by reduction followed by acetylation. The decomposition 
of anhydride $\mathbf{6}$ at high temperature yielded A-norandrosterone 7. The keto group on the five membered ring was converted into a mixture of oximes $\mathbf{8}$ followed by Beckmann rearrangement to produce azasteroid 9.
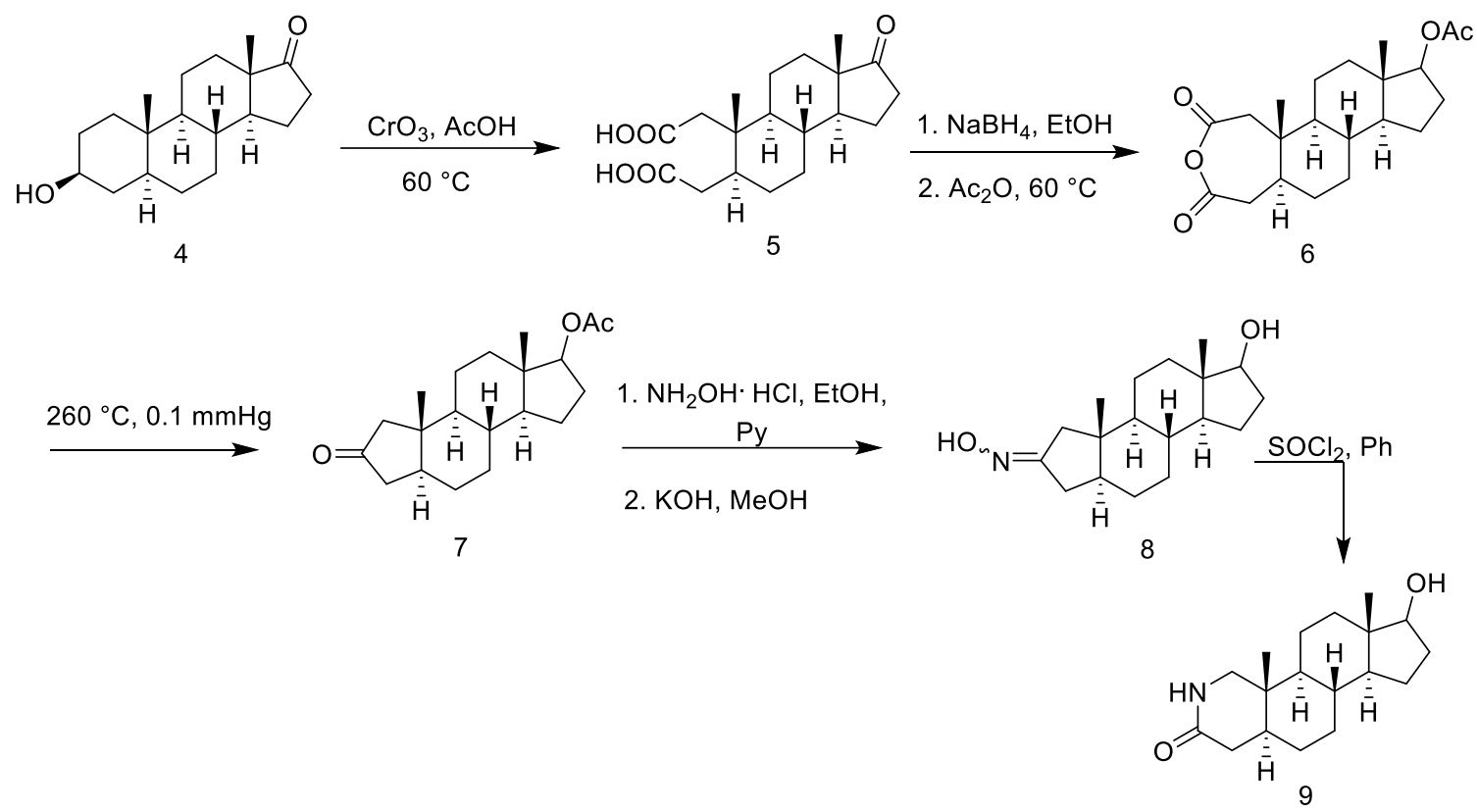

Scheme 1: Ring contraction and expansion strategy in azasteroidal synthesis.

\subsubsection{Ring opening and closing strategy by using oxidative cleavage}

The opening of a steroidal ring by oxidative cleavage to introduce a nitrogen atom is one of the commonly used method in azasteroidal synthesis. As previously mentioned, novel azasteroidal selective androgen receptor modulators 12-14 were synthesized by Mitchell et al. ${ }^{22}$ using oxidative cleavage to insert a nitrogen atom at the 4-position, starting from testosterone. The azasteroid $\mathbf{1 2}$ was obtained in two steps via oxidative cleavage of the A-ring of testosterone $\mathbf{1 0}$ with $\mathrm{KMnO}_{4}$ followed by treatment with methylamine in ethylene glycol with subsequent platinum catalyzed hydrogenation. The formed azasteroidal intermediate 12 was converted into other azasteroidal derivatives $13 \& 14$. 


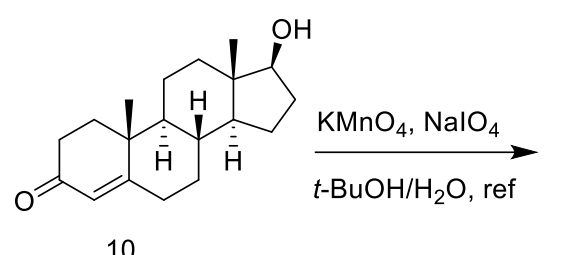

10

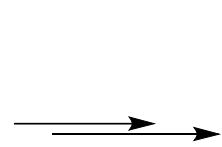

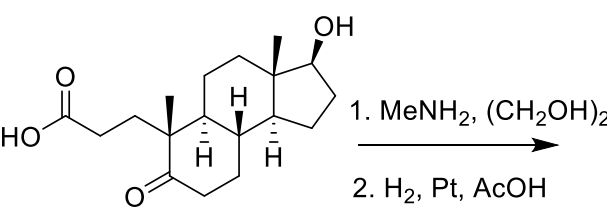

11

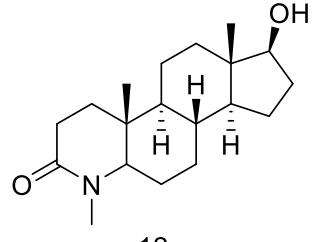

12
13

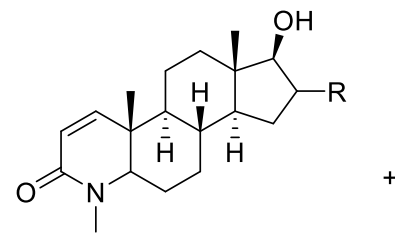

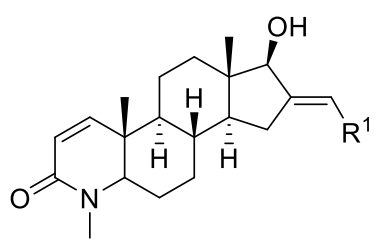

14

Scheme 2: Ring opening and closing strategy in azasteroidal synthesis.

\subsubsection{A combinatorial one step approach}

Ma et al. ${ }^{82}$ described a bimolecular cyclization reaction between two bis-allenes in presence of a $\mathrm{Rh}[\mathrm{I}]$ catalyst to synthesize 2 -aza and 2,16-diazasteroids, a combinatorial one step approach (Scheme 3). In the reaction they were able to synthesize four steroid like products $\mathbf{1 7 - 2 0}$ in moderate yields started with two different bis allens $\mathbf{1 5} \& \mathbf{1 6}$ with at least one hetero atom as tether in presence of the catalyst trans-[RhCl$\left.(\mathrm{CO})\left(\mathrm{PPh}_{3}\right)_{2}\right]$ complex.

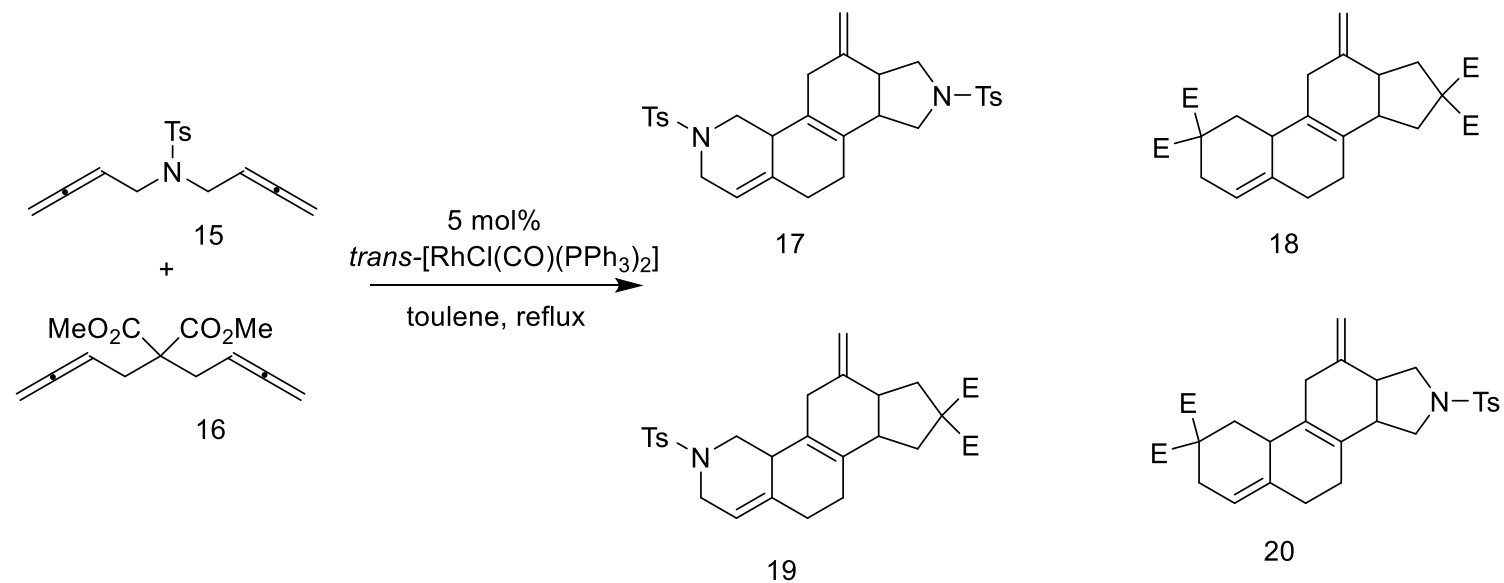

Scheme 3: One step approach in azasteroidal synthesis. 
This combinatorial one step approach is the most efficient method in the synthesis of particular azasteroids. However, the starting materials (15 \& 16) are not commercially available and two steps are needed to synthesize each compound. ${ }^{83-84}$ Moreover, no biological properties have been reported so far for these synthesized azasteroids and missing functionality at $\mathrm{C}-17$ could be a major disadvantage.

\subsubsection{Intramolecular Diels-alder strategy}

Intramolecular Diels-alder and cyclization strategies are excessively used synthetic methods in the synthesis of azasteroids as they form cyclic ring structures needed for the steroidal backbone. Recently, Ibrahim-Quali et al. reported two different reaction schemes (4\&5) for the synthesis of 3-azasteroidal type compounds involving a Diels-alder cyclization approach. 6,85
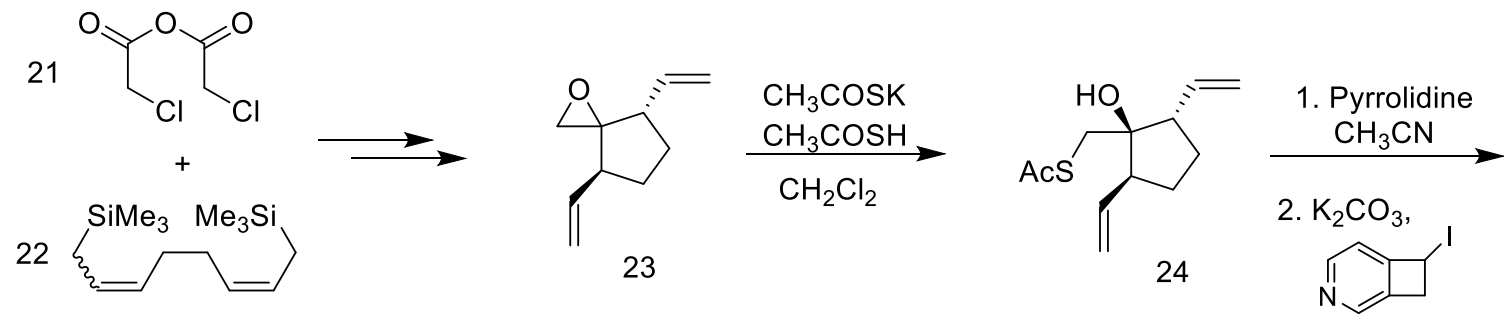

25

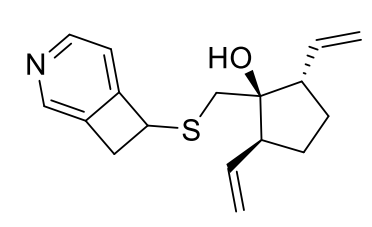

26

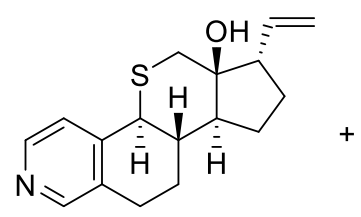

27

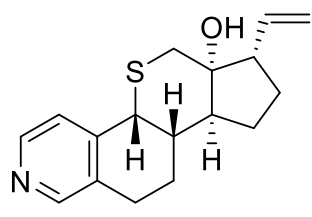

28

Scheme 4: Intramolecular Diels-alder strategy-1 in azasteroidal synthesis.

In both cases, they used intramolecular Diels-Alder cycloaddition of $o$-quinodimethanes as a key step to synthesize 3-aza-11-thia and 3,11-diaza-1,3,5-trieno steroids. These reactions 
start with epoxide compound 23, which is obtained from BISTRO 21 and chloroacetic anhydride 22 in two steps. The opening of the expoxide with potassium thioacetate which is followed by conversion to the intermediary thiol. The thiol was treated with 3 -aza-1,3,5triene compound 25 followed by thermolysis to the 3-aza-11-thia-1,3,5-trieno steroids $\mathbf{2 7 \& 2 8}$ (scheme 4). A similar methodology was applied in a second strategy to make 3,11diaza-1,3,5-trieno steroids $\mathbf{3 3} \& \mathbf{3 4}$ (scheme 5).

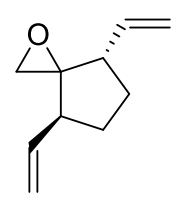

23

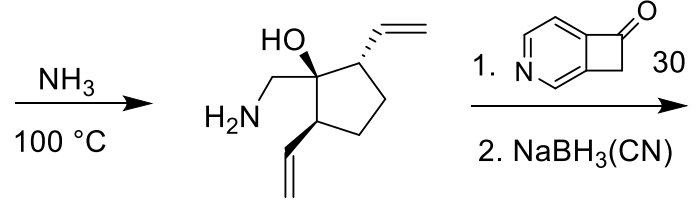

29

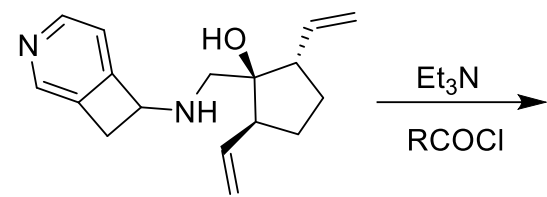

31

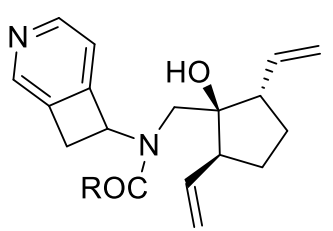

32

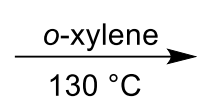

(30

Scheme 5: Intramolecular Diels-alder strategy-2 in azasteroidal synthesis

\subsubsection{Electrocylization involving Stille and Heck coupling}

Sunnemann et al. synthesized azasteroidal compounds by using Stille and Heck coupling as key steps (Scheme 6) ${ }^{86-87}$ Stille coupling on bromoenol triflates $\mathbf{3 6}$, obtained from bromopiperidinones $\mathbf{3 5}$, with bicycloalkenylstannanes $\mathbf{3 7}$ in presence of $\mathrm{Pd}$ and $\mathrm{Cu}$ catalysts yielded the intermediate compound 38. Compound $\mathbf{3 8}$ is then immediately coupled with $t$-butyl acrylate by using a modified Heck coupling. Upon heating the formed product 39, involved in an electrocyclization led to steroidal compound 40. The unstable 
steroids formed during electrocyclization further rearranged on heating to stable steroids

41.

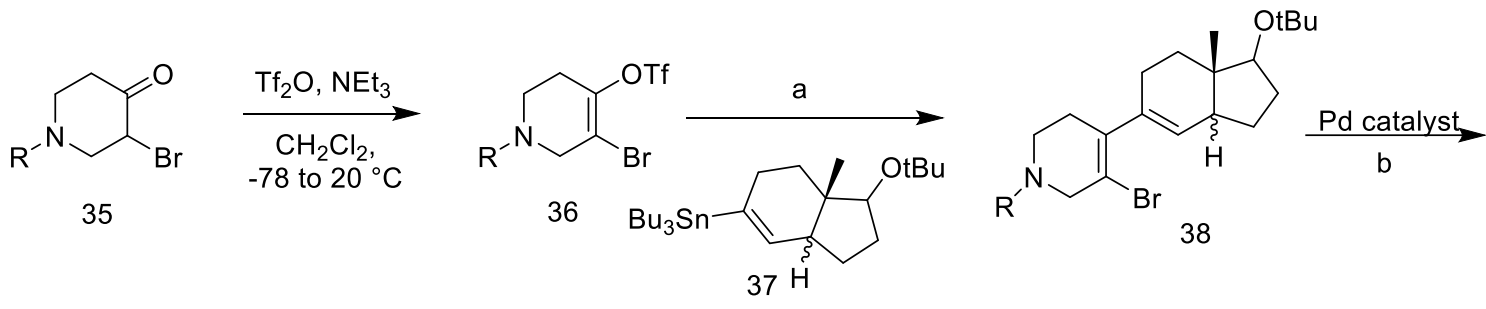

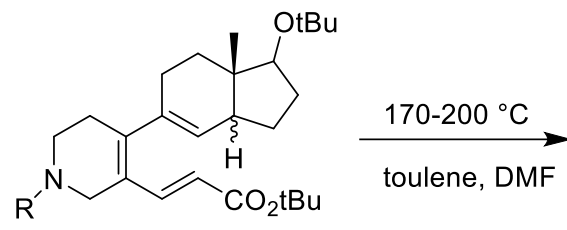

39

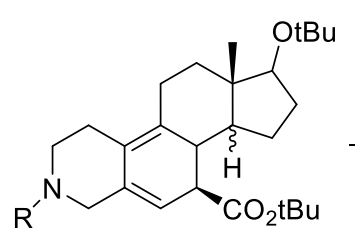

40

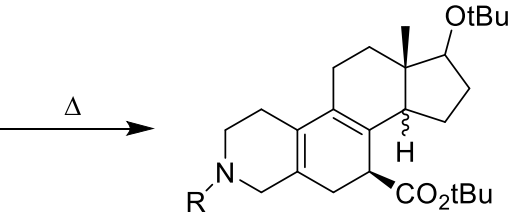

41

(a) $\left[\mathrm{Pd}_{2}(\mathrm{dba})_{3}{ }^{\circ} \mathrm{CHCl}_{3}\right], \mathrm{Cul}, \mathrm{LiCl}, \mathrm{NMP}, 65^{\circ} \mathrm{C}, 10 \mathrm{~h}$ (b) dppb, tert-butyl acrylate, $\mathrm{NEt}_{3}, \mathrm{DMF} / \mathrm{H}_{2} \mathrm{O}, 105^{\circ} \mathrm{C}$

Scheme 6: Electrocyclization strategy in azasteroidal synthesis. 


\section{CHAPTER 2: SYNTHESIS OF AZASTEROIDS}

\subsection{Design and synthesis of azasteroids}

The purpose of this research was to design various novel azasteroids with concise synthetic routes to such compounds. The challenges in the synthesis of steroids, particularly azasteroids, and the potential of azasteroids as novel drugs has prompted numerous investigations in the synthesis of azasteroids. The synthetic methods leading to steroidal derivatives (azasteroids) with one or more nitrogen atoms are very limited. Generally, oxidative cleavage of the steroidal rings is needed to introduce nitrogen atom(s) to synthesize azasteroids. ${ }^{22,} 77$ Even though several azasteroidal synthesis have been reported, there is still a need for the development of new methodologies as the previous synthetic methods are limited to particular steroidal structures. Preparation of novel azasteroidal compounds and the modification of substituents on their steroidal skeletons might provide congeners with useful biological properties.

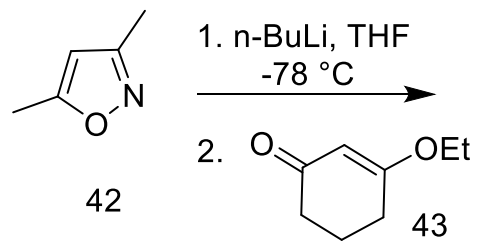

3. $\mathrm{H}_{3} \mathrm{O}^{+}$

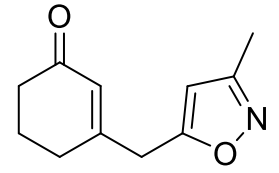

44

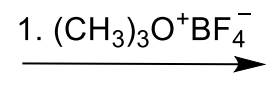

2. n-BuLi, THF $-78{ }^{\circ} \mathrm{C}$<smiles>CN/C(C)=C1\C(=O)c2c(cc(C)c3c2CCCC3=O)C1C1=CC(=O)CCC1</smiles>

46

Benzene, $50^{\circ} \mathrm{C}$

Scheme 7: Synthesis of tricyclic benz $[e]$ indenedione (Dimer, 46). 
Anhydrobases, a class of heterocyclic compounds, are known for their extreme instability. ${ }^{88-89}$ With the intent of exploring interesting reactivities of anhydrobases, Becker et al. synthesized and examined the chemistry of anhydrobases in the isoxazole series because of their weak nitrogen-oxygen bond ${ }^{89} \mathrm{~A}$ facile process involving commercially available starting materials such as 3,5-dimethylisoxazole $\mathbf{4 2}$ and carbocyclic vinylogous ester 43 led to the enone product $\mathbf{4 4}$ which was subsequently converted into the corresponding oxocycloalkenyl isoxazolium anhydrobase 45. Specifically, the lithiation of 3,5-dimethylisoxazole 42 with $\mathrm{nBLi}$ in THF at $-78{ }^{\circ} \mathrm{C}$ was performed by following the Micetich method ${ }^{90-91}$ that allows the lithiated intermediate to participate in a nucleophilic reaction by addition of 3-ethoxy-2-cyclohexen-1-one 43 . After acidification of the reaction mixture with $2 \mathrm{~N} \mathrm{HCl}$, the corresponding enone $\mathbf{4 4}$ was obtained in good yield. The $\mathrm{N}$ alkylation of enone $\mathbf{4 4}$ with trimethyloxonium tetrafluoroborate followed by deprotonation with addition of a solution of $\mathrm{n}-\mathrm{BuLi}$ in THF at $-78{ }^{\circ} \mathrm{C}$ afforded the desired anhydrobase 45. It has been observed that a new tricyclic benz $[e]$ indenedione 46 , a compound produced via initial dimerization of the anhydrobase, was formed when warming $\mathbf{4 5}$ in benzene at 50 ${ }^{\circ} \mathrm{C}$.

The structure of dimer compound $\mathbf{4 6}$ caused us to speculate on plans for synthetic routes to new steroid congeners, particularly azasteroids with potential biological activity. We were especially intrigued by the fact that the tricyclic ring structure and the keto functional group next to the aromatic ring provides a platform to establish a new six membered A-ring (or a mimic there of) needed for a steroidal skeleton. Moreover, the dimer compound $\mathbf{4 6}$ is equipped with interesting functionality at C-17 along with never before explored vinylogous amide functionality at $\mathrm{C}-15$ and $\mathrm{C}-16$. Here, we planned to 
synthesize a novel 1, 2-diazasteroid (pyridazinone) 47 and the azasteroidal mimic compounds 48 and 49 . The triazole moiety in 48 and furazan moiety in 49 were expected to align in the position of the A-ring, as a result of steric repulsion with the methyl group present on the aromatic C-ring, thus providing overall correspondence to a tetracyclic steroid skeleton.

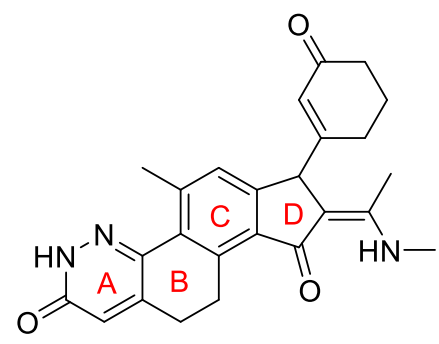

47

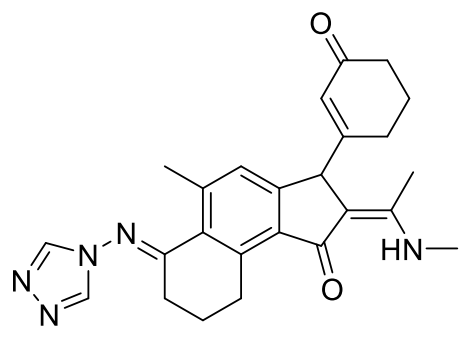

48

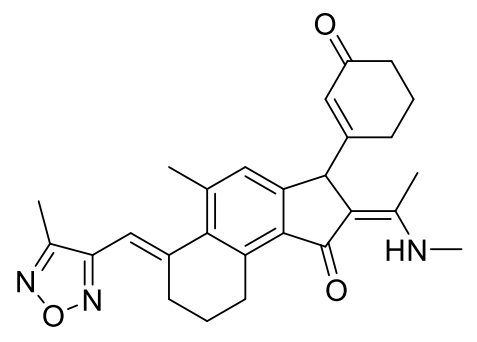

49

Figure 20. Structures of novel azasteroid and azasteroidal mimics.

\subsubsection{One-pot pyridazinone formation method from ketones}

There are many reported one-pot methods for the synthesis of pyridazinone molecules from ketones (acetophenone, 1-tetralone). ${ }^{92-96}$ Similar methodology could, in theory, be used to develop a new ring on dimer 46. An attempt to make a new ring was first performed on a model compound, 1-tetralone 50, which is similar to the moiety that is present in the dimer molecule (Scheme 8). Installment of the new ring on 1-tetralone was achieved by treating with glyoxylic acid in acidic medium at $110^{\circ} \mathrm{C}$, followed by treatment with hydrazine hydrate at $120{ }^{\circ} \mathrm{C}$ in one pot. However, the same chemistry failed on compound 46. The reaction of glyoxylic acid at the $\alpha$-position of the benzylic ketone moiety was also not observed when the reaction was performed in two steps.

With these results we postulate that the reaction failed because of the weak nucleophilicity or inefficient enolization of the ketone required for the desired aldol 
condensation. To increase the electrophilicity of the aldol partner, we made a second attempt using a reactive keto reagent, diethyl ketomalonate, at $100{ }^{\circ} \mathrm{C}$ for $12 \mathrm{~h}($ Scheme 9).<smiles>O=C1CCCc2ccccc21</smiles>

50

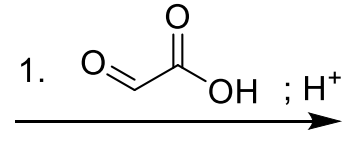

2. $\mathrm{H}_{2} \mathrm{~N}-\mathrm{NH}_{2}$<smiles>O=c1cc2c(n[nH]1)-c1ccccc1CC2</smiles>

51<smiles>CN/C(C)=C1\C(=O)c2c(cc(C)c3c2CCCC3=O)C1C1=CC(=O)CCC1</smiles>

46<smiles>O=C(O)C=[PH+]</smiles>

2. $\mathrm{H}_{2} \mathrm{~N}-\mathrm{NH}_{2}$<smiles>CN/C(C)=C1\C(=O)c2c(cc(C)c3c2CCc2cc(=O)[nH]nc2-3)C1C1=CC(=O)CCC1</smiles>

52

Scheme 8: Pyridazinone formation reaction on 1-tetralone and dimer.<smiles>O=C1CCCc2ccccc21</smiles>

50

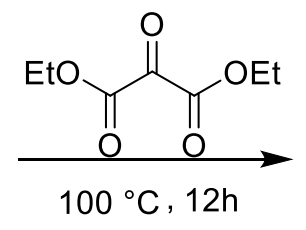<smiles>CCOCC(O)(C(=O)OCC)C1CCc2ccccc2C1=O</smiles>

53<smiles>CCOC(=O)c1c2c(n[nH]c1=O)-c1ccccc1CC2</smiles>

54<smiles>CCOC(=O)C(=O)OCC</smiles><smiles>CCOC(=O)C(O)(C(=O)OCC)C1CCc2c(c(C)cc3c2C(=O)C(=C(C)NC)C3C2=CC(=O)CCC2)C1=O</smiles>

Scheme 9: Second attempt of making Pyridazinone on dimer. 
A subsequent closing of the ring using hydrazine hydrate was hypothesized. Similar results were obtained such that it was successful on 1-tetralone but not on the desired dimer compound 46. According to proton NMR data it has been assumed that the diethyl ketomalonate was reacting with the vinylogous amide instead of with the benzylic ketone. More data are needed to confirm the structure of the product.

\subsubsection{Hydrazone formation methods}

After difficulties with the aldol reactions, the focus shifted towards the reactivity of the benzylic ketone moiety. Hydrazone formation is one of the feasible reactions that takes place readily on ketones. ${ }^{97-98}$ Such a strategy was tried using a substituted hydrazine as a reagent with an appropriate side chain (such as aminoguanidine and cyanoacetohydrazide) needed for ring closure. Two reactions were performed on 1tetralone by using aminoguanidine ${ }^{97}$ and cyanoacetohydrazide ${ }^{98}$ with a subsequent plan of closing the ring (Scheme 10).<smiles>O=C1CCCc2ccccc21</smiles>

50<smiles>O=C1CCCc2ccccc21</smiles>

50
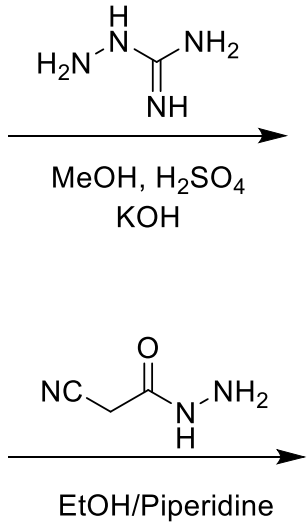

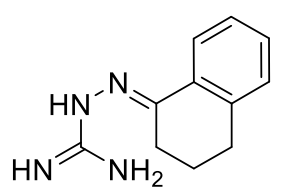

56

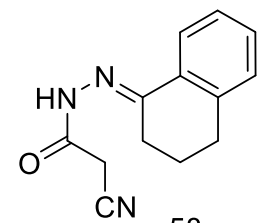

58
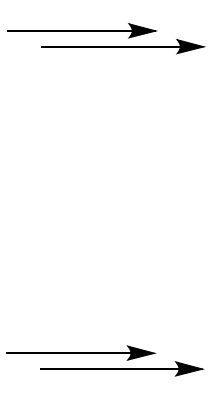

Scheme 10: Hydrozone formations on 1-tetralone.<smiles>N=c1nc2c(n[nH]1)-c1ccccc1CC2</smiles>

57<smiles></smiles> 
Protic solvents were used in both cases and the products formed in good yields. Piperidine was used as catalyst in the second reaction with cyanoacetohydrazide. Unfortunately these reactions were not successful on dimer compound even with excess quantity of reagents. The reactions might have taken place preferentially at the enone functionality.<smiles>CNC(C)C(C)NC(N)=NC(=O)C1C(=O)c2c(cc(C)c3c2CCCC3=O)C1C1=CC(=O)CCC1</smiles>

46<smiles>CNC(C)=C1C(=O)c2c(cc(C)c3c2CCCC3=O)C1C1=CC(=O)CCC1</smiles>

46

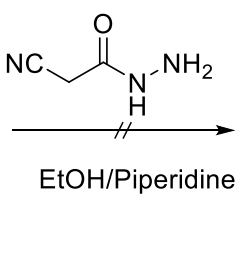

$\overbrace{C N}$

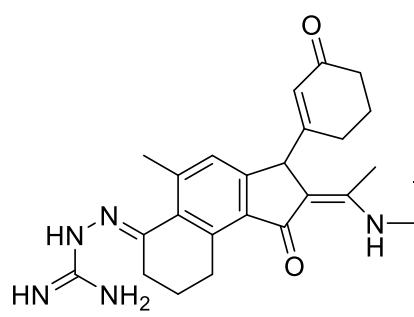

60

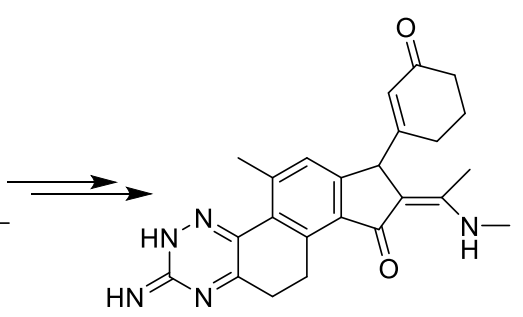

61

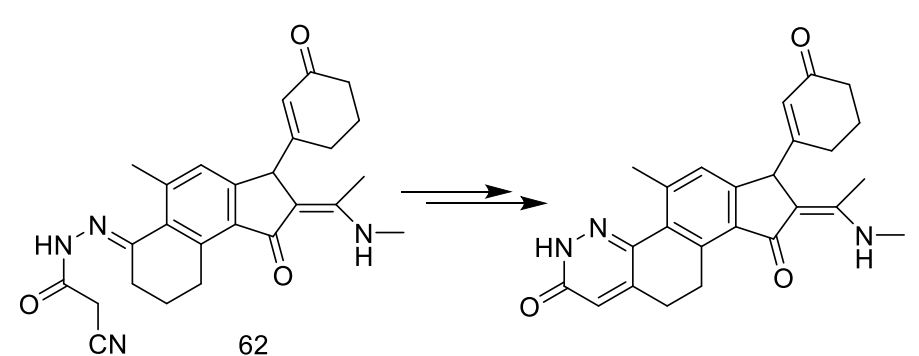

63

Scheme 11: Hydrazone formation attempts on dimer.

\subsubsection{Attempts to activate the benzylic ketone moiety}

The results from previous reactions revealed that the $\alpha$-position of the benzylic ketone or the ketone itself is a poor reactive site. The poor reactivity of this carbonyl group is not surprising because of steric interactions with the methyl group present on the neighboring aromatic ring. It was decided to try reactions that can improve the reactivity of the ketone and its $\alpha$-position. Neber rearrangement is one of those organic reactions that can activate the $\alpha$-position of ketones by converting the corresponding oximes into $\alpha$-amino ketones and $\alpha$-amino acetals. ${ }^{179}$ For our purposes, the acetal group is required to close the 
ring with the chain that is formed after reacting the $\alpha$-amino group with ethyl oxamate. In model studies, 1-tetralone was successfully converted into the corresponding tosylated oxime 65 that is needed for the rearrangement, with excellent yields in two steps (Scheme 12). ${ }^{99-100}$ However, Neber rearrangement was not attempted on 46 since the model studies employing 1-tetralone failed to give any of the desired rearrangement product.

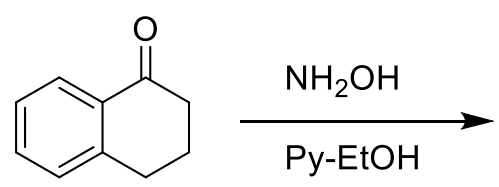

50

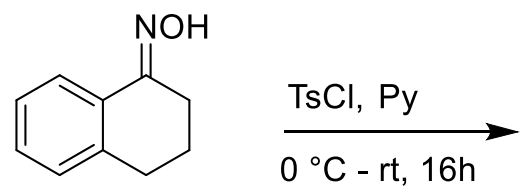

64

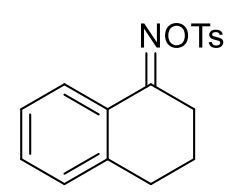

65

KOEt, EtOH, $0^{\circ} \mathrm{C}$
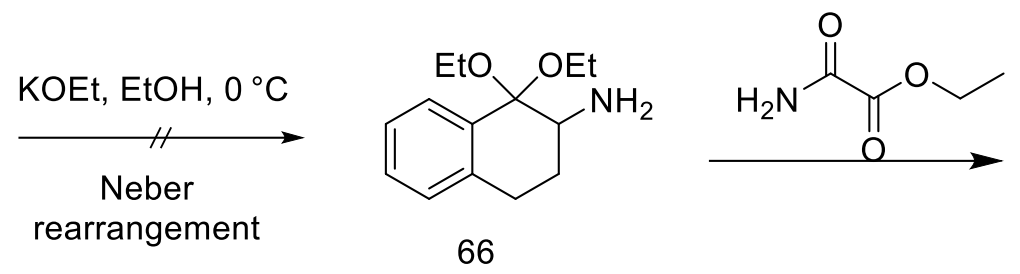<smiles>CCOC(=NC1CCc2ccccc2C1(OCC)OCC)C(N)=O</smiles>

67<smiles>CCOC1=NC2CCc3ccccc3C2=NC1=O</smiles>

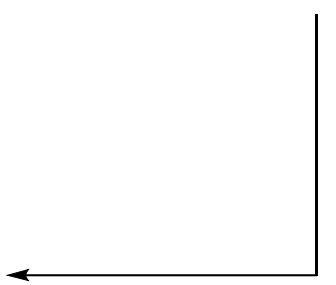

68

Scheme 12: Neber rearrangement on 1-tetralone.

\subsubsection{Attempted synthesis of compound 49}

A model reaction was performed on 1-tetralone in order to find conditions that might be used for preparing compound 49. Thus, the addition reaction between 1-tetralone and lithiated 3,4-dimethylfurazan 69 with subsequent dehydration in presence of acidic 
acid was explored (Scheme 13). The method failed in the initial stages as the alkylation reaction was not produced the corresponding alcohol product $\mathbf{7 0}$.

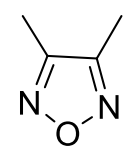

69

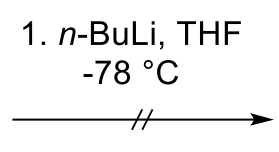

2. 1-tetralone

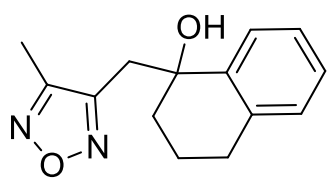

70

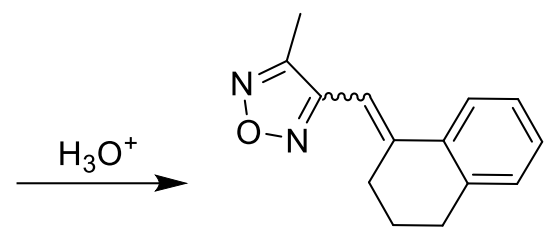

71

Scheme 13: An alkylation reaction on 1-tetralone.

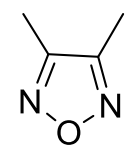

69
1. $n$-BuLi, THF $-78^{\circ} \mathrm{C}$

2. Diethylchloro-phosphate

Scheme 14: Horner-Wadsworth-Emmons reaction on 1-tetralone.

The Horner- Wadsworth - Emmons strategy was also investigated to convert 1tetralone into the corresponding olefin. The first step, which is the making of phosphorous ylide 72 was successfully performed (45\% yield) by treating lithiated 3,4-dimethylfurazan with diethylchlorophosphate (Scheme 14). The obtained phosphonate was then converted into the corresponding phosphonate stabilized carbanion by treatment with $n$-BuLi, which was then allowed to react with 1-tetralone. The strategy failed to generate the desired product.

The reason behind the above failed reactions was that 1-tetralone is too readily enolized, thus precluding nucleophilic additions to the keto group. ${ }^{101}$ Interestingly, a reaction took place at the $\alpha$-position of 1 -tetralone when it was treated with $n$-BuLi followed by diethyl ketomalonate (Scheme 15). 
<smiles>O=C1CCCc2ccccc21</smiles>

50

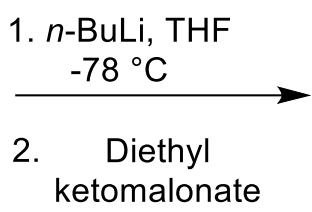

ketomalonate

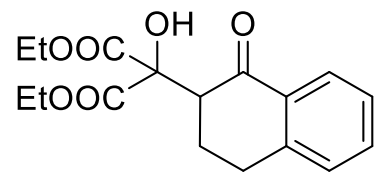

53

Scheme 15: Enolization reaction of 1-tetralone.

\subsubsection{Hydrazone formation using 4-amino-4H-1,2,4-triazole}

After failures in the formation of tetralone hydrazones with compound 46, it was decided to fully explore perfect conditions for this reaction on 1-tetralone using various reaction conditions. Further trials were started that were directed toward the synthesis of the second target molecule $\mathbf{4 8}$ as the synthesis of $\mathbf{4 8}$ involves the formation of a hydrazone from dimer 46. The hydrazonation reaction on 1-tetralone was investigated using 4-amino4H-1,2,4-triazole 73 under several conditions (Scheme 16), especially in different solvents at various temperatures. The results are summarized in Table 1 . The yield was very low in alcohols and some other organic solvents such as benzene, toluene and pyridine (entries 15). In contrast, the yields were moderate with the addition of catalysts $(\mathrm{BaO}, \mathrm{TsOH})($ entries 6\&7). Heating at high temperature without any solvent or in isoquinoline as well as stirring in acetic acid provided good yields (entries 8-10). In all cases, $4 \mathrm{~A}^{\circ}$ molecular sieves were used to maintain dry conditions.<smiles>O=C1CCCc2ccccc21</smiles>

50

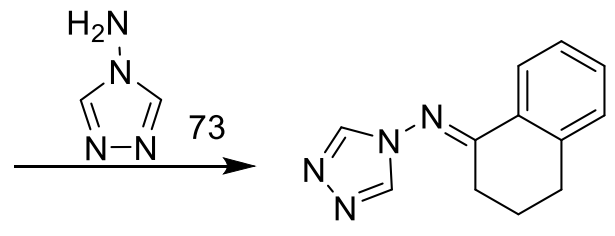

74

Scheme 16: Hydrazone formation employing 4-amino-4H-1,2,4-triazole moiety on 1tetralone. 


\begin{tabular}{ccccc}
\hline Entry & Solvent & Catalyst & Temp $^{\circ} \mathbf{C}$ & Yield \% (74) \\
\hline 1 & EtOH & $\mathrm{H}^{+}$ & 70 & 15 \\
\hline 2 & $\mathrm{Et}_{3} \mathrm{~N}$ & - & 80 & 20 \\
\hline 3 & Benzene & - & 80 & 16 \\
\hline 4 & Toluene & - & 100 & 26 \\
\hline 5 & Pyridine & - & 100 & 22 \\
\hline 6 & EtOH & $\mathrm{BaO}$ & 25 & 48 \\
\hline 7 & Toluene & $\mathrm{TsOH}$ & 100 & 50 \\
\hline 8 & AcOH & - & 25 & 72 \\
\hline 9 & - & - & 100 & 83 \\
\hline 10 & Isoquinoline & - & 150 & 85 \\
\hline
\end{tabular}

Table 1. Reaction conditions and yields for the hydrazonation of 1-tetralone with 4amino-4H-1,2,4-triazole.

Thus, the high yielding reaction conditions (such as acetic acid as a solvent, isoquinoline at $150{ }^{\circ} \mathrm{C}$, and without solvent at $100{ }^{\circ} \mathrm{C}$ ) were applied to dimer $\mathbf{4 6}$ (Scheme 17). In all cases, the hydrazone formation was observed to occur at the cyclohexenone carbonyl with both stereo isomers present ( $E$ and $Z$ of 75) in a 3:1 ratio. No hydrazone formation at the benzylic ketone of $\mathbf{4 6}$ took place even with an excess of 4-amino-4H-1,2,4triazole.

These failed hydrazonation attempts demonstrated that the benzylic ketone is under the steric influence of the methyl group of the aromatic ring. The effect of steric hindrance of methyl group on adjacent carbonyl carbon was then confirmed by conducting a model 
study with 5,8-dimethyl-1-tetralone $\mathbf{7 7}$ which yielded no product when treated with 4amino-4H-1,2,4-triazole (Scheme 18), in contrast, the same reaction was successful with 1-tetralone.<smiles>CNC(C)=C1C(=O)c2c(cc(C)c3c2CCCC3=O)C1C1=CC(=O)CCC1</smiles>

46

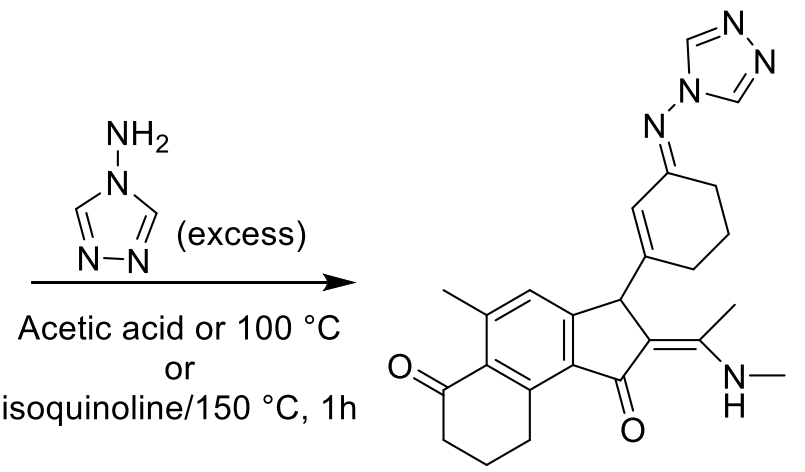

75<smiles>CN/C(C)=C1\C(=O)c2c(cc(C)c3c2CCC/C3=N\n2cnnc2)C1C1=C/C(=N/n2cnnc2)CCC1</smiles>

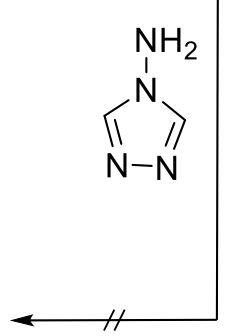

Scheme 17: Hydrazone formation attempts using 4-amino-4H-1,2,4-triazole on dimer.<smiles>Cc1ccc(C)c2c1CCCC2=O</smiles>

77

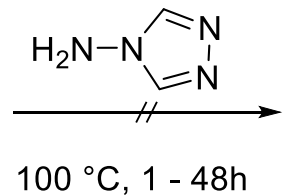

$100{ }^{\circ} \mathrm{C}, 1-48 \mathrm{~h}$<smiles>Cc1ccc(C)c2c1CCC/C2=N\n1cnnc1</smiles>

78

Scheme 18: Attempted hydrazone formation between 5,8-dimethyl-1-tetralone and 4amino-4H-1,2,4-triazole. 
From the above results, it has been concluded that the benzylic ketone is not as reactive as expected and that the aromatic ring is not providing any additional advantage. There are some other reactive sites on dimer $\mathbf{4 6}$ such as the cyclohexenone, the enaminone, and the tertiary benzylic hydrogen present on the five membered ring. We can presume that the reason behind the poor reactivity of this benzylic ketone is because it is located on the tricyclic rigid structure, and primarily, that is under the steric hindrance of the methyl group present on the aromatic ring (Figure 1).

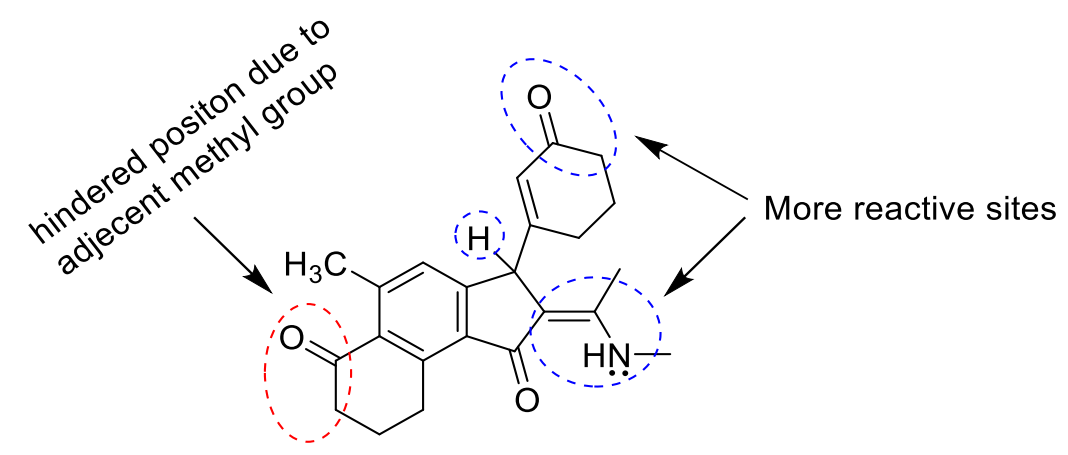

Figure 21. Reactive and hindered moieties on dimer 46.

\subsubsection{Hydrazone formation catalyzed by $\mathrm{Sc}(\mathrm{OTf})_{3}$}

To increase the reactivity of the benzylic ketone, the hydrazone formation reaction has been carried out on 5,8-dimethyl-1-tetralone in the presence of ketone activating catalysts such as titanium isopropoxide, cerium(III) chloride and scandium triflate. Of these catalysts, scandium triflate showed promising results when 5,8-dimethyl-1-tetralone and 4-amino- $4 H-1,2,4$-triazole were heated at $100{ }^{\circ} \mathrm{C}$ in the presence of 15 mole percent of scandium triflate without any solvent for $3 \mathrm{~h}, 40 \%$ yield of the corresponding hydrazone was obtained (Scheme 19). 
<smiles>Cc1ccc(C)c2c1CCCC2=O</smiles>

77

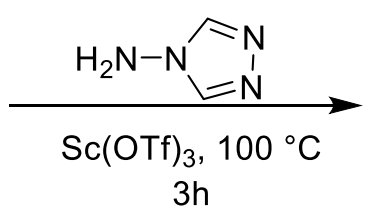

3h

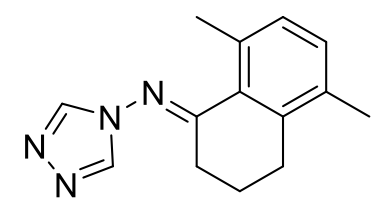

78

Scheme 19: Scandium triflate catalyzed hydrazonation of 5,8-dimethyl-1-tetralone.

The same reaction conditions were applied to dimer $\mathbf{4 6}$ and it has been observed that the triazole reacted with both ketones yielding $30 \%$ of monohydrazone product (75) (reacting at cyclohexenone carbonyl) and nearly the same percent of bishydrazone product (76) (reacting at both keto groups) (Scheme 20).

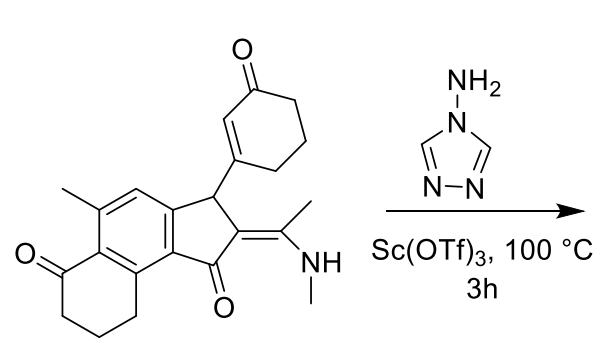

46

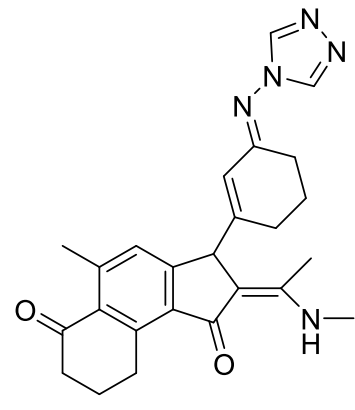

75

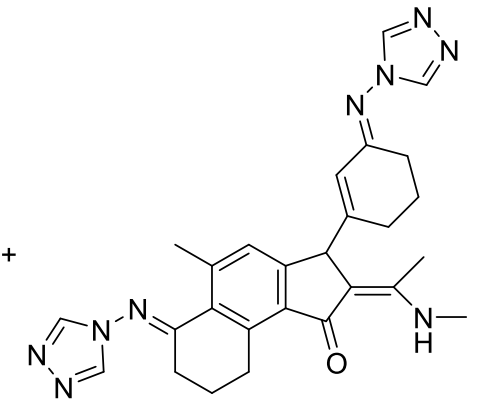

76

Scheme 20: Hydrazone formation on dimer in presence of catalyst.

Geometric hydrazone isomers were observed in the NMR data for both products. Similar results were obtained when the reaction was performed in the absence of catalyst for one hour (converting dimer compound into monohydrazone) and stirred in presence of catalyst for another $2 \mathrm{~h}$ in one pot. Some improvement in yield of bishydrazone product was observed when the reaction was carried out in two steps (Scheme 21). Thus, a $75 \%$ yield of monohydrazone product was realized in the first reaction without catalyst. The monohydrazone is then reacted with the triazole reagent in the presence of scandium triflate 
to afford $40 \%$ yield of the bishydrazone product along with $20 \%$ of unreacted starting material.<smiles>CNC(C)=C1C(=O)c2c(cc(C)c3c2CCCC3=O)C1C1=CC(=O)CCC1</smiles>

46

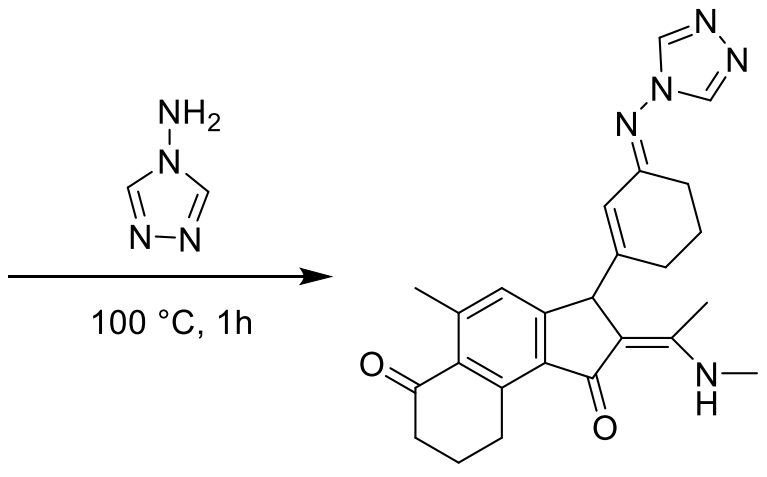

75<smiles>CN/C(C)=C1\C(=O)c2c(cc(C)c3c2CCC/C3=N\n2cnnc2)C1C1=C/C(=N/n2cnnc2)CCC1</smiles>

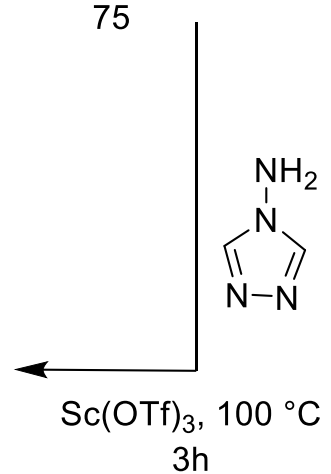

76

Scheme 21: Hydrazone formation (two steps) on dimer in presence of catalyst.

The facile formation of the monohydrazone product in the presence/absence of catalyst showed the higher reactivity and availability of the cyclohexenone carbonyl. Similar selectivity was expected and observed when a dehydrazonation reaction was performed on bishydrazone 76. Thus, treatment of bis-hydrazone $\mathbf{7 5}$ in THF with $\mathrm{CuCl}_{2} / \mathrm{H}_{2} \mathrm{O}$ solution over $10 \mathrm{~h}$ at $\mathrm{rt}$ yielded the desired monohydrazone 48 (Scheme 22). ${ }^{102}$ It is gratifying to confirm that the selective dehydrazonation occurs on the cyclohexenone hydrazone and leaves the benzylic hydrazone unaffected. Moreover, importantly, it is not 
surprising that we identified only one isomer in the product by using $\mathrm{H}^{1}-\mathrm{NMR}$ spectroscopy, indicating that the initial hydrazone formation took place stereoselectively on the benzylic ketone as expected (directed away from the methyl group present on the aromatic ring).

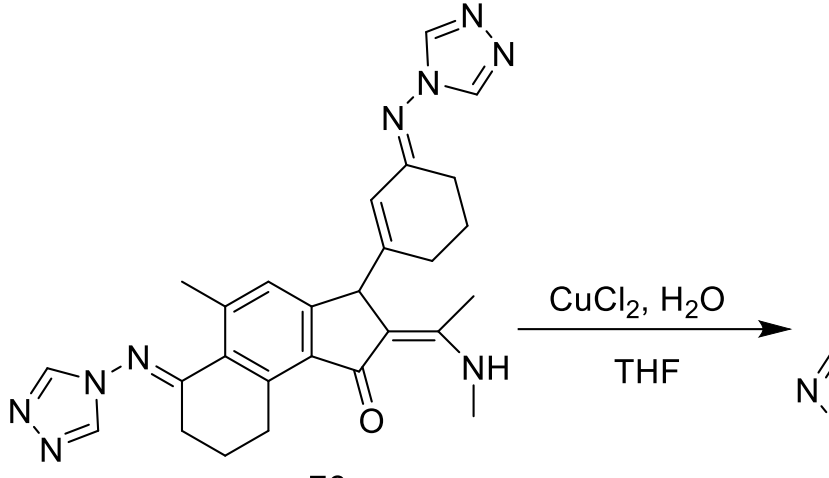

76

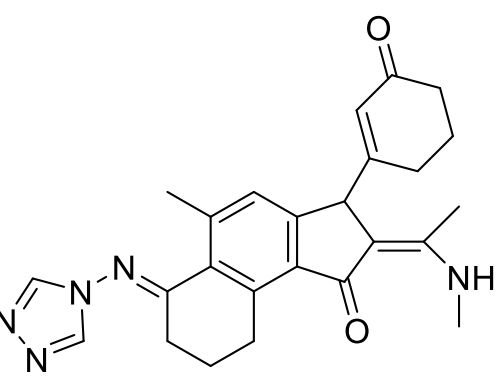

48

Scheme 22: Selective dehydrazone reaction on Bishydrazone compound 76.

With the novel steroid mimic $\mathbf{4 8}$ now in hand, we are eager to ascertain if it possesses interesting biological properties. We also intend to pursue purification of both enantiomers via chiral HPLC in the near future.

\subsection{Conclusion regarding azasteroidal synthesis}

Natural and synthetic steroids are very important in chemistry as well as in medicinal biology. Steroids have tremendous therapeutic properties including antiinflammatory, growth stimulation and also used as oral contraceptives. Steroids and their biological properties can widely vary in the configuration of gonane (steroidal nucleus) and the nature/position of attached groups. We can produce significant differences in their biological properties by making modifications in steroidal molecular structure. 


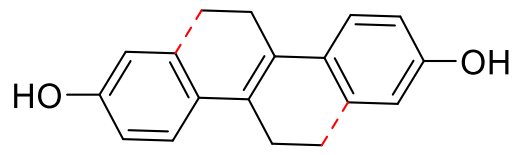

Diethylstilbestrol

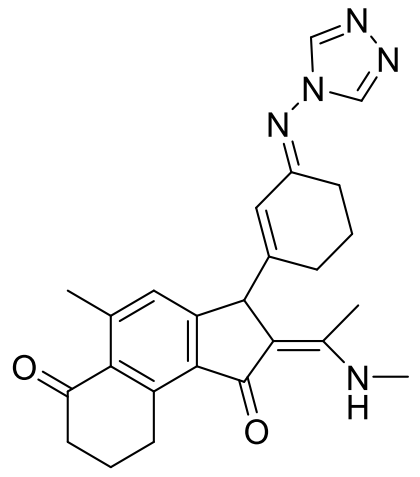

75

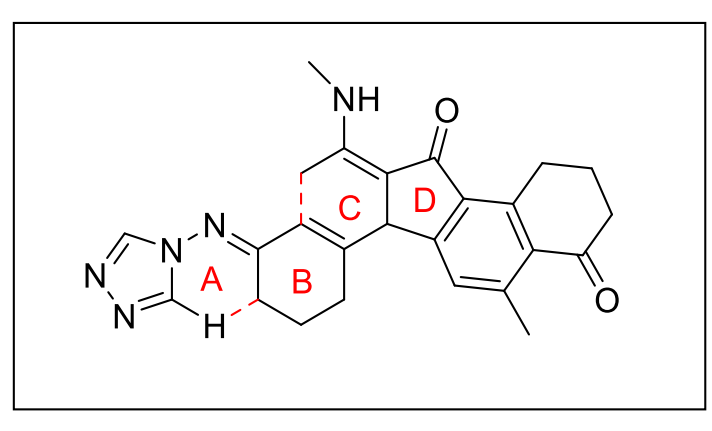

Secosteroidal structure of 75

Figure 22. Secosteroids.

Among those three compounds $(\mathbf{7 5}, \mathbf{7 6}$ and $\mathbf{4 8})$ obtained from hydrazone reactions, compound 48 grasping most of our attention as it is a mimic of azasteroidal molecular structure. However, the other two compounds also have a salient feature of secosteroidal structure. The steroidal compounds with broken ring structure are classified as secosteroids. These are similar to the non-steroidal compounds in their physical appearance but having steroidal biological properties. Cholecalciferol (vitamin $\mathrm{D}_{3}$ ) and diethylstilbestrol are good examples of known secosteroids. It is hypothesized that these compounds mimic the molecular structures of steroids with formation of rings by virtual bonding. 


\section{PSEUDO AZULENYL NITRONES}

\section{CHAPTER 3: INTRODUCTION}

\subsection{Free radicals in biological systems}

Atoms, molecules or ionic species which possess one or more unpaired electrons are called free radicals. The species of free radicals containing oxygen or nitrogen atoms in which the unpaired electron resides on the oxygen or nitrogen are referred to as reactive oxygen species (ROS) or reactive nitrogen species (RNS), respectively. The concept of free radicals was discovered and identified many decades ago. ${ }^{103-105}$ However, the importance of free radicals in physiological functions and their role in biological disorders have been explored only in the last few decades. ${ }^{106}$

Free radicals such as ROS and RNS are generated during cellular metabolism. They can be either harmful or beneficial to the biological system. ${ }^{107}$ At low or moderate concentration, they play an important beneficial role in mediating cellular signaling (as a part of the body's defense mechanism), and in various physiological functions. ${ }^{108}$ The biological damages referred to oxidative stress and nitrosative stress are a harmful hallmark of the free radical generation. ${ }^{109-111}$ The adverse effects can occur by either a massive production of ROS and RNS radicals or by the deficiency of enzymatic and non-enzymatic antioxidants in living organisms. The ROS radicals are highly reactive species and create oxidative stress by damaging vital biological molecules such as lipids, nucleic acids, DNA, carbohydrates and proteins. Overproduction of ROS radicals is deleterious and leads to oxidative stress which is responsible for many pathological conditions such as cancer, aging, stroke, cardiovascular pathology and many neurodegenerative diseases. ${ }^{104,}$ 112-116 
Hydroxide radical $(\bullet \mathrm{OH})$, superoxide anion radical $\left(\mathrm{O}_{2} \bullet^{-}\right)$, and nitric oxide radical $(\mathrm{NO} \bullet)$ are some examples of ROS. Some other non-radical compounds, generated from ROS radicals, such as hydrogen peroxide $\left(\mathrm{H}_{2} \mathrm{O}_{2}\right)$ and peroxynitrite ion are also harmful.

\subsubsection{Generation of reactive oxygen species (ROS) in the human body}

The genesis of free radicals occurs either through external sources such as x-rays, UV-rays, smoking, pollution and industrial chemicals, or by normal metabolic enzymatic or non-enzymatic processes. The ROS radicals are the most important radicals among all free radicals generated in living systems. Superoxide radical or superoxide anion radical is treated as a primary ROS radical, which is produced by either metabolic processes or by reduction of molecular oxygen via photochemical reactions. Superoxide radical itself is not a dangerous ROS radical but it further interacts with other molecules in order to give rise to harmful secondary ROS radicals and non-radical compounds.

\subsubsection{Superoxide radical anion}

Mitochondria are the main source of superoxide radicals. ${ }^{117}$ Adenosine triphosphate (ATP) synthesis is an enzymatic and respiratory biological process that occurs inside the mitochondria. The co-enzyme nicotinamide adenine dinucleotide 'NADH' produced in glycolysis is responsible for the formation of electrons at mitochondria via redox reactions. These generated electrons participate in the electron transport chain through a series of transition molecules, such as coenzymes, cytochrome to generate ATP (Figure 23). Oxygen, at the terminus of the electron transport chain, serves as a natural terminator of these free radical reactions by reducing itself into water. The enzymatic process is kept under control by physical and chemical couplings of the intermediates. 


$$
\begin{aligned}
& \mathrm{NADH} \longrightarrow \mathrm{NAD}^{+}+\mathrm{H}^{+}+2 \mathrm{e}^{-} \\
& \mathrm{O}_{2}+4 \mathrm{e}^{-}+4 \mathrm{H}^{+} \longrightarrow 2 \mathrm{H}_{2} \mathrm{O}+\text { Energy }
\end{aligned}
$$

Every time an electron goes from a higher energy state to a lower energy state over the course of this electron transport chain, it releases energy. The released energy is used to pump protons across the inner membrane of the mitochondria. ${ }^{118}$ Because of the pumping of protons from the inner membrane (matrix) to the outer membrane of the mitochondria, the matrix or inner membrane becomes slightly nucleophilic.

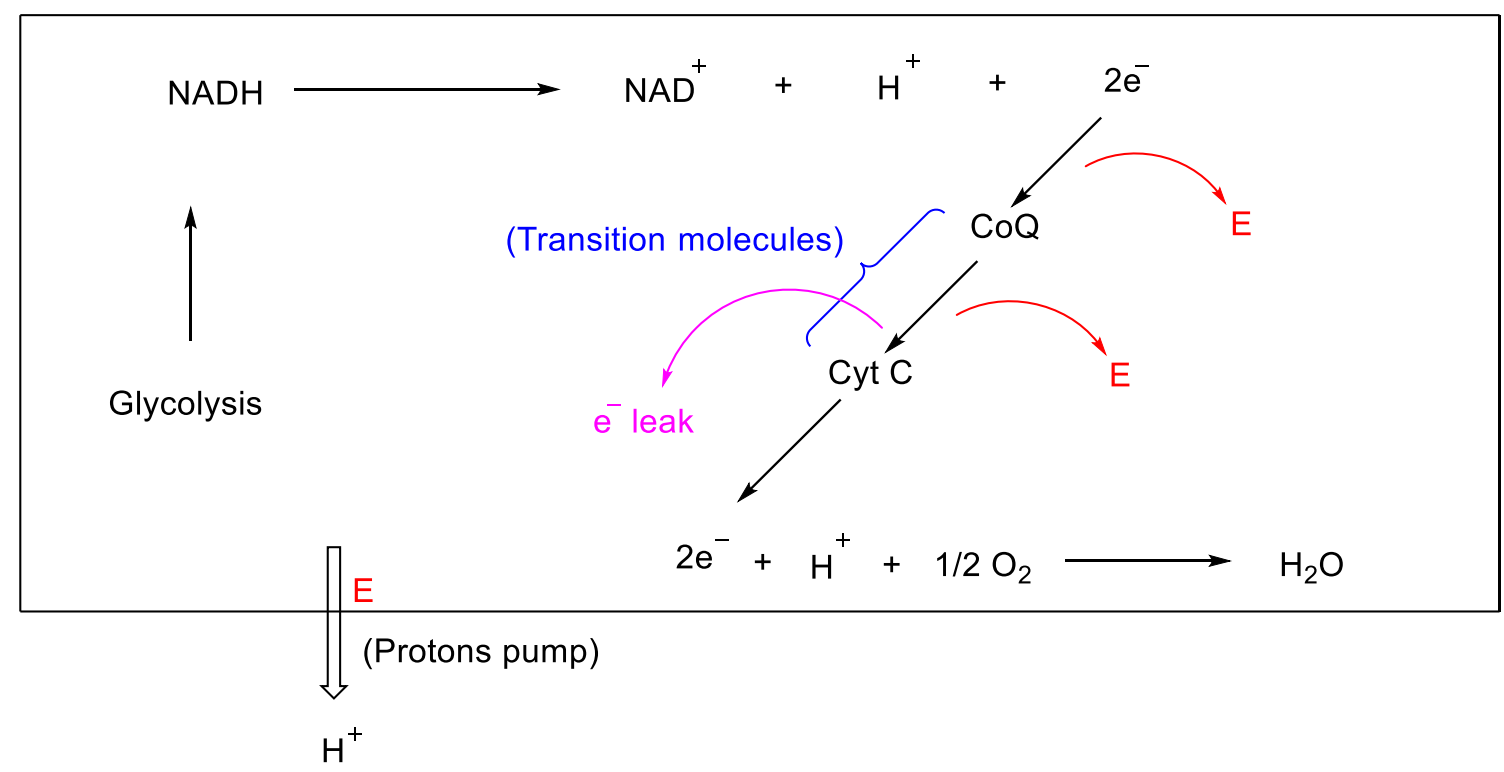

Figure 23. Electron transport chain

On the other hand, during the electron transport process, a small amount (1-3\%) of premature electron leakage to molecular oxygen takes place. ${ }^{108}$ The leaked electrons are involved in the generation of deleterious superoxide radicals by a univalent reduction reaction with oxygen molecules.

$$
\mathrm{O}_{2}+\mathrm{e}^{-} \longrightarrow \mathrm{O}_{2}^{--}
$$


Superoxide radicals are also produced by an enzyme called NADPH oxidase during the respiratory burst or oxidative burst, an immune defense mechanism to combat infections. ${ }^{119}$ The NADH or NADPH oxidase is used to reduce molecular oxygen into superoxide radical and then $\mathrm{H}_{2} \mathrm{O}_{2}$, which are employed in destroying bacteria. Superoxide radicals are also generated by another enzyme, xanthine oxidase, which converts hypoxanthine to xanthine (then to uric acid). ${ }^{120}$ In both oxidation reactions, it produces superoxide radicals and causes some oxidative damage via oxidative stress. The other prominent pathway for generating superoxide radical is the oxidation of $\mathrm{NADH}$ in the presence of catalase. ${ }^{121}$ The mechanism involves the conversion of NADH to NAD radical by catalase in the presence of hydrogen peroxide. The resulting NAD radical transfers its electron to an oxygen molecule in order to produce the superoxide radical.

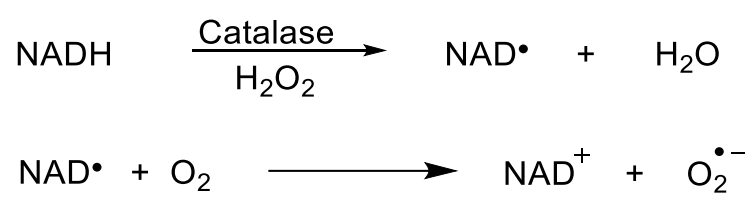

Several other enzymes producing superoxide radicals have been reported such as peroxidases, lipoxygenase ${ }^{122}$ and cycloxygenase. ${ }^{123}$ On the other hand, non-enzymatic sources of superoxide radicals have also been reported. For example, thiols undergo several one electron reactions and produce disulfide radical anions and which are responsible for the donation of one electron to an oxygen molecule with the formation of the superoxide radical. $^{124}$ 


\subsubsection{Secondary free radicals}

Superoxide radical itself is not a dangerous ROS radical. However it further interacts with other molecules to develop harmful secondary ROS radicals such as hydroxyl radicals and peroxyl radicals. Superoxide dismutase (SOD) is an important enzyme in the body's antioxidant defense system that can protect cells from superoxide toxicity by converting superoxide into either molecular oxygen molecule or hydrogen peroxide. ${ }^{125}$

$$
2 \mathrm{O}_{2}^{--}+2 \mathrm{H}^{+} \stackrel{\mathrm{SOD}}{\longrightarrow} \mathrm{H}_{2} \mathrm{O}_{2}+\mathrm{O}_{2}
$$

Peroxisomes are the major sites where most of oxygen consumption takes place in the cell and they participate in several metabolic functions. These oxygen consumption functions also produce hydrogen peroxide. ${ }^{126}$ The vast accumulation of hydrogen peroxide is prevented by catalase, present in peroxisomes to maintain a gentle balance of electron transport chain. However, the disturbance in balance may happen with leakage of hydrogen peroxides taking place when the peroxisomes are damaged. This leakage, in turn, makes a significant contribution to oxidative stress.

Iron and copper are essential metals and they occur throughout the body as central molecules in hemoglobin and also involve in protein synthesis. During stress conditions involving excess superoxide, free iron is released from iron containing molecules. ${ }^{127}$ The released $\mathrm{Fe}^{2+}$ can participate in a Fenton reaction (7 and 8) with hydrogen peroxide which generates the highly reactive hydroxyl radical. The superoxide radical produces the hydroxyl radical by involvement in a reaction with hydrogen peroxide called the HaberWeiss reaction (9) which contains a Fenton reaction. 


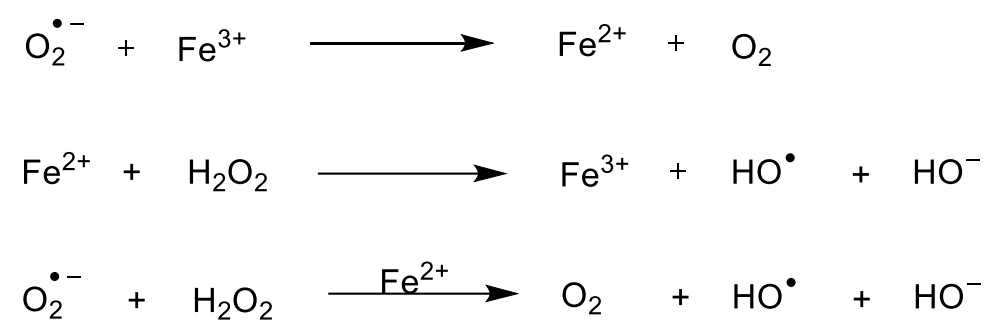

The hydroxyl radical is the most dangerous radical among ROS as it has very high reactivity in vivo (half-life $10^{-9} \mathrm{~S}$ approximately). ${ }^{128}$ Thus, it reacts instantly with macromolecules close to its generation site such as carbohydrates, nucleic acids, amino acids, lipids, DNA and proteins. Peroxyl radicals are another type of radicals derived from oxygen. Hydroperoxyl radical or perhydroxyl radical is the simplest one among these and it is a protonated form of the superoxide radical anion. It has been reported that hydroperoxyl radicals may participate in the initiation of fatty acid peroxidation. ${ }^{129}$

\subsubsection{Reactive nitrogen species (RNS)}

Besides ROS, there is another group of free radicals containing nitrogen as a central atom, in which unpaired electron(s) resides on nitrogen, called reactive nitrogen species (RNS). Nitric oxide radical (NO) is a significant radical among RNS because of its biological importance. It is generated by some tissues via specific nitric oxide synthase in order to maintain essential biological and physiological signaling processes including defense mechanism, muscle relaxation, neurotransmission, blood pressure and immune regulations. ${ }^{130-131}$ The overproduction of RNS may occur, called nitrosative stress, when the production of RNS exceeds the system's ability to neutralize them. ${ }^{132}$ Nitrosylation reactions are the results of nitrosative stress and these reactions interrupt the functions of proteins by making modifications in their structure. 
Because of instability and a very short half-life, NO may react with superoxide radical anion during the oxidative burst and produce the more oxidatively active molecule, peroxynitrite anion $\left(\mathrm{ONOO}^{-}\right)$, which subsequently leads to the generation of hydroxyl and nitrogen dioxide radicals. Peroxynitrite anion is capable of oxidizing other molecules and may cause lipid oxidation and DNA fragmentation. ${ }^{133}$

$$
\begin{aligned}
& \mathrm{O}_{2}^{--}+\mathrm{NO}^{-} \longrightarrow \mathrm{ONOO}^{-} \\
& \mathrm{ONOO}^{-}+\mathrm{H}^{+} \longrightarrow \mathrm{ONOOH} \longrightarrow \mathrm{OH}^{-}+\mathrm{NO}_{2}^{-}
\end{aligned}
$$

Some oxidants, such as hydrogen peroxide $\left(\mathrm{H}_{2} \mathrm{O}_{2}\right)$, hypochlorous acid $(\mathrm{HOCl})$, nitrous acid $\left(\mathrm{HNO}_{2}\right)$, and dinitrogen trioxide $\left(\mathrm{N}_{2} \mathrm{O}_{3}\right)$ are not free radicals, but easily engender radical reactions similar to peroxynitrite anion $\left(\mathrm{ONOO}^{-}\right) .{ }^{134}$

\subsubsection{The body's antioxidant defenses}

The generation of free radicals in biological system is inevitable, but the system adapted to produce several antioxidant defense mechanisms to reduce their impact. The body's antioxidants are divided into two categories: enzymatic and non-enzymatic. Superoxide dismutase (SOD), catalase and glutathione peroxidases are three major enzymatic antioxidant processes involved in the direct neutralization of ROS and RNS radicals. ${ }^{106}$ In 1969, McCord and Fridovich discovered an antioxidant enzyme called superoxide dismutase (SOD) that acts against superoxide radical anions by converting them into hydrogen peroxide and oxygen molecules. ${ }^{135}$

$$
2 \mathrm{O}_{2}^{\cdot-}+2 \mathrm{H}^{+} \stackrel{\mathrm{SOD}}{\longrightarrow} \mathrm{H}_{2} \mathrm{O}_{2}+\mathrm{O}_{2}
$$


The enzyme catalase is highly efficient in converting hydrogen peroxide molecules into water and molecular oxygen. It neutralizes millions of hydrogen peroxide molecules and finishes the detoxification process started by SOD. Glutathione peroxidases also reduce hydroperoxides similarly to catalase.

$$
2 \mathrm{H}_{2} \mathrm{O}_{2} \stackrel{\text { Catalase }}{\longrightarrow} 2 \mathrm{H}_{2} \mathrm{O}+\mathrm{O}_{2}
$$

Non-enzymatic antioxidants are further divided into metabolic and nutrient antioxidants. Metabolic antioxidants such as glutathione, uric acid, lipoid acid, melatonin etc., are the endogenous antioxidants produced by metabolism in the body and nutrient antioxidants such as vitamin $\mathrm{E}$, vitamin $\mathrm{C}$, carotenoids, fatty acids, trace metals etc., are the exogenous antioxidants that must be provided through the diet.

\subsubsection{Pathological conditions caused by free radicals}

The role of free radicals does not end up with antioxidants. Excess generation of free radicals i.e., an imbalance between the generation and neutralization of ROS radicals in biological system creates a pathological condition called oxidative stress. ${ }^{112}$ Oxidative stress is involved in many pathological conditions including cancer, cardiovascular diseases, ischemia, ageing, diabetes and several other neurodegenerative disorders. ${ }^{112-116}$ Free radicals produced in mitochondria create 'mitochondrial oxidative stress' that is an indication of a pro-oxidative shift in the plasma thiol/disulfide redox state which impairs glucose tolerance. Cancer and diabetes are the typical pathological conditions observed during mitochondrial oxidative stress. ${ }^{136-137}$ The process of aging is an enduring damage developed by free radical activity on lipids, DNA and proteins. ${ }^{104}$ Other pathological implications involve chronic inflammations and ischemia/reperfusion injury that are 
characterized by enhanced activity of either $\mathrm{NAD}(\mathrm{P}) \mathrm{H}$ oxidase or xanthine-oxidase and inflammatory oxidative stress.

Low density lipoproteins (LDL, known as bad cholesterol) becomes more dangerous when it gets oxidized with ROS radicals, this process is called lipid peroxidation. ${ }^{107}$ Oxidized LDL accumulates on the walls of arteries and encourages the accumulation of inflammatory cells, macrophages and platelets. The plaque begins to grow thicker and block blood vessels in the brain. The condition of arterial formation of blockages is called atherosclerosis. The blockage creates oxidative stress in the brain and leads to ischemic stroke. The ROS radicals also damage adjacent vital biological molecules such as nucleic acids, proteins, RNA and DNA. Oxidative DNA damage leads to DNA lesions and mutations.

Stroke is the fifth leading cause of mortality in the USA and is one of the major causes of death worldwide. ${ }^{112-116}$ Stroke results from a disturbance in blood supply to the brain. There are two types of strokes, ischemic and hemorrhagic stroke. Ischemic stroke is due to the lack of blood supply to the brain hindered by particles that impede blood flow. It is further divided into two types, thrombotic and embolic stroke, depending on the way it occurs. In thrombotic stroke, the blood clot forms within one of the arteries that supplies blood to the brain, whereas, the embolic stroke involves a blood clot formed in another location of the body, usually in heart, that travels to the brain until it block a brain vessel. As a result of the lack of blood supply to that particular part of the brain, cells start dying and eventually the ischemic tissue becomes necrotic. The other type of stroke, hemorrhagic stroke, occurs when the blood vessels in a part of the brain accidentally burst and bleed in and around the brain. It creates swelling and pressure around the cells and damages brain 
tissue. The whole brain or part of the brain stops working because of these blood spills. High blood pressure and aged blood vessels may be primary etiological factors in hemorrhagic stroke. ${ }^{116}$

After a period of ischemia, reclamation of blood supply to the brain or part of the brain causes severe injury rather than restoration of normal functions (reperfusion injury). Restoration of blood flow to the ischemic organ is essential in order to prevent irreversible cellular injury. Reperfusion may augment tissue damage in excess of that produced by ischemia alone. ${ }^{138}$ The injury after reperfusion of previously viable ischemic tissue is described as ischemia-reperfusion injury. Multiple organ dysfunction syndrome or systemic inflammatory response syndrome may be the consequences of ischemiareperfusion injury, which accounts for a $30-40 \%$ mortality rate in humans. ${ }^{139}$

Reperfusion of ischemic tissues results in a massive generation of ROS and RNS including superoxide anions, hydroxyl radicals, hypochlorous acid, hydrogen peroxide and nitric oxide radicals. ${ }^{140}$ Lack of blood and oxygen supply during ischemia leads to the accumulation of metabolic intermediates. During ischemia, cellular ATP is degraded to form hypoxanthine and also xanthine dehydrogenase is converted to xanthine oxidase. Normally, xanthine dehydrogenase is used to oxidize hypoxanthine into xanthine by using nicotinamide adenine dinucleotide as its substrate. Xanthine oxidase uses oxygen, so it is unable to process the conversion of hypoxanthine to xanthine as there is no oxygen supply to the ischemic tissue, resulting in a growth of excess levels of hypoxanthine. In this state, the restoration of oxygen supply results in the conversion of the excess hypoxanthine to xanthine by xanthine oxidase leading to the formation of harmful ROS. ${ }^{139}$ The massive increase in radicals destroy the cell's usual defense system and leads to the uncontrolled 
oxidation of vital biological cell components. ${ }^{141}$ Inflammation is also responsible for injury. The white blood cells generate inflammatory factors as well as free radicals after restoration of blood flow. The restored oxygen inside the cell, damages proteins, DNA and finally cell membrane. The cell membrane damage in turn creates more free radicals and this relentless ischemic cascade leads to apoptosis. ${ }^{141}$

\subsection{Tissue plasminogen activator $(t-\mathrm{PA})$}

Tissue plasminogen activator ( $t$-PA) or recombinant tissue plasminogen activator (rt-PA) is a plasminogen activator involved in breakdown of blood clots by catalyzing the conversion of plasminogen to plasmin. The only drug that FDA has approved to treat acute ischemic stroke (AIS) in selected patients is $t$-PA. Because of reperfusion injury the use of $t$-PA is restricted to within three hours of ischemia and in the absence of hemorrhagic stroke. $^{142-143}$

\subsection{Edaravone}

Edaravone is a free radical scavenger and neuroprotective agent. It is a lipid soluble hydroxyl and peroxy radical scavenger, used clinically for the treatment of ischemic stroke within 24 hours of the attack. Edaravone is the only drug in its class in clinical practice. ${ }^{144}$ It is marketed in Japan since 2001 by Mitsubishi Pharma Corporation. A few clinical studies published on the use of edaravone in combination with thrombolytics such as $t$-PA (for both breakdown of blood clots and free radical scavenger activities) have shown

promising results. ${ }^{145}$ There are many clinical trials that need to be performed before edaravone becomes approved as a drug for Ischemic stroke in the United States and elsewhere in the world. 


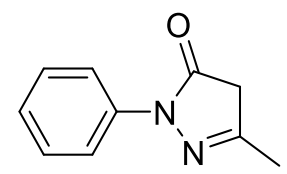

Edaravone

Figure 24. Structure of edaravone.

\subsection{Free radical detection and spin trapping}

Detecting free radicals as targets is very crucial to the study of radical reactions in chemistry and biology. The direct or indirect detection of free radicals formed during biological processes is very important to analyze and understand the mechanism of oxidative damage caused by pathogenic free radicals. ${ }^{146}$ It is very difficult to understand free radical reactions as the formed free radical intermediates are highly unstable and cannot be detected directly, even in pure free radical generating chemical systems. For instance, the half-life of superoxide anion radical is on the order of tenths of microseconds and a few nanoseconds for hydroxyl radical. ${ }^{147}$ However, a number of methods have been developed to detect ROS/RNS radicals but these are often limited by specificity and sensitivity. ${ }^{148}$

Among all of those instruments that make identification of radicals possible, electron spin resonance (ESR) or electron paramagnetic resonance (EPR) spectroscopy is the most commonly used. ${ }^{148}$ Only those free radicals with relatively long half-lives can be measured by ESR. Thus, it is technically possible to directly detect some free radicals in real time, but not in biological systems as the half-lives of those radicals are extremely short. ${ }^{146}$ To overcome these obstacles, varied methods have been tested. Among those methods, ESR-spin trapping has been proven the best because the spin trapping converts 
unstable free radicals into the stable adducts and it allows researchers to identify and differentiate the number of free radicals generated during a biological process. The ESRspin trapping method offers investigators the opportunity to measure and distinguish the major ROS molecules such as hydroxyl and superoxide anion radicals in the biological system. Spin trapping is a technique in which the undetectable transient radicals are converted into corresponding stable adducts and these adducts can be readily detectable by ESR. The compounds used for this conversion method are called spin traps. Usually, nitrosoalkanes, nitrones and sometimes metal complexes such as in case of NO radical $\left(\mathrm{Fe}^{2+}-\mathrm{N}\right.$-methyl-D-glucamine dithiocarbamate), are used as spin traps. ${ }^{149}$

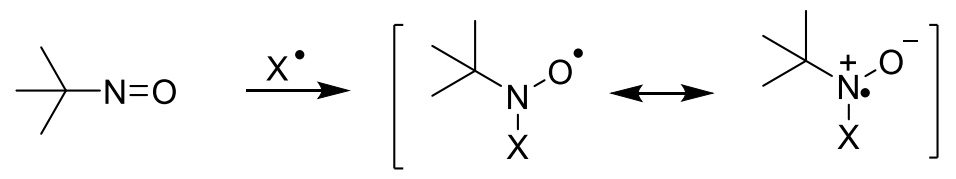

$t$-nitrosobutane

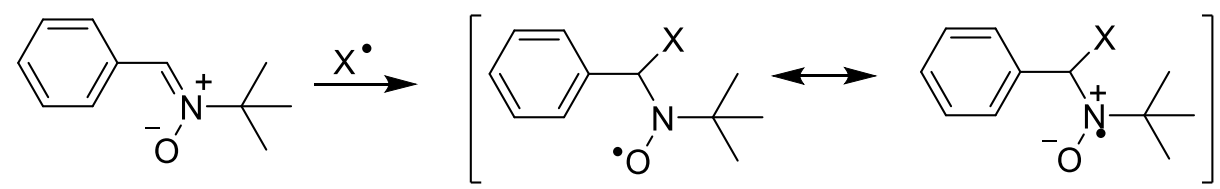

PBN

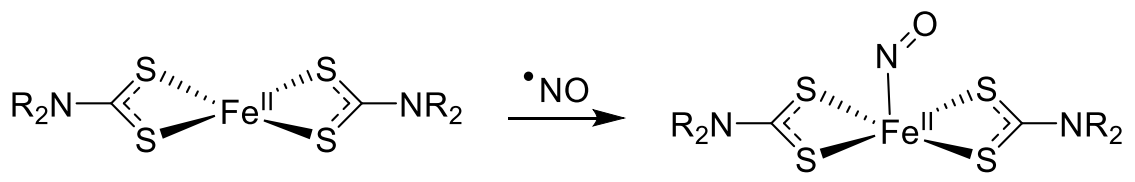

Metal complex spin trap

Nitrosoalkanes are not used often because of their toxicity and they generally form short-lived oxygen-centered radical adducts. ${ }^{144,150}$ Nitrones are the most commonly used spin trap as they are more applicable to trap biological free radicals such as superoxide and 
hydroxyl radicals even though the EPR spectra of the ensuring nitrone spin adducts give less structural information than compared to the spin adducts formed from nitrosoalkanes.

\subsubsection{Nitrones}

Free radicals are extant, but ephemeral, in many chemical reactions as intermediates, so they are difficult to characterize and study. Several experiments have been conducted and reported in mid-1960's show that nitrones act as 'spin traps' by reacting with free radicals to form stable adducts, which can be studied by EPR. ${ }^{151-153}$ Shortly after discovering the use of nitrones as spin traps in chemical reactions, they were also used to trap free radicals generated in biological systems. ${ }^{154}$ Nitrones trap short-lived free radicals and form more stable spin adducts (nitroxides), which are far more stable than the parent radicals. Nitroxide stability is explained by resonance.

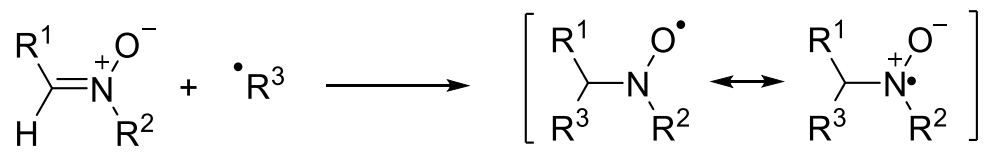

The PBN ( $\alpha$-phenyl- $N$-tert-butyl nitrone) and related nitrones are among the most intensively studied compounds for use as free radical scavengers to treat ischemic stroke (Figure 25). ${ }^{146}$ Administration of PBN, after $1 \mathrm{~h}$ of ischemic stroke, showed promising results in rats. ${ }^{146}$ It reacts mostly with short lived free radicals such as superoxide and hydroxyl radicals in high concentrations and has an ability to prevent lipid peroxide reactions. Another nitrone, 2, 4-disulfophenyl- $N$-tert-butylnitrone known as NXY-059 was synthesized and passed many stages of clinical trials for acute ischemic stroke. The nitrone, NXY-059, has an exceptional capability to trap free radicals and superior neuroprotective ability compared to PBN or S-PBN (another derivative of PBN) in an in vitro study. It 
showed greater promising results among other PBN related nitrones as a protective agent in treatment, in view of an expanded time window in stroke model studies. ${ }^{155}$

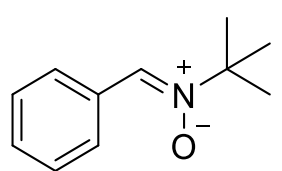

PBN<smiles>CC(C)(C)[N+]([O-])=Cc1ccccc1S(=O)(=O)[O-]</smiles>

S-PBN

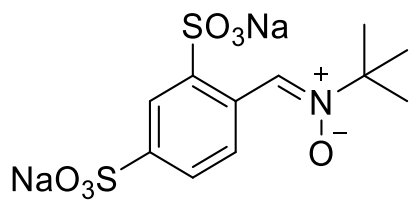

NXY-059

Figure 25. PBN and its derivatives.

Other than PBN related nitrones, the pyrroline based cyclic nitrones such as 5,5dimethyl-1-pyrroline $\mathrm{N}$-oxide (DMPO), 5-diethoxyphosphoryl-5-methyl-1-pyrroline $\mathrm{N}$ oxide (DEPMPO) and 5-ehoxycarbonyl-5-methyl-1-pyrroline $\mathrm{N}$-oxide (EMPO) are another class of commonly used nitrone spin traps. This pyrroline based cyclic nitrones are much superior to PBN for the detection of hydroxyl and superoxide anion radicals because PBN is more suitable for carbon-centered radicals. ${ }^{146}$

DMPO has been used for decades to trap free radicals and it allowed the detection of a variety of radicals generated during important biological processes. ${ }^{149}$ However, a major disadvantage of DMPO is that the formed superoxide adduct (DMPO/OOH) spontaneously decomposes into hydroxyl adduct (DMPO/OH), and as a result, the production of superoxide anion radicals has to be identified via the superoxide dismutase inhibition of the formation of DMPO/OH. To overcome this difficulty, DEPMPO is used as a spin trap for superoxide radical detection and the formed DEPMPO/OOH adduct is stable. ${ }^{156}$ However, the EPR spectra of the formed DEPMPO adducts is somewhat complicated because of additional diastereomers from ${ }^{31} \mathrm{P}$ coupling. These complications are mitigated in the case of EMPO, as it is reported that the formed superoxide adduct 
(EMPO/OOH) is eight times more stable than the corresponding adduct formed from DMPO. Also, the EPR spectra of EMPO adducts are less complicated than the spectra of DEPMPO adducts ${ }^{157}$ but problems with diastereomers of EMPO still exist.

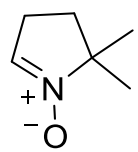

DMPO

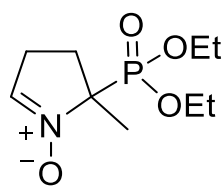

DEPMPO<smiles>CCOC(=O)C1(C)CCC=[N+]1[O-]</smiles>

EMPO

Figure 26. Pyrroline based cyclic nitrones.

\subsubsection{Azulenyl Nitrones}

Naturally occurring azulenes (azulene, guiazulene, lactaroviolin) are reported to possess some therapeutic properties (Figure 27). ${ }^{158}$ In 1996, Becker et al. ${ }^{159}$ synthesized AZN (azulenyl nitrone), a new class of nitrone, from naturally occurring guiazulene (obtained from the wood of Guaiacum officinale). ${ }^{159}$

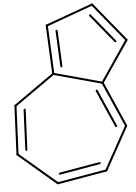

Azulene

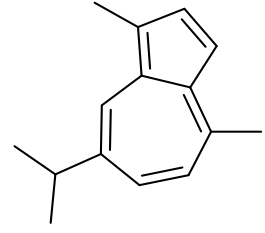

Guiazulene

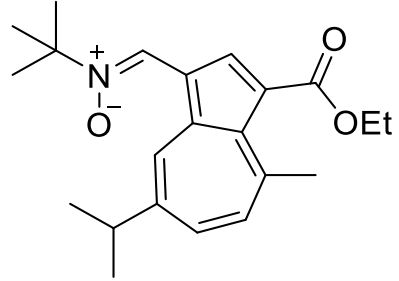

AZN

Figure 27. Azulenes and azulenyl nitrones.

Various biological studies of AZN in animal models showed beneficial properties against neurodegenerative diseases. ${ }^{160-162}$ The oxidation potential of AZN is quite low $(0.84 \mathrm{~V}$ vs. SCE) compared to the oxidation potential of PBN and its derivatives (>1 V). Researchers 
mainly focused on the synthesis of lower oxidation potential nitrones because previous studies showed that antioxidants with low oxidation potentials have greater trapping ability for free radicals in biological systems. ${ }^{163}$

Along these lines, STAZN (stilbazulenyl nitrone) (Figure 28), a second generation of potent free radical scavenging azulenyl dinitrone was synthesized, starting from guiazulene. ${ }^{164}$ Preclinical studies of STAZN in a rodent stroke model showed very promising results. ${ }^{165-168}$ Lipid peroxidation analysis done on STAZN showed remarkable antioxidant activity compared to the widely studied spin traps such as PBN, NXY-059 and conventional antioxidants BHT, $\beta$-carotene and vitamin E. In many investigations, STAZN has shown superior results compared to NXY-059 and some are similar to the compound Edaravone. Because of the high lipophilicity of STAZN, it readily crosses the $\mathrm{BBB}$ and it has a long circulating half-life with low toxicity. ${ }^{165-169}$

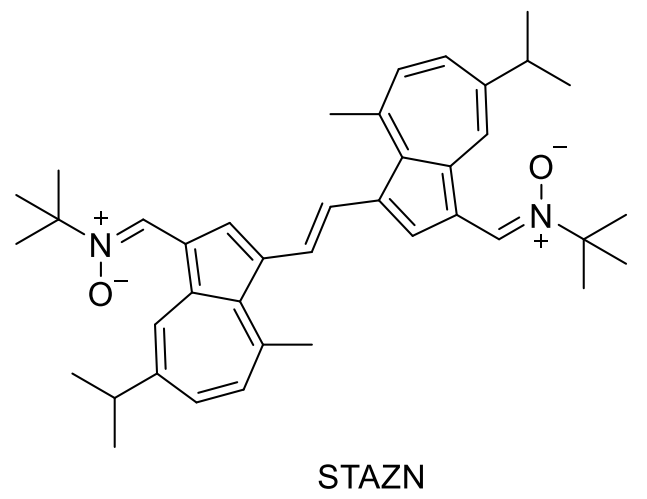

Figure 28. Structure of stilbazulenyl nitrone (STAZN).

\subsubsection{Pseudoazulenes}

Pseudoazulenes are iso- $\pi$-electronic analogues of azulenes containing one or two heteroatoms (Figure 29). Pseudoazulenes possess some antifungal properties. ${ }^{170}$ These 
molecules possess lower oxidation potentials than azulenes because of the presence of heteroatoms (more nucleophilic). Similarly, pseudoazulenyl nitrones are expected to have even lower oxidation potentials than azulenyl nitrones by virtue of the effect of conjugation.

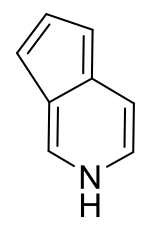

101

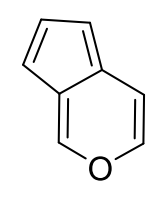

102

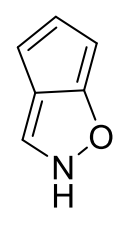

103

Figure 29. General structures of some Pseudoazulenes. 


\section{CHAPTER 4: SYNTHESIS OF PSEUDOAZULENYL NITRONES}

\subsection{Design and synthetic efforts of pseudoazulenyl nitrones}

The objective of this research was to design and synthesize novel azulenyl nitrones with lower oxidation potentials to target ROS radical generation at the site of mitochondria. ${ }^{171} \mathrm{~A}$ predominant source of ROS free radical generation is mitochondria during the respiratory chain process. The matrix or inner membrane of mitochondria becomes nucleophilic as it pumps protons across the inner membrane. To target nitrones to mitochondria, a key strategy was to produce cationic molecules that are attracted to the mitochondrial matrix because of the large mitochondrial membrane potential. ${ }^{171-172}$ To implement this strategy, the objective was to synthesize the following molecules $\mathbf{1 0 4}$ and 105 as potential therapeutic compounds.
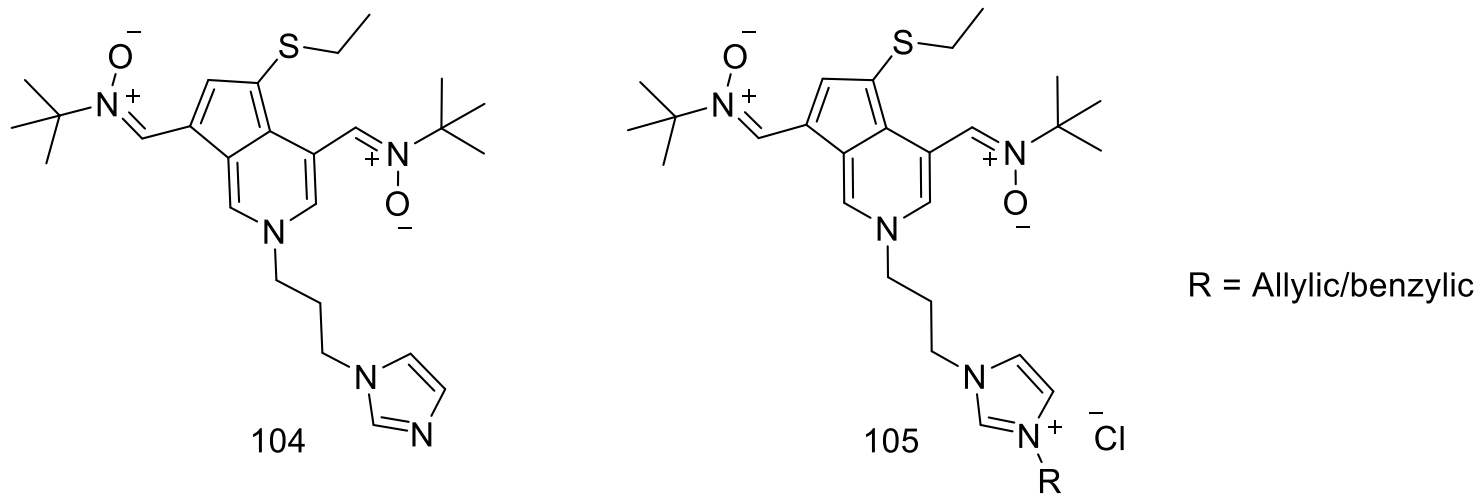

Figure 30. Structures of designed pseudoazulenyl nitrones.

Many studies have been reported on mitochondrial dysfunction as well as possible strategies for mitochondrial drug delivery. ${ }^{171}$ The inner mitochondrial membrane (IMM) is a strong barrier to mediate passage of all kinds of molecules into the mitochondrial matrix. However, the major advantage of targeting mitochondria is that the IMM maintains a 
strong negative potential that is requisite for the electron transport chain (and it is also rich in the phospholipid cardiolipin). ${ }^{173}$ Cationic compounds and a strong carbon backbone structure are attracted and accumulated within the negatively charged mitochondrial matrix.

The electron donating group on the five membered ring of the pseudoazulene should increase electron density and lead to pseudoazulenes with extremely low oxidation potentials. The presence of the imidazole moiety may provide additional biological properties in that imidazole and its derivatives are known to target mitochondria. ${ }^{174}$ The imidazole functionality may also provide a platform to make cationic features needed to reach the inner region of the mitochondria. The dinitrone moieties are the main functional part of the target molecules, which play a crucial role in scavenging radicals similar to STAZN.

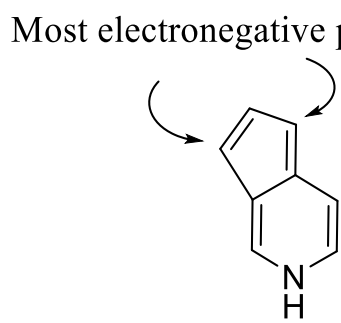

Figure 31. Electronegative sites of pseudoazulenes.

Reduction potentials play a crucial role in scavenging free radical moieties. It is very important to understand the redox chemistry of nitrones for their use as antioxidants. Previous studies showed that antioxidants with low oxidation potentials have greater free radical trapping ability in biological systems. ${ }^{164}$ Pseudoazulenes are rich in electrons and have lower oxidation potentials compared to azulenes. ${ }^{164,175}$ Therefore, the plan was to 
further lower the oxidation potential of pseudoazulenyl nitrones by rising the electron density in the five membered ring of the pseudoazulenyl system, which can be achieved by placing an electron donating group at the most electronegative position of the pseudoazulene (Figure 31).

\subsubsection{Extraction of valtrate and synthesis of baldrinal}

Valtrate was used as the starting compound for the synthesis of the pseudoazulenyl dinitrones. Valtrate was extracted from finely ground Centranthus ruber root by using ethanol as an extraction solvent (Scheme 24). The crude collected from the ethanol extraction was partially purified by chloroform extraction. To obtain pure valtrate $\mathbf{1 0 6}$, silica gel column chromatography is then required, using hexane/ethyl acetate as the mobile phase. The total yield of this extraction and purification method of valtrate depends extensively on the quality of the root used (on average it is $3 \%$ of the total mass of root used). The less expensive dried root Valeriana officinalis was also used to extract valtrate but the yield and effort were inferior.

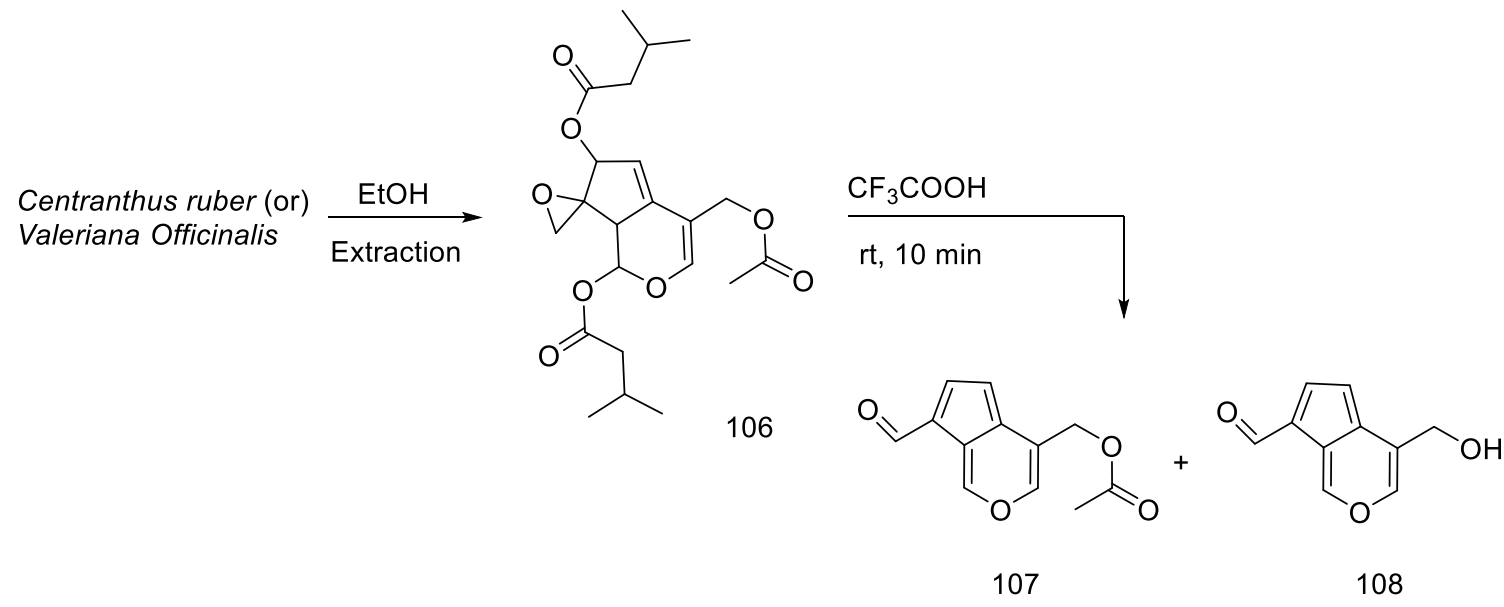

Scheme 23. Synthesis of baldrinal and compound 8. 
The greenish colored oily liquid (valtrate) was treated with trifluoroacetic acid or trichloroacetic acid to get baldrinal, a yellow colored solid compound, which is the crucial precursor to synthesize various pseudoazulenyl dinitrone derivatives. Purification with silica gel column chromatography required the use of a hexane/ethyl acetate mixture in order to get pure baldrinal 107. This degradation reaction also led to another compound $\mathbf{1 0 8}$, as a minor product. Compound $\mathbf{1 0 8}$ is similar to baldrinal in structure, containing a hydroxyl group at the position of the ester in baldrinal. Although the products are colored compounds, the purification process is very challenging as this reaction leads to a number of impurities with similar color (yellow), which significantly lowered the yields of both compounds: 20\% for compound $\mathbf{1 0 7}$ and $11 \%$ for $\mathbf{1 0 8}$.

\subsubsection{Synthesis of pseudoazulenyl dicarbaldehyde with imidazole side chain}

The biogenic amine, histamine, engages in many physiological functions such as immune response and neurotransmission processes. Nitrones having histamine functionality are expected to target the mitochondrial matrix in order to scavenge generated free radicals, since the nitrogen on certain imidazole derivatives is anticipated to be protonated at physiological $\mathrm{pH}$ with the formation of a cationic quaternary salt. Therefore, the pseudoazulene compound containing an imidazole functionality, 2-(propyl imidazole)cyclopenta[c]pyridine-4,7-dicarbaldehyde, was synthesized from baldrinal 107 and 1-(3aminopropyl)imidazole 109 (Scheme 25) by following the method of Seitz et al. ${ }^{176}$ Fortunately, both baldrinal and its derivative compound 108 provided the same product 110. Therefore, it is not necessary to separate these two compounds $\mathbf{1 0 7}$ and $\mathbf{1 0 8}$ from their crude mixture in the above reaction in scheme 24 . 


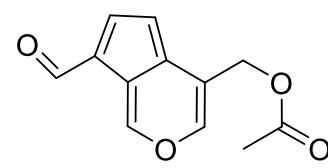

107 (or)

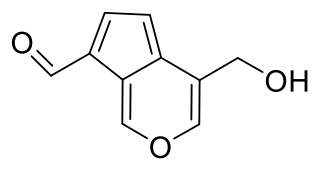

108

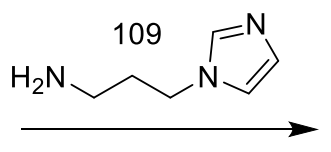

rt, $10-20 \min$

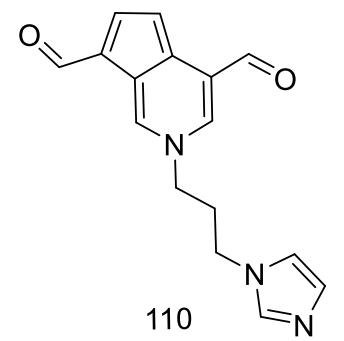

Scheme 24. Synthesis of dialdehyde compound (110).

The reported yields of this method are very poor (around 20\%) and the compound 110 was obtained in $8.2 \%$ yield. It is also reported that the cyclopenta[c]pyridine analog of compound $\mathbf{1 0 8}$ is an intermediate during the process of converting baldrinal into the corresponding cyclopenta $[c]$ pyridine. ${ }^{176}$ Autoxidation is involved in the oxidation of the hydroxyl side chain to yield the carbaldehyde.

\subsubsection{Synthesis of pseudoazulenyl mono and dinitrones}

Introducing an electron donating group at the more electronegative position of fivemembered ring of compound $\mathbf{1 1 0}$ was performed. The ethylthio substituted pseudoazulenyl dialdehyde 111 was synthesized in $24 \%$ yield by reacting dialdehyde compound $\mathbf{1 1 0}$ with ethyl sulfenyl chloride (Scheme 26), which is obtained from an in situ reaction between dietyldisulfide and sulfuryl chloride. The ethylthio substituted dialdehyde so obtained is then converted into pseudoazulenyl dinitrone 104, one of the target molecules, by treating with $N$-tert-butyl hydroxyl amine. In addition to the dinitrone compound, mononitrone 112 was also obtained in a similar yield, $20 \%$ and $19 \%$, respectively. 

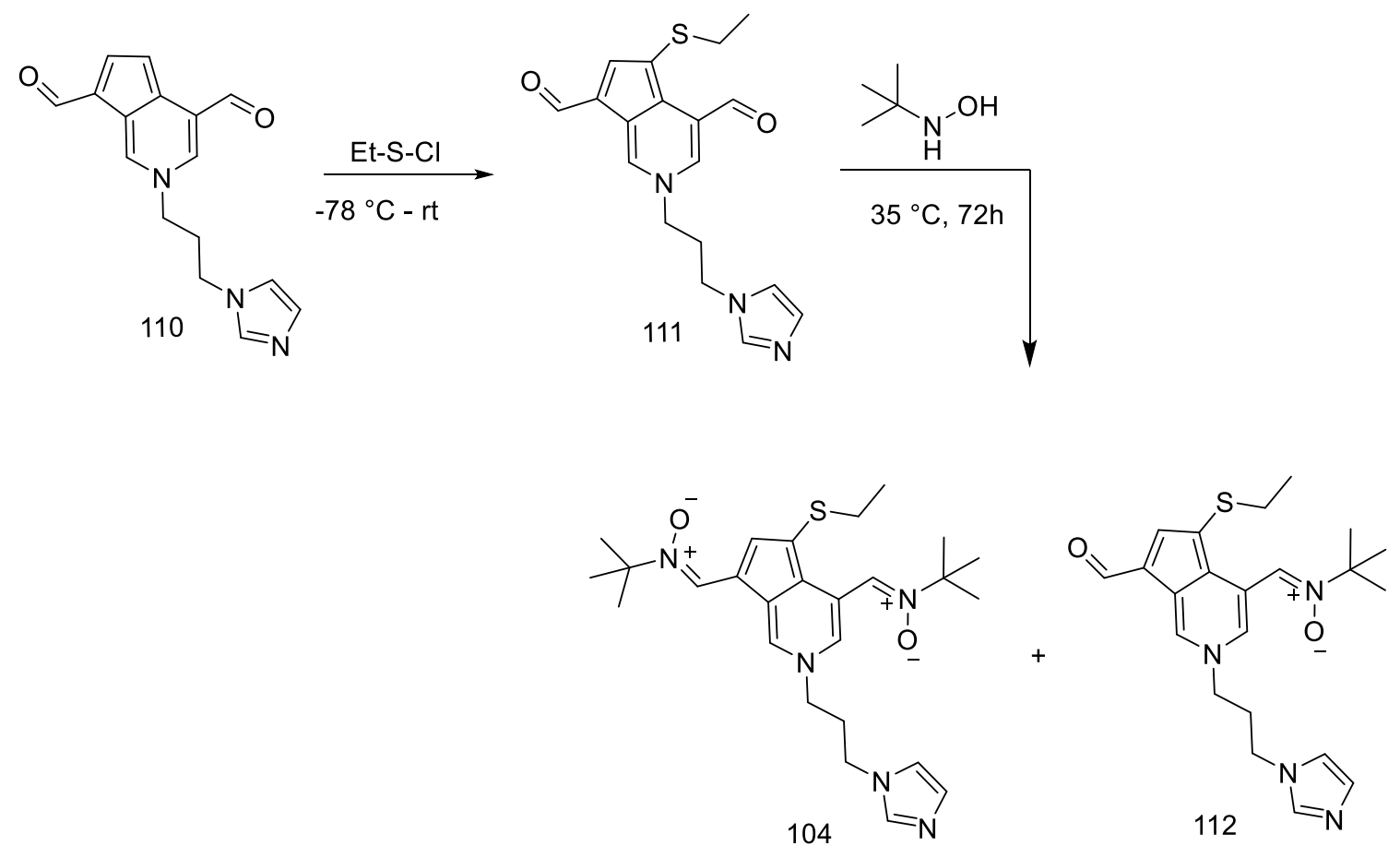

Scheme 25. Synthesis of dinitrone and mono nitrone.

\subsubsection{Attempts at making pseudoazulenyl dinitrone salts and Girard's reagent derivatization (112)}

After successful synthesis of the ethylthio substituted pseudoazulenyl dinitrone, it was treated with allyl/benzylic chlorides $(\mathrm{RCl})$ in a failed attempt to make a quaternary salt at the N-3 position. As an alternative, we turned our attention to derivatization of the aldehyde precursor 112 with Girard's reagent to make cationic hydrazones. Girard's reagent derivatives are effective in photoprotection of retinal pigment epithelial cells (RPE) by quenching singlet-oxygen species generated during photo oxidative stress. ${ }^{177}$ All attempts made on mono nitrone $\mathbf{1 1 2}$ failed to make Girard's reagent derivatives at $35{ }^{\circ} \mathrm{C}$ and at $\mathrm{rt}$ (in both cases the mono nitrone decomposed). 

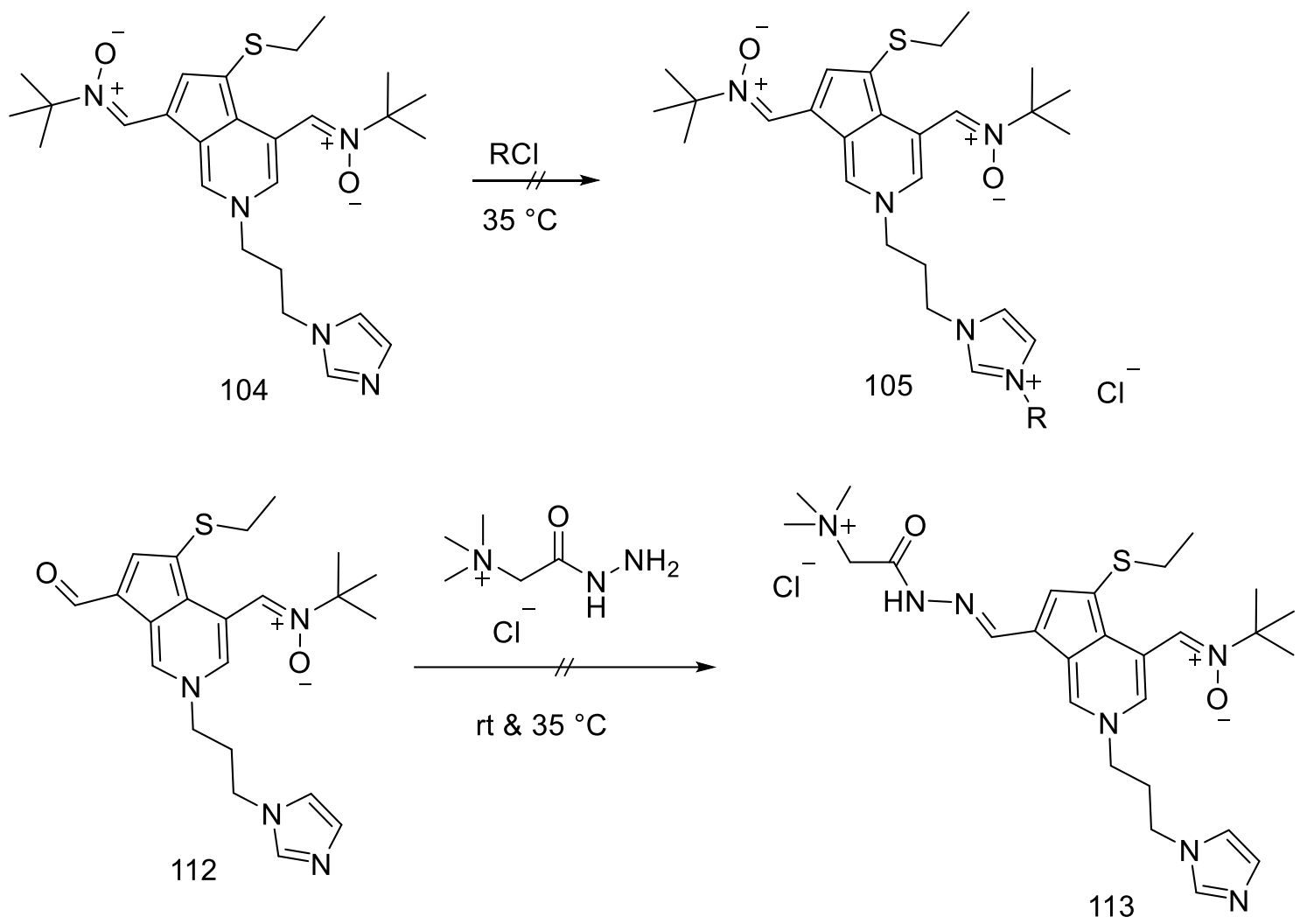

Scheme 26: Reaction attempts to form quaternary salts and Girard's reagent derivative.

\subsection{Conclusion regarding pseudoazulenyl nitrones synthesis}

Mitochondria are the primary reason behind the life and death of many biological cells. They perform many physiological functions such as ATP production, apoptosis, amino acid-nitrogen metabolism, ROS generation and detoxification. However, these processes are not always under control. Excess generation of ROS in or at several sites of mitochondria can damage antioxidant defense systems in mitochondria, which leads to oxidative stress. Considerable research has been reported on developing therapeutic compounds with mitochondriotropic properties. Among those strategies, the large mitochondrial membrane potential is the major consideration, which can lead to the accumulation of cationic compounds within the mitochondrial matrix. This special 
advantage has led to the discovery of bioavailable mitochondria targeted antioxidants such as Mitoquinone (MitoQ), Mitotocopherol (MitoVitE) and MitoTEMPOL. ${ }^{178}$

It is evident that nitrones are the most widely used compounds for spin trapping biogenic free radicals. It has been expected that the synthesis of particular cationic pseudoazulenyl nitrones may act as potent antioxidant compounds in order to target the mitochondrial matrix. In terms of synthesis of such pseudoazulenyl nitrones, compounds 104 and 105 were chosen as synthetic targets. The major structural moiety in these target molecules is a pseudoazulene unit, which is obtained from a precursor that is extracted from Centranthus ruber, a natural root. The complications for synthetic chemists, working with natural compounds, such as poor yields and purification related problems are inevitable. However, the synthesis of one of the target compounds, the interesting dinitrone 104, was successfully completed. Unfortunately, the attempts made to convert 104 into the corresponding cationic compound $\mathbf{1 0 5}$ failed. It will be necessary to carry these reactions in larger quantity from the beginning and make more dinitrone in order to try different strategies to synthesize various pseudoazulenyl nitrone cationic compounds. Also, a pseudoazulenyl mono nitrone compound with an electron donating group was synthesized by leaving a highly reactive aldehyde functionality intact for further use in synthetic study. 


\section{CHAPTER 5: EXPERIMENTAL SECTION}

\section{3-((3-Methylisoxazol-5-yl)methyl)cyclohex-2-ene-1-one (44):}

To a solution of 3,5-dimethylisoxazole $42(5.0 \mathrm{~g}, 51.5 \mathrm{mmol})$ in anhydrous THF $(50 \mathrm{ml})$ was added $2.5 \mathrm{M} n$-BuLi in hexane $(22.6 \mathrm{ml}, 56.65 \mathrm{mmol}, 1.1 \mathrm{eq})$ at $-78{ }^{\circ} \mathrm{C}$ via cannula over $20 \mathrm{~min}$. The solution was stirred for $30 \mathrm{~min}$ at the same temperature, then added 3-ethoxycyclohex-2-ene-1-one $43(7.2 \mathrm{~g}, 51.5 \mathrm{mmol})$ in one lot with vigorous stirring. The resulting reaction mixture was slowly brought back to the room temperature over 90 min period and stirred an additional $30 \mathrm{~min}$. The resulting solution was then acidified with $2 \mathrm{~N} \mathrm{HCl}(35 \mathrm{ml})$, stirred 30 min more at same temperature and extracted with diethyl ether or chloroform $(3 \times 100 \mathrm{ml})$. The combined organics were washed with aqueous ammonium chloride and brine solutions, dried over $\mathrm{MgSO}_{4}$ and evaporated. The

resulting residue was purified by silica gel column chromatography with $20 \%$ ethyl acetate in hexane as eluent to obtain enone product $44(7.02 \mathrm{~g}, 71 \%)$ as a light orange colored semi solid.

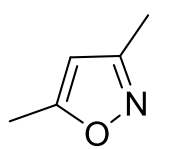

42

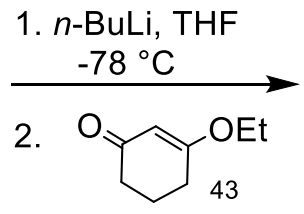

3. $\mathrm{H}_{3} \mathrm{O}^{+}$

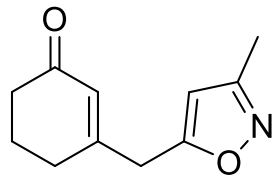

44

${ }^{1}$ H NMR: (400 MHz, $\left.\mathrm{CDCl}_{3}\right): \delta 5.92(\mathrm{~s}, 1 \mathrm{H}), 5.90(\mathrm{t}, J=1.2 \mathrm{~Hz}, 1 \mathrm{H}), 3.62(\mathrm{~s}, 2 \mathrm{H}), 2.38$ $(\mathrm{t}, J=6.8 \mathrm{~Hz}, 2 \mathrm{H}), 2.33(\mathrm{t}, J=5.8 \mathrm{~Hz}, 2 \mathrm{H}), 2.28(\mathrm{~s}, 3 \mathrm{H}), 2.01(\mathrm{~m}, 2 \mathrm{H})$.

${ }^{13}$ C NMR: (100 MHz, $\left.\mathrm{CDCl}_{3}\right): \delta 199.17,167.88,160.04,158.86,127.88,103.47,37.12$, $35.04,29.26,22.52,11.39$. 


\section{3-((2,3-Dimethylisoxazol-5(2H)-ylidene)methyl)cyclohex-2-en-1-one (45):}

Trimethyloxonium tetrafluoroborate $(5.48 \mathrm{~g}, 36.6 \mathrm{mmol})$ and the molten 3-((3methylisoxazol-5-yl)methyl)cyclohex-2-ene-1-one 44 (7.0 g, $36.6 \mathrm{mmol})$ were added into a two-neck dried flask. The resulting mixture stirred under argon until no solid remained. Then the reaction flask was evacuated, refilled with argon and kept at $-78{ }^{\circ} \mathrm{C}$. To this reaction mixture, a solution of $2.5 \mathrm{M} n$-BuLi in hexane (16.1 ml, $40.35 \mathrm{mmol}, 1.1 \mathrm{eq})$ in $60 \mathrm{ml}$ of anhydrous THF was added dropwise via cannula over $30 \mathrm{~min}$ period. The resulting reaction mixture was slowly brought back to the rt over 90 min period and stirred an additional 30 min (excess pressure was released by keeping a argon gas filled balloon on top of reaction flask's septum). To the resulting solution water $(40 \mathrm{ml})$ was added and extracted with chloroform $(3 \times 100 \mathrm{ml})$. The combined organics were dried over anhydrous magnesium sulfate and the solvent was removed under vacuum in dark without heating. The resulting residue was purified by silica gel column chromatography with $10 \%$ methanol in chloroform as eluent to obtain isoxazole anhydrobase $\mathbf{4 5}(7.1 \mathrm{~g}, 74 \%)$ as a dark yellow colored solid.

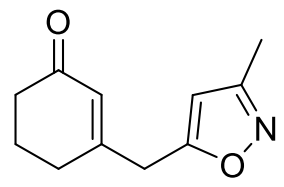

44

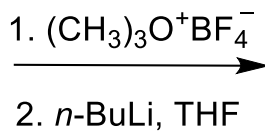

$-78{ }^{\circ} \mathrm{C}$

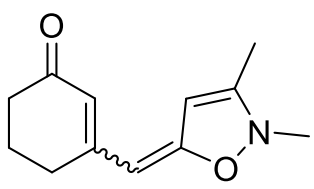

45

${ }^{1}$ H NMR: (400 MHz, $\left.\mathrm{CDCl}_{3}\right): \delta 6.15(\mathrm{~s}, 1 \mathrm{H}), 5.43(\mathrm{~s}, 1 \mathrm{H}), 4.82(\mathrm{~s}, 1 \mathrm{H}), 3.23(\mathrm{~s}, 3 \mathrm{H}), 2.47$ (t, $J=6.0 \mathrm{~Hz}, 2 \mathrm{H}), 2.35(\mathrm{t}, J=6.6 \mathrm{~Hz}, 2 \mathrm{H}), 2.07(\mathrm{~d}, J=0.4 \mathrm{~Hz}, 3 \mathrm{H}), 1.97(\mathrm{~m}, 2 \mathrm{H})$.

${ }^{13}$ C NMR: (100 MHz, $\left.\mathrm{CDCl}_{3}\right): \delta 198.3,165.7,158.7,155.3,116.6,100.7,88.1,39.4,36.6$, $30.0,22.6,10.9$. 


\section{5-Methyl-2-(1-(methylamino)ethylidene)-3-(3-oxocyclohex-1-en-1-yl)-2,3,8,9-}

tetrahydro-1H-cyclopenta[a]naphthalene-1,6(7H)-dione (46):

3-((2,3-dimethylisoxazol-5(2H)-ylidene)methyl)cyclohex-2-en-1-one $\mathbf{4 5}$ $(5.0 \mathrm{~g}, 24.3 \mathrm{mmol})$ was dissolved in anhydrous benzene $(25 \mathrm{ml})$ and heated at $50{ }^{\circ} \mathrm{C}$ for 3 hours. The resulting mixture was evaporated under vacuum and the residue was purified by silica gel column chromatography with $20 \%$ ethyl acetate in hexane as eluent to obtain dimer product $46(0.5 \mathrm{~g}, 12 \%)$ as a red colored solid.

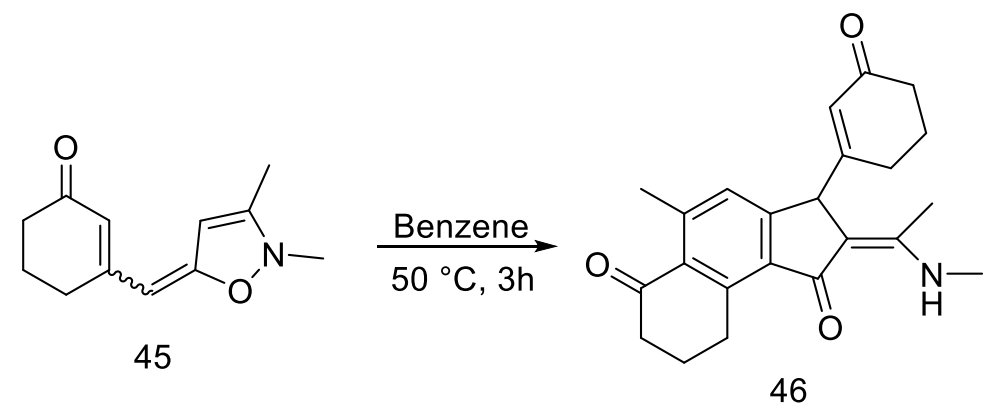

${ }^{1}$ H NMR: $\left(400 \mathrm{MHz}, \mathrm{CDCl}_{3}\right): \delta 10.90(\mathrm{~d}, J=4.8 \mathrm{~Hz}, 1 \mathrm{H}), 7.02(\mathrm{~s}, 1 \mathrm{H}), 6.33(\mathrm{~s}, 1 \mathrm{H}), 4.38$ (s, 1H), $3.64(\mathrm{t}, J=6.0 \mathrm{~Hz}, 2 \mathrm{H}), 3.03(\mathrm{~d}, J=5.2 \mathrm{~Hz}, 3 \mathrm{H}), 2.69-2.66(\mathrm{~m}, 5 \mathrm{H}), 2.38(\mathrm{~m}, 2 \mathrm{H})$, $2.11(\mathrm{~m}, 2 \mathrm{H}) 2.02(\mathrm{~s}, 3 \mathrm{H}), 1.98(\mathrm{~m}, 2 \mathrm{H}), 1.78(\mathrm{~m}, 2 \mathrm{H})$.

${ }^{13}$ C NMR: (100 MHz, $\left.\mathrm{CDCl}_{3}\right): \delta 200.10,199.73,190.58,167.05,161.68,151.18,145.12$, $144.83,135.50,131.69,128.18,126.07,105.62,50.97,41.06,37.80,29.64,25.46,24.37$, $24.17,23.00,22.59,15.39$.

HRMS: (LC/MS, MeOH) $m / z 364.19\left(\mathrm{MH}^{+}\right)$.

\section{5,6-Dihydrobenzo[ $h]$ cinnolin-3(2H)-one (51):}

A reaction mixture of 1-tetralone $\mathbf{5 0}(1.0 \mathrm{~g}, 6.84 \mathrm{mmol})$, glyoxylic acid monohydrate $(0.63 \mathrm{~g}, 6.84 \mathrm{mmol})$ and $1 \mathrm{ml}$ of glacial acetic acid was stirred and heated at 
$110{ }^{\circ} \mathrm{C}$ for $1 \mathrm{~h}$. The resulting solution was cooled to $60^{\circ} \mathrm{C}$, dispersed in water $(4 \mathrm{ml})$ and treated with ammonia solution to get $\mathrm{pH}$. The basic solution was filtered to remove any unreacted 1-tetralone and treated with hydrazine hydrate $(0.34 \mathrm{ml}, 6.84 \mathrm{mmol})$. The resulting suspension was heated reflux at $120{ }^{\circ} \mathrm{C}$ for $1 \mathrm{~h}$. The formed yellow colored reaction mixture was cooled to $\mathrm{rt}$ and filtered, washed with water and recrystallized in aqueous ethanol. The resulting fairly pure solid compound was purified by silica gel column chromatography with hexane/acetone (4:1) as an eluent to obtain pale yellow colored solid product $\mathbf{5 1}(1.06 \mathrm{~g}, 79 \%)$.

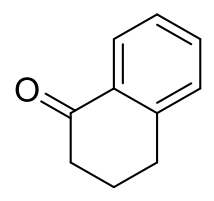

50

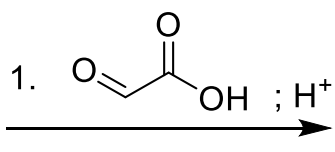

2. $\mathrm{H}_{2} \mathrm{~N}-\mathrm{NH}_{2}$

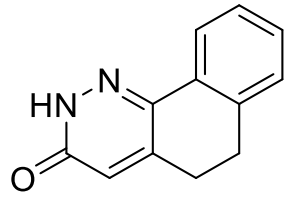

51

${ }^{1}$ H NMR: (400 MHz, DMSO): $\delta 13.00$ (s, 1H), 7.91 (m, 1H), 7.36-7.29 (m, 3H), 6.79 (s, 1H), $2.85(\mathrm{~m}, 4 \mathrm{H})$.

${ }^{13}$ C NMR: (100 MHz, DMSO): $\delta$ 160.74, 144.16, 141.03, 137.64, 130.37, 129.22, 128.34, $127.14,125.37,123.35,27.58,26.57$.

\section{Diethyl 2-hydroxy-2-(1-oxo-1,2,3,4-tetrahydronaphthalen-2-yl)malonate (53):}

A reaction mixture of 1-tetralone $\mathbf{5 0}(0.1 \mathrm{~g}, 0.68 \mathrm{mmol})$ and diethyl ketomalonate $(0.13 \mathrm{~g}, 0.75 \mathrm{mmol})$ in a dried flask was stirred and heated at $100{ }^{\circ} \mathrm{C}$ for $12 \mathrm{~h}$. The resulting crude compound was purified by silica gel column chromatography with hexane/ethyl acetate (4:1) and obtained liquid product $53(0.15 \mathrm{~g}, 70 \%)$.

With $n$-BuLi: The same reaction was also carried out with $n$-BuLi. To a solution of 1tetralone $50(1.0 \mathrm{~g}, 6.8 \mathrm{mmol})$ in anhydrous THF $(40 \mathrm{ml})$ was added $2.5 \mathrm{M} \mathrm{n}$-BuLi in 
hexane $(2.7 \mathrm{ml}, 6.8 \mathrm{mmol})$ dropwise at $-78{ }^{\circ} \mathrm{C}$ and stirred for $30 \mathrm{~min}$. To this reaction mixture diethyl ketomalonate $(1.2 \mathrm{~g}, 6.8 \mathrm{mmol})$ was added and stirred additional $30 \mathrm{~min}$ at same temperature. The resulting reaction mixture was slowly warmed to the rt, stirred 30 min and acidified with acetic acid $(5 \mathrm{ml})$. The resulting solution was extracted with chloroform $(3 \times 100 \mathrm{ml})$. The combined organics were washed with brine, dried over anhydrous magnesium sulfate and evaporated. The formed residue purified by silica gel column chromatography with hexane/ethyl acetate $(9: 1)$ as an eluent to obtain pure liquid product $\mathbf{5 3}(0.85 \mathrm{~g}, 40 \%)$.

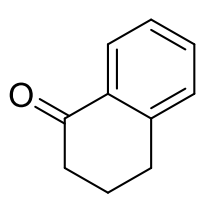

50

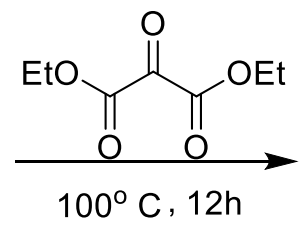

$100^{\circ} \mathrm{C}, 12 \mathrm{~h}$

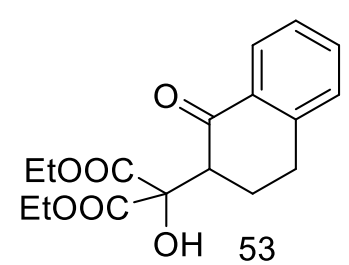

${ }^{1}$ H NMR: $\left(400 \mathrm{MHz}, \mathrm{CDCl}_{3}\right): \delta 8.00(\mathrm{~d}, J=8.0 \mathrm{~Hz}, 1 \mathrm{H}), 7.47(\mathrm{t}, J=7.6 \mathrm{~Hz}, 1 \mathrm{H}), 7.27(\mathrm{~m}$, 2H), $4.33(\mathrm{~m}, 4 \mathrm{H}), 4.05(\mathrm{~d}, J=0.8 \mathrm{~Hz}, 1 \mathrm{H}), 3.79-3.71(\mathrm{~m}, 1 \mathrm{H}), 3.23-2.99(\mathrm{~m}, 2 \mathrm{H}), 2.31-$ $2.13(\mathrm{~m}, 2 \mathrm{H}), 1.31(\mathrm{~m}, 6 \mathrm{H})$.

${ }^{13}$ C NMR: (100 MHz, $\left.\mathrm{CDCl}_{3}\right): \delta$ 195.72, 170.54, 169.47, 143.94, 133.79, 132.13, 128.70, $127.62,126.74,79.82,62.98,62.75,53.40,29.11,24.53,14.09,13.97$.

\section{2-(3,4-Dihydronaphthalen-1(2H)-ylidene)hydrazine-1-carboximidamide (56):}

A reaction mixture of aminoguanidine hydrochloride (0.75 g, $6.8 \mathrm{mmol}), 1$ tetralone 50 (1.0 g, $6.8 \mathrm{mmol})$ and $2 \mathrm{ml}$ of methanol was stirred for five minutes, added concentrated sulfuric acid $(0.5 \mathrm{ml})$ and warmed to $40{ }^{\circ} \mathrm{C}$. The resulting reaction mixture was stirred for $1 \mathrm{~h}$, added a solution of $\mathrm{KOH}$ in methanol $(1.0 \mathrm{gm}$ of $\mathrm{KOH}$ in $5 \mathrm{ml}$ of methanol) and stirred additional $15 \mathrm{~min}$. The reaction suspension was filtered and the 
filtrate was diluted with water, adjusted $\mathrm{pH} 13$ using aqueous $\mathrm{NaOH}$. The resulting basic solution was then extracted rapidly with ethyl acetate and the organics dried over calcium chloride and evaporated. The residue obtained from organic layers was purified by silica gel column chromatography with $10 \%$ methanol in chloroform as an eluent to obtain pure solid product of $\mathbf{5 6}(0.8 \mathrm{~g}, 62 \%)$.<smiles>O=C1CCCc2ccccc21</smiles>

50

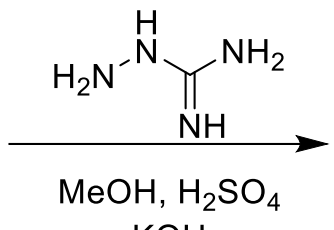

$\mathrm{KOH}$<smiles>N=C(N)NN=C1CCc2ccccc21</smiles>

56

\section{2-Cyano-N'-(3,4-dihydronaphthalen-1(2H)-ylidene)acetohydrazide (58):}

To a solution of 1-tetralone $\mathbf{5 0}(0.5 \mathrm{~g}, 3.4 \mathrm{mmol})$ in $5 \mathrm{ml}$ of ethanol was added cyanoacetohydrazide $(0.34,3.4 \mathrm{mmol})$ and heated at $80^{\circ} \mathrm{C}$ for $5 \mathrm{~h}$ in presence of catalytic amount of piperidine as a catalyst. The resulting reaction mixture was brought back to rt and continued stirring overnight. The reaction residue, after evaporation of solvent remained, was purified by silica gel column chromatography with chloroform/methanol (9:1) as eluent to obtain pure product $\mathbf{5 8}(0.6 \mathrm{~g}, 78 \%)$.<smiles>O=C1CCCc2ccccc21</smiles>

50

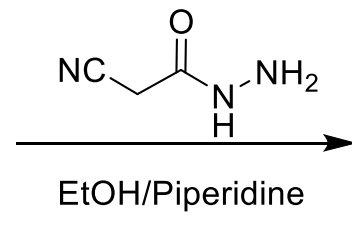

EtOH/Piperidine<smiles>N#CCC(=O)N/N=C1\CCc2ccccc21</smiles> 
${ }^{1}$ H NMR: (400 MHz, $\left.\mathrm{CDCl}_{3}\right): \delta 9.61(\mathrm{~s}, 1 \mathrm{H}), 8.01(\mathrm{~d}, J=7.6 \mathrm{~Hz}, 1 \mathrm{H}), 7.31(\mathrm{~m}, 1 \mathrm{H}), 7.25$ (m, 1H), $7.17(\mathrm{~d}, J=7.6 \mathrm{~Hz}, 1 \mathrm{H}), 3.96(\mathrm{~s}, 2 \mathrm{H}), 2.80(\mathrm{t}, J=6.4 \mathrm{~Hz}, 2 \mathrm{H}), 2.62(\mathrm{t}, J=6.8 \mathrm{~Hz}$, $2 \mathrm{H}), 2.00(\mathrm{~m}, 2 \mathrm{H})$.

\section{3,4-Dihydronaphthalen-1(2H)-one oxime (64):}

To a solution of 1-tetralone $\mathbf{5 0}(0.5 \mathrm{~g}, 3.4 \mathrm{mmol})$ in 1:1 ratio of pyridine: ethanol mixture $(10 \mathrm{ml})$ was added hydroxylamine hydrochloride $(0.47 \mathrm{~g}, 6.8 \mathrm{mmol})$ and stirred over 20-30 min at rt. The resulting reaction mixture was acidified by pouring it into $2 \mathrm{~N}$ hydrochloric acid $(15 \mathrm{ml})$ and extracted with dichloromethane. The combined organics were dried over anhydrous magnesium sulfate and evaporated. The formed solid residue (oxime product 64) $(0.5 \mathrm{~g}, 90 \%)$ was pure enough to use in further reactions (silica gel column chromatography can be used with hexane/acetone (4:1) as eluent, to remove any impurities showed on TLC).

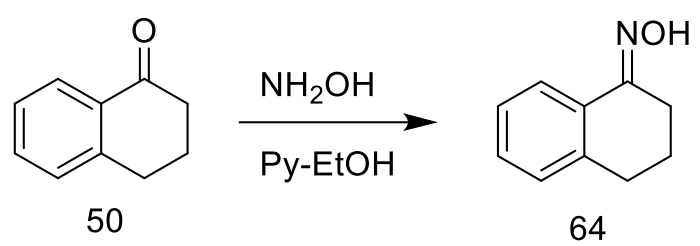

${ }^{1} \mathbf{H}$ NMR: $\left(400 \mathrm{MHz}, \mathrm{CDCl}_{3}\right): \delta 8.08(\mathrm{~s}, 1 \mathrm{H}), 7.89(\mathrm{~d}, J=8.0 \mathrm{~Hz}, 1 \mathrm{H}), 7.27(\mathrm{~m}, 1 \mathrm{H}), 7.20$ (m, 1H), $7.16(\mathrm{~m}, 1 \mathrm{H}), 2.82(\mathrm{t}, J=6.8 \mathrm{~Hz}, 2 \mathrm{H}), 2.77(\mathrm{t}, J=6.0 \mathrm{~Hz}, 2 \mathrm{H}), 1.87(\mathrm{~m}, 2 \mathrm{H})$.

\section{3,4-Dihydronaphthalen-1(2H)-one O-tosyl oxime (65):}

To a solution of $\mathrm{P}-\mathrm{TsCl}(0.53 \mathrm{~g}, 2.78 \mathrm{mmol})$ in anhydrous pyridine $(2 \mathrm{ml})$ was added an ice cold solution of 3,4-dihydronaphthalen-1(2H)-one oxime $\mathbf{6 4}(0.45 \mathrm{~g}, 2.78 \mathrm{mmol})$ in pyridine $(2 \mathrm{ml})$ dropwise and stirred for 16 hours at rt. The resulting reaction mixture was quenched with water and extracted with chloroform. The combined organics were washed 
with $2 \mathrm{~N} \mathrm{HCl}, 0.5 \mathrm{M} \mathrm{NaHCO}_{3}$ and brine solution. The resulting organic solution was evaporated and the residue was purified by silica gel column chromatography with hexane:acetone (4:1) as eluent to obtain pure tosylated oxime $65(0.48 \mathrm{~g}, 55 \%)$.

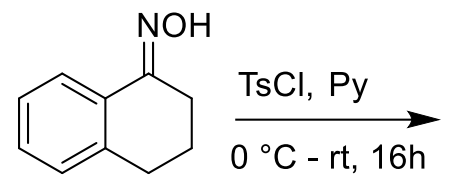

64

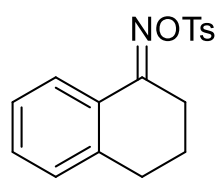

65

${ }^{1}$ H NMR: $\left(400 \mathrm{MHz}, \mathrm{CDCl}_{3}\right): \delta 7.94(\mathrm{~d}, J=8.0 \mathrm{~Hz}, 2 \mathrm{H}), 7.85(\mathrm{~d}, J=8.0 \mathrm{~Hz}, 1 \mathrm{H}), 7.35(\mathrm{~d}$, $J=8.0 \mathrm{~Hz}, 2 \mathrm{H}), 7.30(\mathrm{~m}, 1 \mathrm{H}), 7.16(\mathrm{~m}, 2 \mathrm{H}), 2.83(\mathrm{t}, J=6.8 \mathrm{~Hz}, 2 \mathrm{H}), 2.73(\mathrm{t}, J=6.4 \mathrm{~Hz}$ $2 \mathrm{H}), 1.82(\mathrm{~m}, 2 \mathrm{H})$.

\section{Diethyl ((4-methyl-1,2,5-oxadiazol-3-yl)methyl)phosphonate (72):}

To a solution of 3,4-dimethylfurazan 69 (1.0 g, $10.2 \mathrm{mmol})$ in anhydrous THF (20 $\mathrm{ml}$ ) was added $2.5 \mathrm{M}$-BuLi in hexane $(4.45 \mathrm{ml}, 11.22 \mathrm{mmol}, 1.1 \mathrm{eq})$ dropwise at $-78{ }^{\circ} \mathrm{C}$ and stirred for $1 \mathrm{~h}$. The reaction mixture turned from clear solution to greenish yellow colored. Diethylchlorophosphate (2.11 g, 1.2 eq) was added, stirred for $30 \mathrm{~min}$. The reaction mixture was brought back to rt over $90 \mathrm{~min}$, stirred for additional $30 \mathrm{~min}$ and added water (10ml). The resulting solution was extracted with chloroform, washed with ammonium chloride and brine solution. The combined organics evaporated and the residue was purified by silica gel column chromatography with hexane/ethylacetate (4:1) as an eluent to obtain pure phosphoester product $72(0.85 \mathrm{~g}, 36 \%) . \mathrm{KMnO}_{4}$ staining system was used for TLC. 


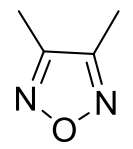

69

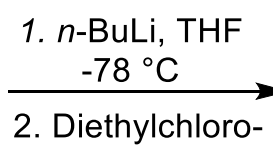

-phosphate

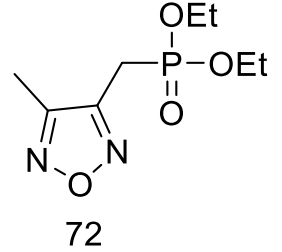

72

${ }^{1}$ H NMR: (400 MHz, $\left.\mathrm{CDCl}_{3}\right): \delta 4.12(\mathrm{~m}, 4 \mathrm{H}), 3.32(\mathrm{~s}, 1 \mathrm{H}), 3.27$ (s, 1H), 2.45 (s, 3H), 1.31 $(\mathrm{t}, J=11.6 \mathrm{~Hz}, 6 \mathrm{H})$.

${ }^{13}$ C NMR: (100 MHz, $\left.\mathrm{CDCl}_{3}\right): \delta 151.22,151.20,147.52,147.46,62.92,62.86,22.70$, $21.28,16.31,16.25,8.22$.

N-(4H-1,2,4-triazol-4-yl)-3,4-dihydronaphthalen-1(2H)-imine (74):

A mixture of 1-tetralone $\mathbf{5 0}(1.0 \mathrm{~g}, 6.8 \mathrm{mmol})$ and 4-amino-4H-1,2,4-tirazole $\mathbf{7 3}$ $(0.57 \mathrm{~g}, 6.8 \mathrm{mmol})$ was heated at $100{ }^{\circ} \mathrm{C}$ for $2 \mathrm{~h}$ in presence of molecular sieves $\left(4 \mathrm{~A}^{\circ}\right)$. The resulting reaction residue was purified by silica gel column chromatography with chloroform/methanol (9:1) to obtain pure hydrazone $74(1.2 \mathrm{~g}, 83 \%)$ as a red colored solid product.<smiles>O=C1CCCc2ccccc21</smiles>

50

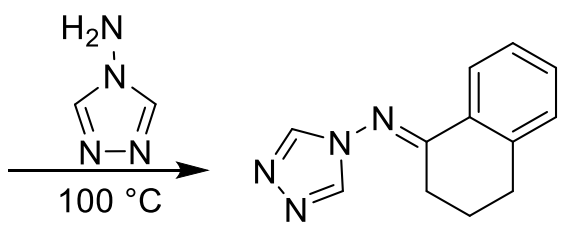

74

${ }^{1}$ H NMR: (400 MHz, $\left.\mathrm{CDCl}_{3}\right): \delta 8.27(\mathrm{~m}, 3 \mathrm{H}), 7.47(\mathrm{~m}, 1 \mathrm{H}), 7.33(\mathrm{t}, J=7.2 \mathrm{~Hz}, 1 \mathrm{H}), 7.27$ $(\mathrm{d}, J=8.0 \mathrm{~Hz}, 1 \mathrm{H}), 2.94(\mathrm{t}, J=6.0,2 \mathrm{H}), 2.68(\mathrm{t}, J=6.4,2 \mathrm{H}), 1.98(\mathrm{~m}, J=6.4,2 \mathrm{H})$.

${ }^{13}$ C NMR: (100 MHz, $\left.\mathrm{CDCl}_{3}\right): \delta 172.69,142.05,139.77,132.57,129.87,129.17,126.92$, $126.36,29.38,28.41,22.35$.

5,8-Dimethyl- $N$-(4H-1,2,4-triazol-4-yl)-3,4-dihydronaphthalen-1(2H)-imine (78): 
A mixture of 5,8-dimethyl-1-tetralone 77 (20 mg, $0.11 \mathrm{mmol})$ and 4-amino-4H1,2,4-tirazole $73(20 \mathrm{mg}, 0.22 \mathrm{mmol})$ was heated at $100{ }^{\circ} \mathrm{C}$ for $3 \mathrm{~h}$ in presence scandium triflate $(15 \mathrm{~mol} \%)$. The resulting reaction residue was purified by silica gel column chromatography with chloroform/methanol (9:1) to obtain corresponding pure hydrazone $78(11 \mathrm{mg}, 40 \%)$ as a solid product.

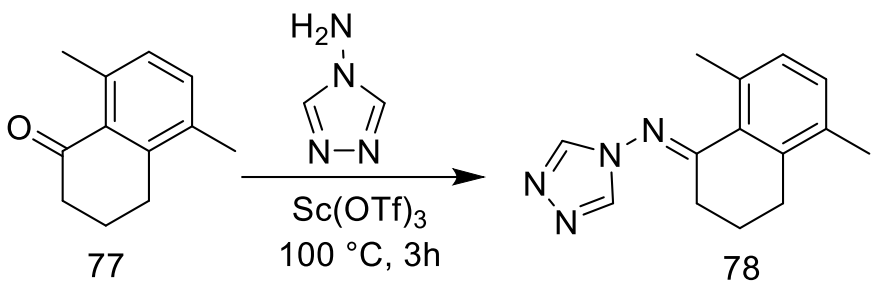

${ }^{1}$ H NMR: $\left(400 \mathrm{MHz}, \mathrm{CDCl}_{3}\right): \delta 8.22(\mathrm{~s}, 2 \mathrm{H}), 7.21(\mathrm{~d}, J=7.6 \mathrm{~Hz}, 1 \mathrm{H}), 7.7 .11(\mathrm{~d}, J=8.0$ $\mathrm{Hz}, 1 \mathrm{H}), 2.77(\mathrm{t}, J=6.4 \mathrm{~Hz}, 2 \mathrm{H}), 2.65(\mathrm{t}, J=6.4 \mathrm{~Hz}, 2 \mathrm{H}), 2.60(\mathrm{~s}, 3 \mathrm{H}), 2.29(\mathrm{~s}, 3 \mathrm{H}), 1.93$ $(\mathrm{m}, J=6.4 \mathrm{~Hz}, 2 \mathrm{H})$.

${ }^{13}$ C NMR: (100 MHz, $\left.\mathrm{CDCl}_{3}\right): \delta 176.36,141.13,139.61,136.76,133.60,132.76,130.22$, $129.73,28.82,26.71,23.80,21.75,19.61$.

\section{3-(3-((4H-1,2,4-triazol-4-yl)imino)cyclohex-1-en-1-yl)-5-methyl-2-(1-} (methylamino)ethylidene)-2,3,8,9-tetrahydro-1H-cyclopenta[a]naphthalene-1,6(7H)dione (75):

A mixture of dimer compound $46(0.1 \mathrm{~g}, 0.27 \mathrm{mmol})$ and 4-amino-4H-1,2,4tirazole 73 (45 mg, $0.54 \mathrm{mmol})$ was heated at $100{ }^{\circ} \mathrm{C}$ for $1 \mathrm{~h}$. The resulting reaction residue was purified by silica gel column chromatography with chloroform/methanol $(9: 1)$ to obtain pure mono-hydrazone $75(83 \mathrm{mg}, 71 \%)$ as a red colored solid product (both isomers $E \& Z$ in 3:1 ratio). 


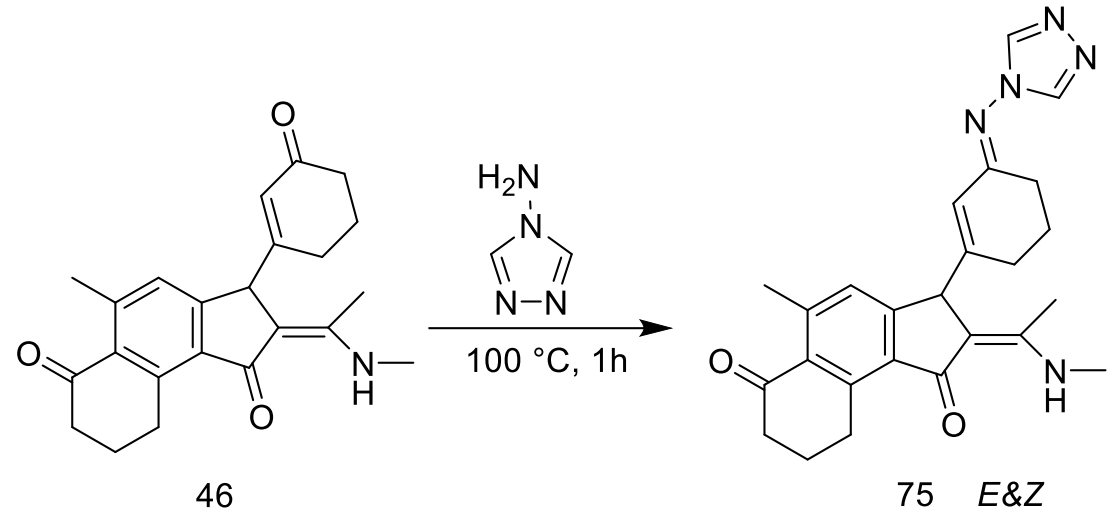

${ }^{1}$ H NMR: (400 MHz, $\left.\mathrm{CDCl}_{3}\right): \delta 10.90(\mathrm{~m}, 1 \mathrm{H}), 8.27$ and $8.22(\mathrm{~s}, 2 \mathrm{H}), 7.06$ and $6.86(\mathrm{~s}$, $1 \mathrm{H}), 6.68$ and $6.35(\mathrm{~s}, 1 \mathrm{H}), 4.47$ and $4.27(\mathrm{~s}, 1 \mathrm{H}), 3.64(\mathrm{~m}, 2 \mathrm{H}), 3.04(\mathrm{~d}, J=5.6,3 \mathrm{H}), 2.69$ (m, 5H), $2.44(\mathrm{~m}, 2 \mathrm{H}), 2.07(\mathrm{~s}, 3 \mathrm{H}), 2.12(\mathrm{~m}, 2 \mathrm{H}), 2.01(\mathrm{~m}, 2 \mathrm{H}), 1.78(\mathrm{~m}, 2 \mathrm{H})$.

${ }^{13}$ C NMR: (100 MHz, $\left.\mathrm{CDCl}_{3}\right): \delta 200.07,199.99,190.52,190.39,173.18,173.08,166.69$, $161.70,161.57,161.30,151.15,150.57,145.15,145.06,144.95,144.87,139.90,139.70$ $135.46,131.82,131.68,125.93,125.70,124.06,123.82,115.44,105.44,105.41,51.34$ $50.97,41.00,31.49,29.61,27.05,26.34,25.42,24.90,24.16,24.01,22.54,22.50,22.19$, $21.97,15.43,15.32$.

HRMS: (LC/MS, MeOH) $m / z 430.22\left(\mathrm{MH}^{+}\right)$.

6-((4H-1,2,4-triazol-4-yl)imino)-3-(3-((4H-1,2,4-triazol-4-yl)imino)cyclohex-1-en-1yl)-5-methyl-2-(1-(methylamino)ethylidene)-2,3,6,7,8,9-hexahydro-1 $H$ cyclopenta[a]naphthalen-1-one (76):

A mixture of dimer compound $46(1.0 \mathrm{~g}, 2.75 \mathrm{mmol})$ and 4-amino-4H-1,2,4tirazole $73(0.92 \mathrm{~g}, 10.90 \mathrm{mmol})$ was heated at $100{ }^{\circ} \mathrm{C}$ for $3 \mathrm{~h}$ in presence of scandium triflate $(0.2 \mathrm{~g}, 15$ mole percent). The resulting reaction residue was purified by silica gel 
column chromatography with chloroform/methanol (9:1) to obtain pure bis-hydrazone 76 $(0.4 \mathrm{~g}, 30 \%)$ along with the monohydrazone compound $75(0.41 \mathrm{~g}, 35 \%)$.

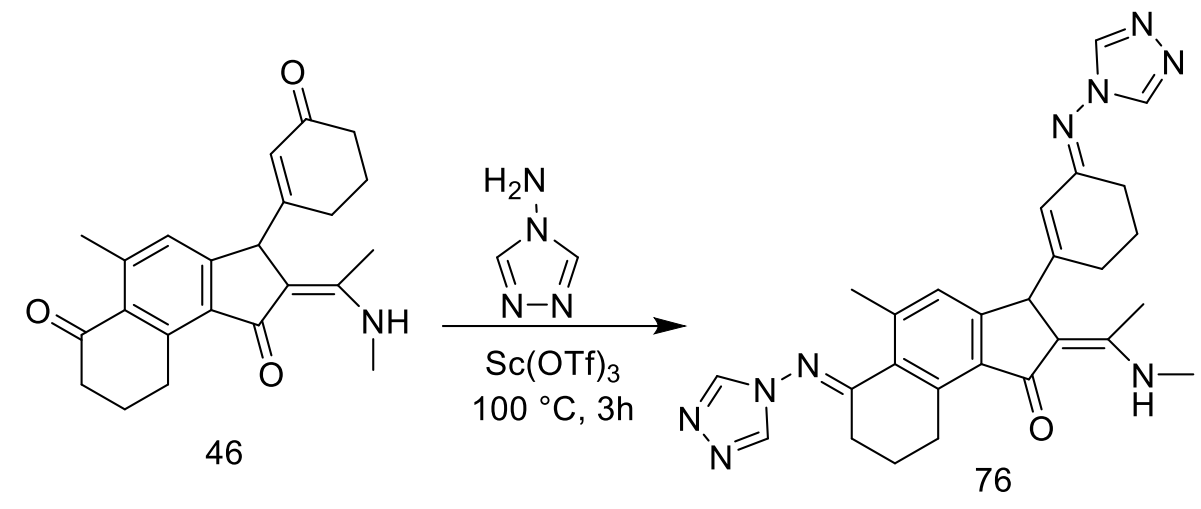

${ }^{1} \mathbf{H}$ NMR: (400 MHz, $\left.\mathrm{CDCl}_{3}\right): \delta 10.93(\mathrm{~m}, 1 \mathrm{H}), 8.24(\mathrm{t}, 4 \mathrm{H}), 7.17$ and $6.97(\mathrm{~s}, 1 \mathrm{H}), 6.70$ and $6.36(\mathrm{~s}, 1 \mathrm{H}) 4.50$ and $4.29(\mathrm{~s}, 1 \mathrm{H}), 3.63(\mathrm{~m}, 1 \mathrm{H}), 3.50(\mathrm{~m}, 1 \mathrm{H}), 3.04(\mathrm{~m}, 3 \mathrm{H}), 2.71(\mathrm{~m}$, 2H), $2.80(\mathrm{~s}, 3 \mathrm{H}) 2.45(\mathrm{~m}, 2 \mathrm{H}), 2.09(\mathrm{~s}, 3 \mathrm{H}), 1.90(\mathrm{~m}, 4 \mathrm{H}), 1.63(\mathrm{~m}, 2 \mathrm{H})$.

${ }^{13}$ C NMR: (100 MHz, $\left.\mathrm{CDCl}_{3}\right): \delta$ 190.20, 190.07, 175.24, 175.11, 173.10, 166.63, 161.97, $161.61,150.15,149.57,142.88,142.81,142.53,142.42,139.97,139.76,139.61,135.25$ $135.19,130.29,130.10,126.31,126.04,123.95,115.53,105.52,51.30,50.93,31.53,81$ $29.75,29.71,29.28,27.12,24.96,24.84,24.36,24.31,24.04,22.25,22.05,21.46,15.57$, $15.46,14.15$

HRMS: (LC/MS, MeOH) m/z $496.26\left(\mathrm{MH}^{+}\right)$.

6-((4H-1,2,4-triazol-4-yl)imino)-5-methyl-2-(1-(methylamino)ethylidene)-3-(3oxocyclohex-1-en-1-yl)-2,3,6,7,8,9-hexahydro-1H-cyclopenta[a]naphthalen-1-one (48):

To a solution of bis-hydrazone compound $76(0.1 \mathrm{~g}, 0.2 \mathrm{mmol})$ in $3 \mathrm{ml}$ of THF was added a solution of cupric chloride $(27 \mathrm{mg}, 0.2 \mathrm{mmol})$ in water $(4 \mathrm{ml})$ dropwise at $\mathrm{rt}$ and 
stirred for 10h (the reaction progress was carefully followed by TLC and quenched with ammonium hydroxide when TLC started forming dimer compound 46). The resulting reaction mixture was extracted with chloroform, washed with brine solution and dried over anhydrous magnesium sulfate. The residue formed on evaporation was purified by silica gel column chromatography with chloroform/methanol (9:1) to obtain pure product 48 (28 $\mathrm{mg}, 33 \%)$ as brown colored solid.

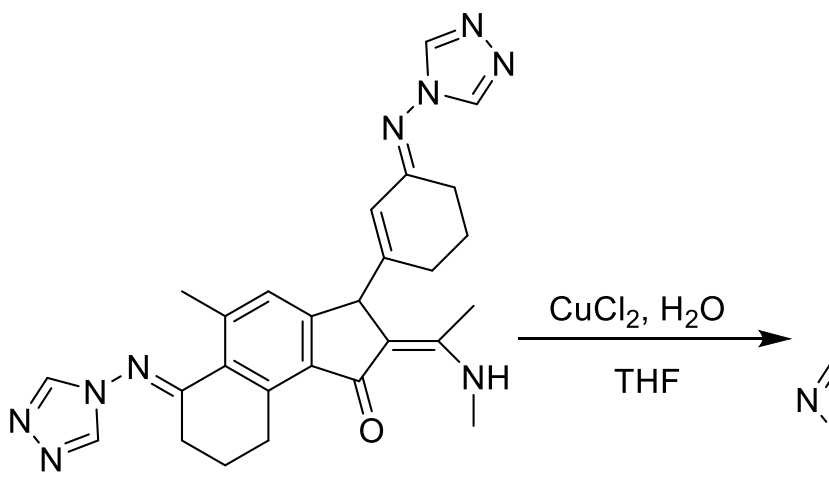

76

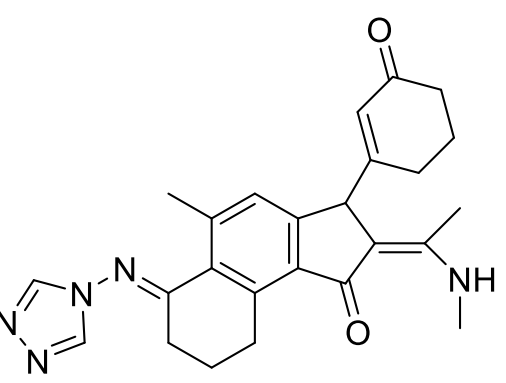

48

${ }^{1}$ H NMR: (400 MHz, $\left.\mathrm{CDCl}_{3}\right): \delta 10.90(\mathrm{~d}, J=5.2,1 \mathrm{H}), 8.23(\mathrm{~s}, 2 \mathrm{H}), 7.12(\mathrm{~s}, 1 \mathrm{H}), 6.32(\mathrm{~s}$, 1H), $4.39(\mathrm{~s}, 1 \mathrm{H}), 3.64-3.55(\mathrm{~m}, 1 \mathrm{H}), 3.51-3.43(\mathrm{~m}, 1 \mathrm{H}), 3.03(\mathrm{~d}, J=5.2,3 \mathrm{H}), 2.70(\mathrm{t}, J=$ 6.8, 2H), $2.65(\mathrm{~s}, 3 \mathrm{H}) 2.36(\mathrm{~m}, 2 \mathrm{H}), 2.02(\mathrm{~s}, 3 \mathrm{H}), 1.95(\mathrm{~m}, 2 \mathrm{H}), 1.82(\mathrm{~m}, 2 \mathrm{H}), 1.61(\mathrm{~m}, 2 \mathrm{H})$. ${ }^{13}$ C NMR: (100 MHz, $\left.\mathrm{CDCl}_{3}\right): \delta$ 199.63, 190.09, 175.22, 166.86, 161.98, 150.09, 142.72, $142.26,139.53,135.19,129.98,128.13,126.32,105.61,50.81,37.72,29.61,29.19,24.63$, $24.35,24.27,22.95,21.39,15.36$.

HRMS: (LC/MS, MeOH) $m / z 430.22\left(\mathrm{MH}^{+}\right)$.

Extraction of 4-(acetoxymethyl)-6,7a-dihydro-1H-spiro[cyclopenta[c]pyran-7,2'oxirane]-1,6-diyl bis(3-methylbutanoate) (Valtrate, 106): 
A finely grounded Centranthus ruber root $(100 \mathrm{~g})$ was stirred in ethanol $(800 \mathrm{ml})$ for overnight at rt. The thick paste of crude compound, obtained from vacuum filtration and evaporation of ethanol, was dissolved in chloroform and filtered. The residue collected from chloroform was purified by silica gel column chromatography with hexane/ethyl acetate $(4: 1)$ to obtain pure valtrate $(4.0 \mathrm{~g})$ as a green colored oil.

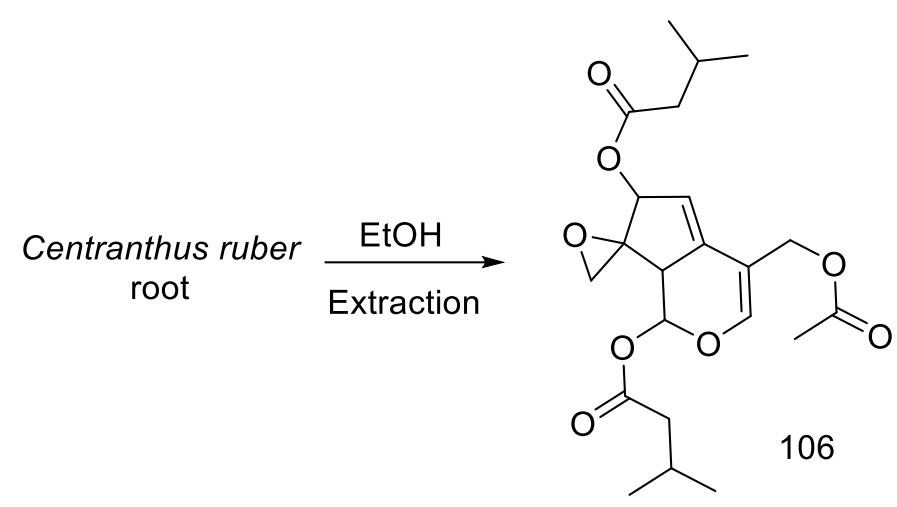

${ }^{1}$ H NMR: $\left(400 \mathrm{MHz}, \mathrm{CDCl}_{3}\right): \delta 6.69(\mathrm{~s}, 1 \mathrm{H}), 5.98(\mathrm{~d}, J=10.0 \mathrm{~Hz}, 1 \mathrm{H}), 5.86(\mathrm{t}, J=2.8$ $\mathrm{Hz}, 1 \mathrm{H}), 5.37(\mathrm{~d}, J=2.8 \mathrm{~Hz}, 1 \mathrm{H}), 4.70(\mathrm{dd}, J=28.4 \mathrm{~Hz}$ and $12.4 \mathrm{~Hz}, 2 \mathrm{H}), 3.43(\mathrm{dd}, J=10$ $\mathrm{Hz}$ and $2.45 \mathrm{~Hz}, 1 \mathrm{H}), 2.95(\mathrm{dd}, J=47.3 \mathrm{~Hz}$ and $4.7 \mathrm{~Hz}, 2 \mathrm{H}), 2.23(\mathrm{~m}, 2 \mathrm{H}), 2.21(\mathrm{~m}, 2 \mathrm{H})$, $2.08(\mathrm{~m}, 2 \mathrm{H}), 2.04(\mathrm{~s}, 3 \mathrm{H}), 0.97(\mathrm{~d}, J=6.5 \mathrm{~Hz}, 6 \mathrm{H}), 0.93(\mathrm{~d}, J=6.5 \mathrm{~Hz}, 6 \mathrm{H})$.

${ }^{13}$ C NMR: (100 MHz, $\left.\mathrm{CDCl}_{3}\right): \delta 172.45,170.8,170.25,148.45,140.9,117.8,108.4,92.6$, 83.0, 64.15, 60.8, 47.8, 43.35, 43.0, 25.8, 25.5, 22.3, 22.1, and 20.90.

LRMS: (LC/MS, MeOH) $m / z 423.1\left(\mathrm{MH}^{+}\right)$.

\section{(7-Formylcyclopenta[c]pyran-4-yl)methyl acetate (Baldrinal, 107):}

To a solution of valtrate $(7.3 \mathrm{~g}, 17.3 \mathrm{mmol})$ in chloroform $(20 \mathrm{ml})$ was added a solution of trifluroacetic acid $(15.7 \mathrm{~g}, 8.0 \mathrm{eq})$ in $35 \mathrm{ml}$ of chloroform and stirred at rt. The dark green color appeared in $10 \mathrm{~min}$ and the reaction mixture was diluted with chloroform 
(100 ml) by following the disappearance of valtrate spot on TLC. The $\mathrm{pH}$ of the resulting solution was adjusted to 7 by using a mixture of saturated aqueous $\mathrm{NaCl}$ and saturated aqueous $\mathrm{NaHCO}_{3}$ solutions. The yellow colored organic layers were collected by successive extractions with chloroform $(3 \times 100 \mathrm{ml})$, dried over anhydrous magnesium sulfate and evaporated. The collected residue was purified by silica gel column chromatography with hexane/ethyl acetate (7:3) as an eluent to obtain pure baldrinal compound $107(0.75 \mathrm{~g}, 20 \%)$ as a yellow colored solid.

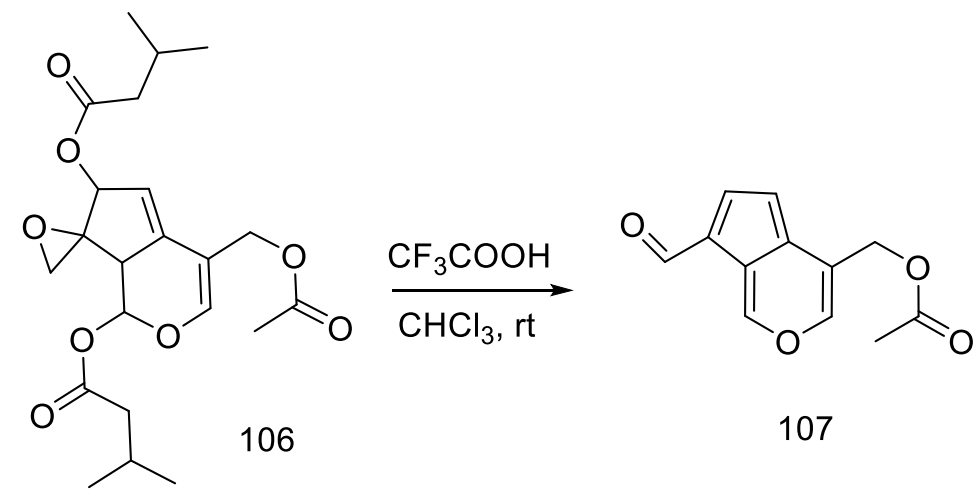

1H NMR: (400 MHz, $\left.\mathrm{CDCl}_{3}\right): \delta 9.94$ (s, 1H), 9.19 (s, 1H), 7.89 (s, 1H), 7.87 (d, J = 3.2 $\mathrm{Hz}, 1 \mathrm{H}), 6.61(\mathrm{dd}, J=3.2 \mathrm{~Hz}$ and $0.4 \mathrm{~Hz}, 1 \mathrm{H}), 5.26(\mathrm{~d}, J=0.8 \mathrm{~Hz}, 2 \mathrm{H}), 2.13(\mathrm{~s}, 3 \mathrm{H})$.

${ }^{13}$ C NMR: (100 MHz, $\left.\mathrm{CDCl}_{3}\right): \delta$ 185.0, 170.72, 150.78, 146.32, 133.90, 125.00, 123.12, $119.45,109.63,60.57,20.88$.

LRMS: (LC/MS, MeOH) $m / z 219.02\left(\mathrm{MH}^{+}\right)$.

\section{2-(Propyl imidazole)-cyclopenta[c]pyridine-4,7-dicarbaldehyde (110):}

To a solution of baldrinal $107(2.0 \mathrm{~g}, 9.15 \mathrm{mmol})$ in $5 \mathrm{ml}$ of chloroform was added 1-(3-aminopropyl)-imidazole $\mathbf{1 0 9}$ (2.3 g, $18.3 \mathrm{mmol})$ with vigorous stirring at rt. The dark yellow color of the baldrinal changed to dark red and the reaction was stopped by following 
the disappearance of baldrinal spot on TLC. The solvent was evaporated and the collected crude compound was purified by silica gel column chromatography with $15 \%$ methanol in chloroform to obtain a pure dialdehyde $\mathbf{1 1 0}(210 \mathrm{mg}, 8.2 \%)$ as a red colored solid.
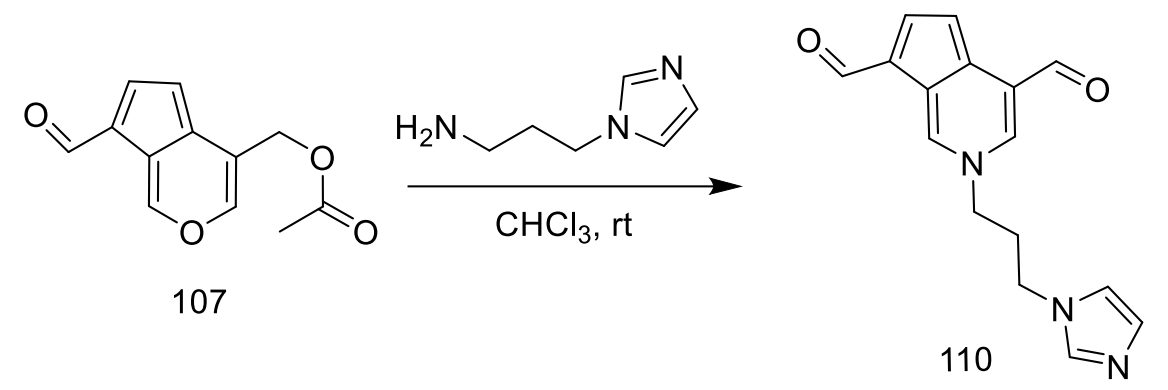

${ }^{1}$ H NMR: (400 MHz, $\left.\mathrm{CDCl}_{3}\right): \delta 10.23(\mathrm{~s}, 1 \mathrm{H}), 9.93(\mathrm{~s}, 1 \mathrm{H}), 9.02(\mathrm{~s}, 1 \mathrm{H}), 8.00(\mathrm{~d}, J=3.6$ $\mathrm{Hz}, 1 \mathrm{H}), 7.73(\mathrm{~d}, J=1.6 \mathrm{~Hz}, 1 \mathrm{H}), 7.59(\mathrm{~s}, 1 \mathrm{H}), 7.25(\mathrm{~s}, 1 \mathrm{H}), 7.16(\mathrm{~s}, 1 \mathrm{H}), 6.96(\mathrm{~s}, 1 \mathrm{H}), 4.28$ $(\mathrm{t}, J=6.8 \mathrm{~Hz}, 2 \mathrm{H}), 4.09(\mathrm{t}, J=6.8,2 \mathrm{H}), 2.53(\mathrm{~m}, J=6.8 \mathrm{~Hz}, 2 \mathrm{H})$.

${ }^{13}$ C NMR: (100 MHz, $\left.\mathrm{CDCl}_{3}\right): \delta 189.12,185.14,145.92,137.01,133.62,132.40,130.52$, $127.68,122.00,121.19,118.51,108.21,55.92,43.51,32.52$.

LRMS: (LC/MS, MeOH) $m / z 282.12\left(\mathrm{MH}^{+}\right)$.

\section{Synthesis of sulfenyl chloride:}

To a solution of sulfuryl chloride $(110.4 \mathrm{mg}, 0.82 \mathrm{mmol})$ in anhydrous methylene chloride (5 ml) was added another solution of 1,2-diethyldisulfide (100 mg, $0.82 \mathrm{mmol})$ in anhydrous methylene chloride $(3 \mathrm{ml})$ dropwise over a period of $10 \mathrm{~min}$ at $0{ }^{\circ} \mathrm{C}$. The resulting solution, containing freshly prepared sulfenyl chloride, kept at $-70{ }^{\circ} \mathrm{C}$ for further synthetic use.<smiles>CCSCl</smiles>

5-Ethylthio-2-(propyl imidazole)-cyclopenta[c]pyridine-4,7-dicarbaldehyde (111): 
To a solution of dialdehyde compound $110(210 \mathrm{mg}, 0.74 \mathrm{mmol})$ in a mixture of 1:1 ratio of anhydrous hexane and anhydrous methylene chloride $(20 \mathrm{ml})$ was added a freshly prepared and cooled $\left(-70^{\circ} \mathrm{C}\right)$ ethyl sulfenyl chloride $(7.5 \mathrm{ml}, 0.75 \mathrm{mmol})$ dropwise over a period of 30 min with vigorous stirring and frequent evacuation. The resulting reaction mixture was continued stirring for additional $30 \mathrm{~min}$ and brought back to $\mathrm{rt}$ gradually over a period of $100 \mathrm{~min}$. At this point, the red of the solution turned green. The resulting solution was partitioned between chloroform and saturated aqueous sodium bicarbonate. The combined organics were washed with brine solution, dried over anhydrous magnesium sulfate and evaporated. The organic residue was purified by silica gel column chromatography with $15 \%$ methanol in chloroform to obtain pure sulfenylated dialdehyde compound 111 (62 mg, 24\%) as a red colored solid.
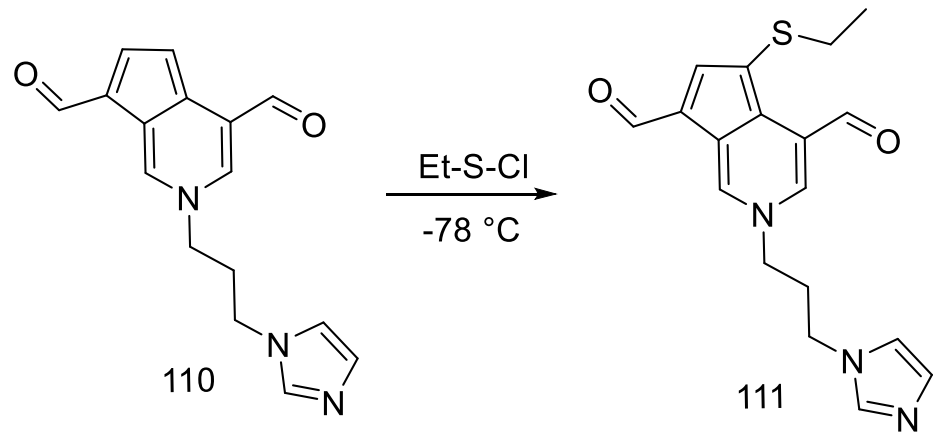

${ }^{1}$ H NMR: (400 MHz, $\left.\mathrm{CDCl}_{3}\right): \delta 11.65$ (s, 1H), 9.89 (s, 1H), 9.04 (d, J=1.6 Hz, 1H), 7.99 $(\mathrm{d}, J=1.6 \mathrm{~Hz}, 1 \mathrm{H}), 7.94(\mathrm{~s}, 1 \mathrm{H}), 7.53(\mathrm{~s}, 1 \mathrm{H}), 7.15(\mathrm{~s}, 1 \mathrm{H}), 6.96(\mathrm{~s}, 1 \mathrm{H}), 4.26(\mathrm{t}, J=6.8$ $\mathrm{Hz}, 2 \mathrm{H}), 4.08(\mathrm{t}, J=6.8 \mathrm{~Hz}, 2 \mathrm{H}), 2.78(\mathrm{~m}, J=7.2 \mathrm{~Hz}, 2 \mathrm{H}), 2.50(\mathrm{~m}, J=6.8 \mathrm{~Hz}, 2 \mathrm{H}), 1.23$ $(\mathrm{t}, J=7.2 \mathrm{~Hz}, 3 \mathrm{H})$.

${ }^{13}$ C NMR: (100 MHz, $\left.\mathrm{CDCl}_{3}\right): \delta$ 190.76, 184.62, 150.05, 136.99, 135.39, 133.66, 130.53, 128.73, 127.64, 123.73, 120.97, 118.50, 109.18, 56.21, 43.50, 32.62, 31.67, 14.96. 
LRMS: (LC/MS, MeOH) $m / z 342.13\left(\mathrm{MH}^{+}\right)$.

5-Ethylthio-2-(propyl imidazole)-cyclopenta[c]pyridine-4,7-dinitrone (104) and 1-(2(3-(1H-imidazol-1-yl)propyl)-5-(ethylthio)-7-formyl-2H-cyclopenta[c]pyridin-4-yl)$N$-(tert-butyl)methanimine oxide (112):

To a solution of 5-ethylthio-2-(propyl imidazole)-cyclopenta[c]pyridine-4,7dicarbaldehyde 111 (62 $\mathrm{mg}, 0.18 \mathrm{mmol})$ in pyridine $(3 \mathrm{ml})$ was added $N$ - $t$ butylhydroxylamine hydrochloride $(115 \mathrm{mg}, 0.9 \mathrm{mmol})$ and anhydrous magnesium sulfate (110 mg, $0.9 \mathrm{mmol})$ in a dried flask. The reaction mixture was stirred for $72 \mathrm{~h}$ at $35{ }^{\circ} \mathrm{C}$ under argon. The resulting reaction mixture was partitioned between a saturated solution of aqueous sodium carbonate and chloroform. The combined organics were washed with brine solution, dried over anhydrous magnesium sulfate and evaporated. The crude residue was purified by silica gel column chromatography with $\mathrm{CHCl}_{3} / \mathrm{MeOH} / \mathrm{N}\left(\mathrm{CH}_{3}\right)_{3}$ mixture (83:15:2) to obtain pure compounds of mono nitrone $\mathbf{1 1 2}(14 \mathrm{mg}, 19 \%)$ and dinitrone 104 (15 mg, 20\%) as a red colored solids. The pure compounds were washed with saturated sodium thiosulfate, before storage, to avoid oxidation in presence of air.
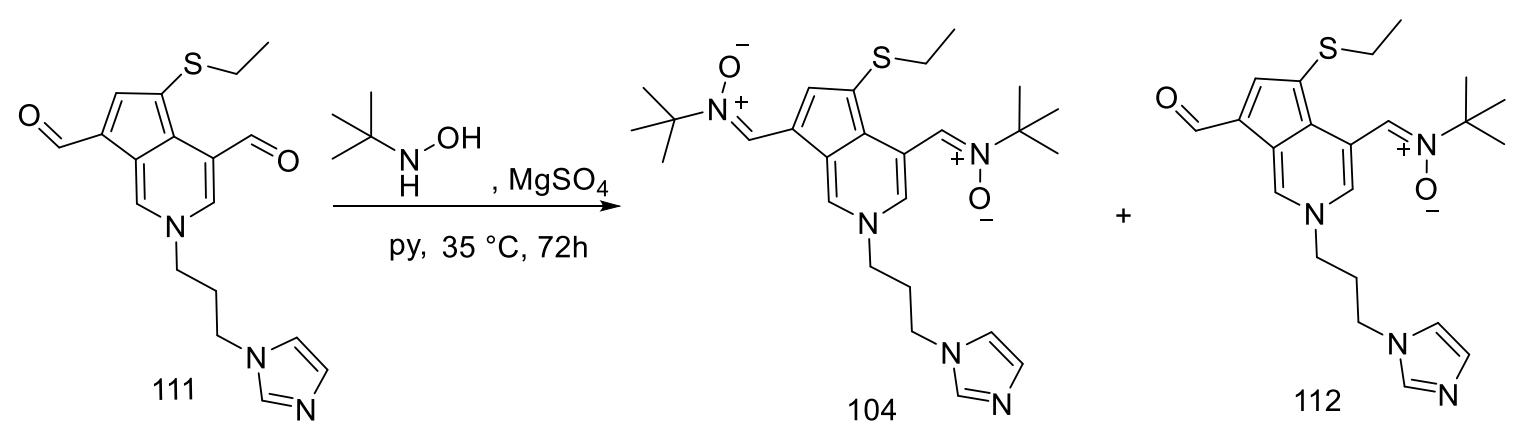
Mono nitrone data:

${ }^{1}$ H NMR: $\left(400 \mathrm{MHz}, \mathrm{CDCl}_{3}\right): \delta 10.08(\mathrm{~d}, J=1.6 \mathrm{~Hz}, 1 \mathrm{H}), 9.96(\mathrm{~s}, 1 \mathrm{H}), 9.84(\mathrm{~s}, 1 \mathrm{H}), 9.04$ $(\mathrm{d}, J=1.6 \mathrm{~Hz}, 1 \mathrm{H}), 7.82(\mathrm{~s}, 1 \mathrm{H}), 7.56(\mathrm{~s}, 1 \mathrm{H}), 7.12(\mathrm{~s}, 1 \mathrm{H}), 6.98(\mathrm{~s}, 1 \mathrm{H}), 4.25(\mathrm{t}, J=6.8$ $\mathrm{Hz}, 2 \mathrm{H}), 4.06(\mathrm{t}, J=6.8 \mathrm{~Hz}, 2 \mathrm{H}), 2.71(\mathrm{~m}, J=7.2 \mathrm{~Hz}, 2 \mathrm{H}), 2.51(\mathrm{~m}, J=6.8 \mathrm{~Hz}, 2 \mathrm{H}), 1.68$ $(\mathrm{s}, 12 \mathrm{H}), 1.18(\mathrm{t}, J=7.2 \mathrm{~Hz}, 3 \mathrm{H})$.

Dinitrone Data:

${ }^{1}$ H NMR: (400 MHz, $\left.\mathrm{CDCl}_{3}\right): \delta 9.99(\mathrm{~s}, 1 \mathrm{H}), 9.86(\mathrm{~s}, 1 \mathrm{H}), 9.84(\mathrm{~s}, 1 \mathrm{H}), 7.77(\mathrm{~s}, 1 \mathrm{H}), 7.67$ (s, 1H), $7.62(\mathrm{~s}, 1 \mathrm{H}), 7.10(\mathrm{~s}, 1 \mathrm{H}), 7.01(\mathrm{~s}, 1 \mathrm{H}), 4.20(\mathrm{t}, J=7.2 \mathrm{~Hz}, 2 \mathrm{H}), 4.04(\mathrm{t}, J=7.2 \mathrm{~Hz}$, 2H), $2.70(\mathrm{~m}, J=7.2 \mathrm{~Hz}, 2 \mathrm{H}), 2.48(\mathrm{~m}, J=7.2 \mathrm{~Hz}, 2 \mathrm{H}), 1.68(\mathrm{~s}, 12 \mathrm{H}), 1.63(\mathrm{~s}, 12 \mathrm{H}) 1.16$ (t, $J=7.2 \mathrm{~Hz}, 3 \mathrm{H})$.

${ }^{13}$ C NMR: (100 MHz, $\left.\mathrm{CDCl}_{3}\right): \delta$ 144.23, 137.24, 136.95, 131.21, 129.94, 126.03, 125.92, $124.85,118.77,118.48,111.44,106.56,71.69,67.84,55.94,43.66,32.18,29.34,28.54$ $28.40,14.74$

HRMS: (LC/MS, MeOH) $m / z 484.27\left(\mathrm{MH}^{+}\right)$.

\section{REFERENCES}

1. Ibrahim-Ouali, M.; Rocheblave, L., Recent advances in azasteroids chemistry. Steroids 2008, 73 (4), 375-407.

2. Sacher, J. R. Progress toward a total synthesis of the Lycopodium alkaloid lycopladine h. 2012.

3. Singh, H.; Parashar, V. V.; Padmanabhan, S.; Mathur, R. B., Azasteroids: syntheses and significance. Indian J. Pharm. Educ. 1970, 4 (2), 2-20.

4. Chamberlin, J. W.; Chaney, M. O.; Chen, S.; Demarco, P. V.; Jones, N. D.; Occolowitz, J. L., Structure of antibiotic A 25822 B, a novel nitrogen-containing C28sterol with antifungal properties. J Antibiot (Tokyo) 1974, 27 (12), 992-993. 
5. Ibrahim-Ouali, M., First total synthesis of 11-selena steroids. Tetrahedron Lett. 2009, 50 (14), 1607-1609.

6. Ibrahim-Ouali, M.; Romero, E., Synthesis and characterization of ( \pm )-13-hydroxy3,11-diaza steroids. Steroids 2012, 77 (1-2), 157-167.

7. Cachoux, F.; Ibrahim-Ouali, M.; Santelli, M., A new efficient synthesis of 11-aza steroids. Tetrahedron Lett. 2001, 42 (5), 843-845.

8. Gandhi, D.; Mehta, P., Dillenia indica Linn. and Dillenia pentagyna Roxb.: pharmacognostic, phytochemical and therapeutic aspects. J. Appl. Pharm. Sci. 2013, 3 (11), 134-142.

9. Burbiel, J.; Bracher, F., Azasteroids as antifungals. Steroids 2003, 68 (7-8), 587594.

10. Kedderis, G. L.; Argenbright, L. S.; Miwa, G. T., The role of metabolism and covalent binding in the cytotoxicity of a nitrogen-containing steroid toward rat hepatocytes. Toxicol. Appl. Pharmacol. 1990, 103 (2), 222-227.

11. Alauddin, M.; Martin-Smith, M., Biological activity in steroids possessing nitrogen atoms. I. Synthetic nitrogenous steroids. J. Pharm. Pharmacol. 1962, 14, 325-349.

12. Singh, H.; Parashar, V. V.; Mathur, R. B.; Malhotra, R. K., Heterosteroids. Indian J. Pharm. 1972, 34 (1), 1-8.

13. Amory, J. K.; Kalhorn, T. F.; Page, S. T., Pharmacokinetics and pharmacodynamics of oral testosterone enanthate plus dutasteride for 4 weeks in normal men: implications for male hormonal contraception. J. Androl. 2008, 29 (3), 260-271.

14. Dwivedy, I.; Singh, A. K.; Singh, M. M.; Ray, S., Synthesis of novel 6-aza- $\beta$ - and 11-aza-C-homoestranes as antifertility agents. Steroids 1993, 58 (2), 69-73.

15. Sudduth, S. L.; Koronkowski, M. J., Finasteride: the first 5 alpha-reductase inhibitor. Pharmacotherapy 1993, 13 (4), 309-25; discussion 325-329.

16. Andriole, G. L.; Humphrey, P.; Ray, P.; Gleave, M. E.; Trachtenberg, J.; Thomas, L. N.; Lazier, C. B.; Rittmaster, R. S., Effect of the dual $5 \alpha$-reductase inhibitor dutasteride on markers of tumor regression in prostate cancer. J. Urol. (Hagerstown, MD, U. S.) 2004, $172(3), 915-919$.

17. Rabasseda, X., Dutasteride: a potent dual inhibitor of $5 \alpha$-reductase for benign prostatic hyperplasia. Drugs Today 2004, 40 (8), 649-661. 
18. Cadoni, C.; Gee, K. W., Complex interactions between the steroid derivative RU 5135 and the GABAA-receptor complex. Eur. J. Pharmacol., Mol. Pharmacol. Sect. 1992, $227(2), 147-151$.

19. Mohler, M. L.; Bohl, C. E.; Jones, A.; Coss, C. C.; Narayanan, R.; He, Y.; Hwang, D. J.; Dalton, J. T.; Miller, D. D., Nonsteroidal Selective Androgen Receptor Modulators (SARMs): Dissociating the Anabolic and Androgenic Activities of the Androgen Receptor for Therapeutic Benefit. J. Med. Chem. 2009, 52 (12), 3597-3617.

20. Chen, J.; Kim, J.; Dalton, J. T., Discovery and therapeutic promise selective androgen receptor modulators. Mol. Interventions 2005, 5 (3), 173-188.

21. Geyer, H.; Schanzer, W.; Thevis, M., Anabolic agents: recent strategies for their detection and protection from inadvertent doping. Br J Sports Med 2014, 48 (10), 820-826.

22. Mitchell, H. J.; Dankulich, W. P.; Hartman, G. D.; Prueksaritanont, T.; Schmidt, A.; Vogel, R. L.; Bai, C.; McElwee-Witmer, S.; Zhang, H. Z.; Chen, F.; Leu, C.-T.; Kimmel, D. B.; Ray, W. J.; Nantermet, P.; Gentile, M. A.; Duggan, M. E.; Meissner, R. S., Design, Synthesis, and Biological Evaluation of 16-Substituted 4-Azasteroids as TissueSelective Androgen Receptor Modulators (SARMs). J. Med. Chem. 2009, 52 (15), 45784581.

23. Robinson, A. J.; DeLucca, I.; Drummond, S.; Boswell, G. A., Steroidal nitrone inhibitors of 5 $\alpha$-reductase. Tetrahedron Lett. 2003, 44 (25), 4801-4804.

24. Garcia-Granados, A.; Lopez, P. E.; Melguizo, E.; Moliz, J. N.; Parra, A.; Simeo, Y.; Dobado, J. A., Epoxides, Cyclic Sulfites, and Sulfate from Natural Pentacyclic Triterpenoids: Theoretical Calculations and Chemical Transformations. J. Org. Chem. 2003, 68 (12), 4833-4844.

25. Sabale, P. M.; Prajapati, P.; Kalal, P. G.; Nagar, D. B., Azasteroids as promising neuromuscular blockers: a review. J. Appl. Pharm. Sci. 2012, 2 (11), 164-173, 10 pp.

26. Lee, C., Conformation, action, and mechanism of action of neuromuscular blocking muscle relaxants. Pharmacol. Ther. 2003, 98 (2), 143-169.

27. Nicholson, W. T.; Sprung, J.; Jankowski, C. J., Sugammadex: a novel agent for the reversal of neuromuscular blockade. Pharmacotherapy 2007, 27 (8), 1181-1188.

28. Papapetropoulos, S.; Singer, C., Botulinum toxin in movement disorders. Semin Neurol 2007, 27 (2), 183-194.

29. Raghavendra, T., Neuromuscular blocking drugs: discovery and development. $J . R$. Soc. Med. 2002, 95 (7), 363-367. 
30. Bowman, W. C.; Rodger, I. W.; Houston, J.; Marshall, R. J.; McIndewar, I., Structure:action relationships among some desacetoxy analogues of pancuronium and vecuronium in the anesthetized cat. Anesthesiology 1988, 69 (1), 57-62.

31. Denman, W. T.; Goudsouzian, N. G.; Gelb, C., Comparison of neuromuscular, cardiovascular, and histamine-releasing properties of doxacurium and pipecuronium. $J$. Clin. Anesth. 1996, 8 (2), 113-118.

32. England, A. J.; Panikkar, K.; Redai, I.; Haxby, E.; Gopinath, S.; Feldman, S. A., Is rocuronium an exception to the relation between onset and offset? A comparison with pipecuronium. Eur. J. Anaesthesiol. 1996, 13 (4), 385-388.

33. McKenzie, A. G., Prelude to pancuronium and vecuronium. Anaesthesia 2000, 55 (6), 551-556.

34. Storm-Mathisen, J.; Iversen, L. L., Uptake of [3H]-glutamic acid in excitatory nerve endings: light and electronmicroscopic observations in the hippocampal formation of the rat. Neuroscience 1979, 4 (9), 1237-1253.

35. Winfield, D. A.; Gatter, K. C.; Powell, T. P., An electron microscopic study of the types and proportions of neurons in the cortex of the motor and visual areas of the cat and rat. Brain 1980, 103 (2), 245-258.

36. Winfield, D. A.; Brooke, R. N.; Sloper, J. J.; Powell, T. P., A combined Golgielectron microscopic study of the synapses made by the proximal axon and recurrent collaterals of a pyramidal cell in the somatic sensory cortex of the monkey. Neuroscience 1981, 6 (7), 1217-1230.

37. Smialowska, M.; Szewczyk, B.; Wozniak, M.; Wawrzak-Wlecial, A.; Domin, H., Glial degeneration as a model of depression. Pharmacol. Rep. 2013, 65 (6), 1572-1579.

38. Petroff, O. A. C., GABA and glutamate in the human brain. Neuroscientist 2002, 8 (6), 562-573.

39. Mennerick, S.; Zeng, C.-M.; Benz, A.; Shen, W.; Izumi, Y.; Evers, A. S.; Covey, D. F.; Zorumski, C. F., Effects on $\gamma$-aminobutyric acid (GABA)A receptors of a neuroactive steroid that negatively modulates glutamate neurotransmission and augments GABA neurotransmission. Mol. Pharmacol. 2001, 60 (4), 732-741.

40. Covey, D. F.; Evers, A. S.; Mennerick, S.; Zorumski, C. F.; Purdy, R. H., Recent developments in structure-activity relationships for steroid modulators of GABAA receptors. Brain Res. Rev. 2001, 37 (1-3), 91-97. 
41. Hosie, A. M.; Wilkins, M. E.; da Silva, H. M. A.; Smart, T. G., Endogenous neurosteroids regulate GABAAreceptors through two discrete transmembrane sites. Nature (London, U. K.) 2006, 444 (7118), 486-489.

42. Kelley, S. P.; Alan, J. K.; O'Buckley, T. K.; Mennerick, S.; Krishnan, K.; Covey, D. F.; Leslie Morrow, A., Antagonism of neurosteroid modulation of native $\gamma$-aminobutyric acid receptors by $(3 \alpha, 5 \alpha)$-17-phenylandrost-16-en-3-ol. Eur. J. Pharmacol. 2007, 572 (23), 94-101.

43. Aoki, S.; Watanabe, Y.; Sanagawa, M.; Setiawan, A.; Kotoku, N.; Kobayashi, M., Cortistatins A, B, C, and D, anti-angiogenic steroidal alkaloids, from the marine sponge Corticium simplex. J. Am. Chem. Soc. 2006, 128 (10), 3148-3149.

44. Lee, H. M.; Nieto-Oberhuber, C.; Shair, M. D., Enantioselective Synthesis of (+)Cortistatin A, a Potent and Selective Inhibitor of Endothelial Cell Proliferation. J. Am. Chem. Soc. 2008, 130 (50), 16864-16866.

45. Czako, B.; Kurti, L.; Mammoto, A.; Ingber, D. E.; Corey, E. J., Discovery of Potent and Practical Antiangiogenic Agents Inspired by Cortistatin A. J. Am. Chem. Soc. 2009, 131 (25), 9014-9019.

46. Neumann, H. C.; Potts, G. O.; Ryan, W. T.; Stonner, F. W., Steroidal heterocycles.

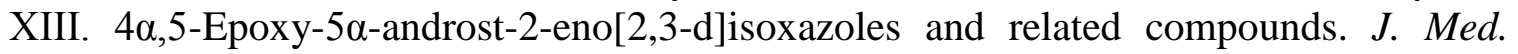
Chem. 1970, 13 (5), 948-951.

47. Dmowski, W. P., Danazol in the treatment of endometriosis and infertility. Prog. Clin. Biol. Res. 1982, 112 Pt B, 167-186.

48. Duncan, D. R.; Johnston, D., Synthesis of stanozolol-14C. J. Labelled Compd. Radiopharm. 1983, 20 (11), 1227-1228.

49. Resegotti, L.; Dolci, C.; Bertero, L.; Genovese, A.; Podesta, F.; Testa, D., Treatment of aplastic anaemia with methenolone, stanozolol and nandrolone. A report of 130 cases. Panminerva Med 1981, 23 (4), 243-248.

50. Gardner, R., On Performance-Enhancing Substances and the Unfair Advantage Argument. Journal of the Philosophy of Sport 1989, 16 (1), 59-73.

51. Vasaitis, T. S.; Bruno, R. D.; Njar, V. C. O., CYP17 inhibitors for prostate cancer therapy. J. Steroid Biochem. Mol. Biol. 2011, 125 (1-2), 23-31.

52. $\quad$ Brossard, D.; Zhang, Y.; Haider, S. M.; Sgobba, M.; Khalid, M.; Legay, R.; Duterque-Coquillaud, M.; Galera, P.; Rault, S.; Dallemagne, P.; Moslemi, S.; El Kihel, L., N-substituted Piperazinopyridylsteroid Derivatives as Abiraterone Analogues Inhibit 
Growth and Induce Pro-apoptosis in Human Hormone-independent Prostate Cancer Cell Lines. Chem. Biol. Drug Des. 2013, 82 (5), 620-629.

53. Courtney, K. D.; Taplin, M.-E., The evolving paradigm of second-line hormonal therapy options for castration-resistant prostate cancer. Curr. Opin. Oncol. 2012, 24 (3), 272-277.

54. Agrawal, A. A.; Petschenka, G.; Bingham, R. A.; Weber, M. G.; Rasmann, S., Toxic cardenolides: chemical ecology and coevolution of specialized plant-herbivore interactions. New Phytol. 2012, 194 (1), 28-45.

55. Malcolm, S. B., Milkweeds, monarch butterflies and the ecological significance of cardenolides. Chemoecology 1995, 5/6 (3/4), 101-117.

56. Kamboj, A.; Rathour, A.; Kaur, M., Bufadienolides and their medicinal utility: a review. Int. J. Pharm. Pharm. Sci. 2013, 5 (4), 20-27.

57. Ponnusamy, S.; Haldar, S.; Mulani, F.; Zinjarde, S.; Thulasiram, H.; RaviKumar, A., Gedunin and azadiradione: human pancreatic alpha-amylase inhibiting limonoids from neem (Azadirachta indica) as anti-diabetic agents. PLoS One 2015, 10 (10), e0140113/1e0140113/19.

58. Kushwaha, P.; Khedgikar, V.; Haldar, S.; Gautam, J.; Mulani, F. A.; Thulasiram, H. V.; Trivedi, R., Azadirachta indica triterpenoids promote osteoblast differentiation and mineralization in vitro and in vivo. Bioorg. Med. Chem. Lett. 2016, 26 (15), 3719-3724.

59. Nanduri, S.; Thunuguntla, S. S. R.; Nyavanandi, V. K.; Kasu, S.; Kumar, P. M.; Ram, P. S.; Rajagopal, S.; Kumar, R. A.; Deevi, D. S.; Rajagopalan, R.; Venkateswarlu, A., Biological investigation and structure-activity relationship studies on azadirone from Azadirachta indica A. Juss. Bioorg. Med. Chem. Lett. 2003, 13 (22), 4111-4115.

60. Singh, R.; Mishra, V.; Pandeti, S.; Palit, G.; Barthwal, M. K.; Pandey, H. P.; Narender, T., Cytoprotective and Anti-secretory Effects of Azadiradione Isolated from the Seeds of Azadirachta indica (neem) on Gastric Ulcers in Rat Models. Phytother. Res. 2015, 29 (6), 910-916.

61. Gupta, S. C.; Francis, S. K.; Nair, M. S.; Mo, Y.-Y.; Aggarwal, B. B., Azadirone, a Limonoid Tetranortriterpene, Induces Death Receptors and Sensitizes Human Cancer Cells to Tumor Necrosis Factor-related Apoptosis-inducing Ligand (TRAIL) through a p53 Protein-independent Mechanism. J. Biol. Chem. 2013, 288 (45), 32343-32356.

62. Kong, Y.; Li, F.; Nian, Y.; Zhou, Z.; Chen, C.; Yang, R.; Qiu, M.-H., KHF16 is a Leading Structure from Cimicifuga foetida that Suppresses Breast Cancer Partially by Inhibiting the NF-kB Signaling Pathway. Theranostics 2016, 6 (6), 875-886. 
63. Kong, Y.; Chen, J.; Zhou, Z.; Xia, H.; Qiu, M.-H.; Chen, C., Cucurbitacin E induces cell cycle G2/M phase arrest and apoptosis in triple negative breast cancer. PLoS One 2014, 9 (7), e103760/1-e103760/8, 8 pp.

64. Shao, Y.; Harris, A.; Wang, M.; Zhang, H.; Cordell, G. A.; Bowman, M.; Lemmo, E., Triterpene Glycosides from Cimicifuga racemosa. J. Nat. Prod. 2000, 63 (7), 905-910.

65. Sakurai, N.; Kozuka, M.; Tokuda, H.; Mukainaka, T.; Enjo, F.; Nishino, H.; Nagai, M.; Sakurai, Y.; Lee, K.-H., Cancer preventive agents. Part 1: Chemopreventive potential of cimigenol, cimigenol-3,15-dione, and related compounds. Bioorg. Med. Chem. 2005, 13 (4), 1403-1408.

66. Bordet, T.; Buisson, B.; Michaud, M.; Drouot, C.; Galea, P.; Delaage, P.; Akentieva, N. P.; Evers, A. S.; Covey, D. F.; Ostuni, M. A.; Lacapere, J.-J.; Massaad, C.; Schumacher, M.; Steidl, E.-M.; Maux, D.; Delaage, M.; Henderson, C. E.; Pruss, R. M., Identification and characterization of cholest-4-en-3-one, oxime (TRO19622), a novel drug candidate for amyotrophic lateral sclerosis. J. Pharmacol. Exp. Ther. 2007, 322 (2), 709720.

67. Bordet, T.; Berna, P.; Abitbol, J.-L.; Pruss, R. M., Olesoxime (TRO19622): a novel mitochondrial-targeted neuroprotective compound. Pharmaceuticals 2010, 3, 345-368.

68. Ghanizadeh, A., Targeting mitochondria by olesoxime or complement 1q binding protein as a novel management for autism: a hypothesis. Mol. Syndromol. 2011, 2 (1), 5052.

69. Eckmann, J.; Clemens, L. E.; Eckert, S. H.; Hagl, S.; Yu-Taeger, L.; Bordet, T.; Pruss, R. M.; Muller, W. E.; Leuner, K.; Nguyen, H. P.; Eckert, G. P., Mitochondrial Membrane Fluidity is Consistently Increased in Different Models of Huntington Disease: Restorative Effects of Olesoxime. Mol. Neurobiol. 2014, 50 (1), 107-118.

70. Weber, J. J.; Ortiz, R. M. M.; Riess, O.; Nguyen, H. P.; Clemens, L. E., The calpainsuppressing effects of olesoxime in Huntington's disease. Rare Dis 2016, 4 (1), e1153778.

71. Lee, S.; La Cour, T. G.; Fuchs, P. L., Chemistry of Trisdecacyclic Pyrazine Antineoplastics: The Cephalostatins and Ritterazines. Chem. Rev. (Washington, DC, U. S.) 2009, 109 (6), 2275-2314.

72. Pettit, G. R.; Kamano, Y.; Dufresne, C.; Inoue, M.; Christie, N.; Schmidt, J. M.; Doubek, D. L., Antineoplastic agents. 165. Isolation and structure of the unusual Indian Ocean Cephalodiscus gilchristi components, cephalostatins 5 and 6. Can. J. Chem. 1989, 67 (10), 1509-1513.

73. Bhasin, S.; Jasuja, R., Selective androgen receptor modulators as function promoting therapies. Curr. Opin. Clin. Nutr. Metab. Care 2009, 12 (3), 232-240. 
74. Narayanan, R.; Mohler, M. L.; Bohl, C. E.; Miller, D. D.; Dalton, J. T., Selective androgen receptor modulators in preclinical and clinical development. Nucl. Recept. Signal 2008, 6 , e010.

75. Maximov, P. Y.; Lee, T. M.; Jordan, V. C., The discovery and development of selective estrogen receptor modulators (SERMs) for clinical practice. Curr. Clin. Pharmacol. 2013, 8 (2), 135-155.

76. Malkowicz, S. B., The role of diethylstilbestrol in the treatment of prostate cancer. Urology 2001, 58 (2 Suppl 1), 108-113.

77. Kim, S.; Kim, Y.-u.; Ma, E., Synthesis and 5 $\alpha$-reductase inhibitory activity of C21 steroids having 1,4-diene or 4,6-diene 20-ones and 4-azasteroid 20-oximes. Molecules 2012, 17 (1), 355-368.

78. Esposito, D.; Rathinasabapathy, T.; Poulev, A.; Komarnytsky, S.; Raskin, I., AktDependent Anabolic Activity of Natural and Synthetic Brassinosteroids in Rat Skeletal Muscle Cells. J. Med. Chem. 2011, 54 (12), 4057-4066.

79. Doorenbos, N. J.; Huang, C.-L., Steroids. IV. Synthesis of some 4-azacholestanes. J. Org. Chem. 1961, 26, 4548-4550.

80. Doorenbos, N. J.; Wu, M. T., Steroids. III. Synthesis of 3-aza-A-homocholestanes by the Beckmann and Schmidt rearrangements in polyphosphoric acid. J. Org. Chem. 1961, $26,2548-2549$.

81. Jacobs, T. L.; Brownfield, R. B., The introduction of oxygen and nitrogen into the B Ring of the steroid nucleus. J. Am. Chem. Soc. 1960, 82, 4033-4039.

82. Ma, S.; Lu, L., RhI-catalyzed bimolecular cyclization between two different 1,5bisallenes: a combinatorial one-step approach to heterosteroids and mechanistic implications. Chem. - Asian J. 2007, 2 (1), 199-204.

83. Kang, S.-K.; Baik, T.-G.; Kulak, A. N.; Ha, Y.-H.; Lim, Y.; Park, J., PalladiumCatalyzed Carbocyclization/Silastannylation and Distannylation of Bis(allenes). J. Am. Chem. Soc. 2000, 122 (46), 11529-11530.

84. Ogasawara, M.; Ikeda, H.; Nagano, T.; Hayashi, T., Chloroprene as a Source of Fine Chemicals: Palladium-Catalyzed Synthesis of Terminal Allenes. Org. Lett. 2001, 3 (16), 2615-2617.

85. Oumzil, K.; Ibrahim-Ouali, M.; Santelli, M., First total synthesis of 3-aza-11-thia1,3,5(10)-trieno steroids. Tetrahedron Lett. 2005, 46 (35), 5799-5801. 
86. Suennemann, H. W.; Hofmeister, A.; Magull, J.; de Meijere, A., An efficient access to novel enantiomerically pure steroidal $\delta$-amino acids. Chem. - Eur. J. 2006, 12 (32), 8336-8344.

87. Singh, R.; Panda, G., An overview of synthetic approaches for heterocyclic steroids. Tetrahedron 2013, 69 (14), 2853-2884.

88. Decker, H.; Klauser, O., On Papaverinium Bases. [machine translation]. Ber. Dtsch. chem. Ges. 1904, 37, 520-531.

89. Becker, D. A.; Anderson, F. E., III; McKibben, B. P.; Merola, J. S.; Glass, T. E., Oxocycloalkenyl isoxazolium anhydrobases: synthesis and reactivity studies. Synlett 1993, (11), 866-868.

90. Brunelle, D. J., Isoxazoles as $\beta$-diketone synthons. Selective anion formation on 3,5-dialkylisoxazoles. Tetrahedron Lett. 1981, 22 (38), 3699-3702.

91. Micetich, R. G., Lithiation of five-membered heteroaromatic compounds. Methyl substituted 1,2-azoles, oxadiazoles, and thiadiazoles. Can. J. Chem. 1970, 48 (13), 20062015.

92. Boigegrain, R.; Brodin, R.; Kan, J. P.; Olliero, D.; Bourguignon, J. J.; Worms, P. Pyridazine derivatives useful as ligands of muscarinic cholinergic receptors. US5461053A, 1995.

93. Biziere, K.; Wermuth, C. G.; Worms, P.; Bourguignon, J. J. Preparation of tricyclic pyridazine derivatives as cholinergic agonists. EP251937A1, 1988.

94. Warrington, B. H. Indenopyridazinones and benzocinnolinones. EP181145A2, 1986.

95. Coates, W. J.; McKillop, A., One-pot preparation of 6-substituted 3(2H)pyridazinones from ketones. Synthesis 1993, (3), 334-342.

96. Takagi, K.; Tanaka, M.; Morita, H.; Ogura, K.; Ishii, K.; Nakata, N.; Ozeki, M., Synthesis and analgesic activity of 4-amino-1,2-dihydro-5-(2-hydroxyphenyl)-3Hpyrazol-3-ones and 5-amino-6-(2-hydroxyphenyl)pyrimidin-4(3H)-ones. Eur. J. Med. Chem. 1987, 22 (3), 239-242.

97. Pitzele, B. S.; Moormann, A. E.; Gullikson, G. W.; Albin, D.; Bianchi, R. G.; Palicharla, P.; Sanguinetti, E. L.; Walters, D. E., Potential antisecretory antidiarrheals. 1. a2-Adrenergic aromatic aminoguanidine hydrazones. J. Med. Chem. 1988, 31 (1), 138144. 
98. Girgis, A. S.; Hosni, H. M.; Ahmed-Farag, I. S., A convenient regioselective synthesis of 6-amino-2-oxo-3,5-pyridinedicarbonitriles. Z. Naturforsch., B: Chem. Sci. 2003, 58 (7), 678-685.

99. Delgado, A.; Garcia, J. M.; Mauleon, D.; Minguillon, C.; Subirats, J. R.; Feliz, M.; Lopez, F.; Velasco, D., Synthesis and conformational analysis of 2-amino-1,2,3,4tetrahydro-1-naphthalenols. Can. J. Chem. 1988, 66 (3), 517-527.

100. Delgado, A.; Mauleon, D.; Rosell, G.; Granados, R., Synthesis and adrenergic properties of cyclic analogs of methoxamine: 2-amino-1-arylcyclohexanols and 2-amino1,2,3,4-tetrahydro-1-naphthalenols. Eur. J. Med. Chem. 1988, 23 (1), 31-38.

101. Takeda, N.; Imamoto, T., Use of cerium(III) chloride in the reactions of carbonyl compounds with organolithiums or Grignard reagents for the suppression of abnormal reactions: 1-butyl-1,2,3,4-tetrahydro-1-naphthol. Org. Synth. 1999, 76, 228-238.

102. Mino, T.; Fukui, S.; Yamashita, M., Hydrolysis of $\beta, \gamma$-Unsaturated Aldehyde Dimethylhydrazones with Copper Dichloride: A New Synthesis of Lavandulol. J. Org. Chem. 1997, 62 (3), 734-735.

103. Gerschman, R.; Gilbert, D. L.; Nye, S. W.; Dwyer, P.; Fenn, W. O., Oxygen poisoning and $\mathrm{x}$-irradiation: mechanism in common. Science (Washington, DC, $U$. S.) 1954, 119, 623-626.

104. Harman, D., Aging: a theory based on free radical and radiation chemistry. $J$ Gerontol 1956, 11 (3), 298-300.

105. Commoner, B.; Townsend, J.; Pake, G. E., Free radicals in biological materials. Nature (London, U. K.) 1954, 174, 689-691.

106. Pham-Huy, L. A.; He, H.; Pham-Huy, C., Free radicals, antioxidants in disease and health. Int. J. Biomed. Sci. (Monterey Park, CA, U. S.) 2008, 4 (2), 89-96.

107. Valko, M.; Rhodes, C. J.; Moncol, J.; Izakovic, M.; Mazur, M., Free radicals, metals and antioxidants in oxidative stress-induced cancer. Chem.-Biol. Interact. 2006, 160 (1), 1-40.

108. Valko, M.; Leibfritz, D.; Moncol, J.; Cronin, M. T. D.; Mazur, M.; Telser, J., Free radicals and antioxidants in normal physiological functions and human disease. Int $J$ Biochem Cell Biol 2007, 39 (1), 44-84.

109. Kovacic, P.; Jacintho, J. D., Mechanisms of carcinogenesis. Focus on oxidative stress and electron transfer. Curr. Med. Chem. 2001, 8 (7), 773-796. 
110. Ridnour, L. A.; Isenberg, J. S.; Espey, M. G.; Thomas, D. D.; Roberts, D. D.; Wink, D. A., Nitric oxide regulates angiogenesis through a functional switch involving thrombospondin-1. Proc. Natl. Acad. Sci. U. S. A. 2005, 102 (37), 13147-13152.

111. Valko, M.; Morris, H.; Mazur, M.; Rapta, P.; Bilton, R. F., Oxygen free radical generating mechanisms in the colon: do the semiquinones of vitamin $\mathrm{K}$ play a role in the etiology of colon cancer? Biochim. Biophys. Acta, Gen. Subj. 2001, 1527 (3), 161-166.

112. Weinstock, M., The pharmacotherapy of Alzheimer's disease based on the cholinergic hypothesis: an update. Neurodegeneration 1995, 4 (4), 349-356.

113. Jenner, P., Oxidative stress in Parkinson's disease. Ann. Neurol. 2003, 53 (Suppl. 3), S26-S38.

114. Flamm, E. S.; Demopoulos, H. B.; Seligman, M. L.; Poser, R. G.; Ransohoff, J., Free radicals in cerebral ischemia. Stroke 1978, 9 (5), 445-447.

115. Demopoulos, H. B., Basis of free radical pathology. Fed. Proc., Fed. Amer. Soc. Exp. Biol. 1973, 32 (8), 1859-1861.

116. Watson, B. D.; Busto, R.; Goldberg, W. J.; Santiso, M.; Yoshida, S.; Ginsberg, M. D., Lipid peroxidation in vivo induced by reversible global ischemia in rat brain. $J$. Neurochem. 1984, 42 (1), 268-74.

117. Cadenas, E.; Sies, H., The lag phase. Free Radical Res. 1998, 28 (6), 601-609.

118. Morin, D.; Hauet, T.; Spedding, M.; Tillement, J. P., Mitochondria as target for antiischemic drugs. Adv. Drug Delivery Rev. 2001, 49 (1-2), 151-174.

119. Babior, B. M., NADPH oxidase: an update. Blood 1999, 93 (5), 1464-1476.

120. Pandey, N. R.; Kaur, G.; Chandra, M.; Sanwal, G. G.; Misra, M. K., Enzymatic oxidant and antioxidants of human blood platelets in unstable angina and myocardial infarction. Int. J. Cardiol 2000, 76 (1), 33-38.

121. Halliwell, B., Generation of the superoxide radical during the peroxidatic oxidation of NADH by catalase at acid pH values. FEBS Lett. 1977, 80 (2), 291-293.

122. Lynch, D. V.; Thompson, J. E., Lipoxygenase-mediated production of superoxide anion in senescing plant tissue. FEBS Lett. 1984, 173 (1), 251-254.

123. Kulkarni, M.; Armstead, W. M., Superoxide generation links nociceptin/orphanin FQ (NOC/oFQ) release to impaired N-methyl-D-aspartate cerebrovasodilation after brain injury. Stroke 2000, 31 (8), 1990-1996. 
124. Clement, M.-V.; Sivarajah, S.; Pervaiz, S., Production of Intracellular Superoxide Mediates Dithiothreitol-Dependent Inhibition of Apoptotic Cell Death. Antioxid. Redox Signaling 2005, 7 (3 \& 4), 456-464.

125. Yu, B. P., Cellular defenses against damage from reactive oxygen species. Physiol. Rev. 1994, 74 (1), 139-162.

126. Valko, M.; Izakovic, M.; Mazur, M.; Rhodes, C. J.; Telser, J., Role of oxygen radicals in DNA damage and cancer incidence. Mol. Cell. Biochem. 2004, 266 (1\&2), 3756.

127. Liochev, S. I.; Fridovich, I., The role of O2.bul.- in the production of HO.bul.: in vitro and in vivo. Free Radical Biol. Med. 1994, 16 (1), 29-33.

128. Pastor, N.; Weinstein, H.; Jamison, E.; Brenowitz, M., A detailed interpretation of $\mathrm{OH}$ radical footprints in a TBP-DNA complex reveals the role of dynamics in the mechanism of sequence-specific binding. J. Mol. Biol. 2000, 304 (1), 55-68.

129. Aikens, J.; Dix, T. A., Perhydroxyl radical (HOO.bul.) initiated lipid peroxidation. The role of fatty acid hydroperoxides. J. Biol. Chem. 1991, 266 (23), 15091-15098.

130. Ghafourifar, P.; Cadenas, E., Mitochondrial nitric oxide synthase. Trends Pharmacol. Sci. 2005, 26 (4), 190-195.

131. Bergendi, L.; Benes, L.; Durackova, Z.; Ferencik, M., Chemistry, physiology and pathology of free radicals. Life Sci. 1999, 65 (18/19), 1865-1874.

132. Klatt, P.; Lamas, S., Regulation of protein function by S-glutathiolation in response to oxidative and nitrosative stress. Eur. J. Biochem. 2000, 267 (16), 4928-4944.

133. Carr, A. C.; McCall, M. R.; Frei, B., Oxidation of LDL by myeloperoxidase and reactive nitrogen species. Reaction pathways and antioxidant protection. Arterioscler., Thromb., Vasc. Biol. 2000, 20 (7), 1716-1723.

134. Genestra, M., Oxyl radicals, redox-sensitive signalling cascades and antioxidants. Cell. Signalling 2007, 19 (9), 1807-1819.

135. McCord, J. M.; Fridovich, I., Superoxide dismutase. Enzymic function for erythrocuprein (hemocuprein). J. Biol. Chem. 1969, 244 (22), 6049-6055.

136. Hack, V.; Schmid, D.; Breitkreutz, R.; Stahl-Henning, C.; Drings, P.; Kinscherf, R.; Taut, F.; Holm, E.; Droege, W., Cystine levels, cystine flux, and protein catabolism in cancer cachexia, HIV/SIV infection, and senescence. FASEB J. 1997, 11 (1), 84-92. 
137. De Mattia, G.; Bravi, M. C.; Laurenti, O.; Cassone-Faldetta, M.; Armiento, A.; Ferri, C.; Balsano, F., Influence of reduced glutathione infusion on glucose metabolism in patients with non-insulin-dependent diabetes mellitus. Metab., Clin. Exp. 1998, 47 (8), 993-997.

138. Parks, D. A.; Granger, D. N., Contributions of ischemia and reperfusion to mucosal lesion formation. Am. J. Physiol 1986, 250 (6 Pt 1), G749-53.

139. Collard, C. D.; Gelman, S., Pathophysiology, clinical manifestations, and prevention of ischemia-reperfusion injury. Anesthesiology 2001, 94 (6), 1133-1138.

140. Kasparova, S.; Brezova, V.; Valko, M.; Horecky, J.; Mlynarik, V.; Liptaj, T.; Vancova, O. g.; Ulicna, O. g.; Dobrota, D., Study of the oxidative stress in a rat model of chronic brain hypoperfusion. Neurochem. Int. 2005, 46 (8), 601-611.

141. Broughton, B. R. S.; Reutens, D. C.; Sobey, C. G., Apoptotic mechanisms after cerebral ischemia. Stroke 2009, 40 (5), e331-339.

142. Roth, J. M., Recombinant tissue plasminogen activator for the treatment of acute ischemic stroke. Proc (Bayl Univ Med Cent) 2011, 24 (3), 257-259.

143. Wardlaw, J. M.; Murray, V.; Berge, E.; del Zoppo, G.; Sandercock, P.; Lindley, R. L.; Cohen, G., Recombinant tissue plasminogen activator for acute ischemic stroke: an updated systematic review and meta-analysis. Lancet 2012, 379 (9834), 2364-2372.

144. El Hassan, I.; Lauricella, R.; Tuccio, B., Preparation of N-aryl-ketonitrone spin traps. Cent. Eur. J. Chem. 2006, 4 (2), 338-350.

145. Sun, Y.-Y.; Morozov, Y. M.; Yang, D.; Li, Y.; Dunn, R. S.; Rakic, P.; Chan, P. H.; Abe, K.; Lindquist, D. M.; Kuan, C.-Y., Synergy of combined tPA-edaravone therapy in experimental thrombotic stroke. PLoS One 2014, 9 (6), e98807/1-e98807/12, 12 pp.

146. Togashi, H.; Shinzawa, H.; Matsuo, T.; Takeda, Y.; Takahashi, T.; Aoyama, M.; Oikawa, K.; Kamada, H., Analysis of hepatic oxidative stress status by electron spin resonance spectroscopy and imaging. Free Radical Biol. Med. 2000, 28 (6), 846-853.

147. Karoui, H.; Clement, J.-L.; Rockenbauer, A.; Siri, D.; Tordo, P., Synthesis and structure of 5,5-diethoxycarbonyl-1-pyrroline N-oxide (DECPO). Application to superoxide radical trapping. Tetrahedron Lett. 2004, 45 (1), 149-152.

148. Villamena, F. A.; Zweier, J. L., Detection of Reactive Oxygen and Nitrogen Species by EPR Spin Trapping. Antioxid. Redox Signaling 2004, 6 (3), 619-629. 
149. Britigan, B. E.; Cohen, M. S.; Rosen, G. M., Detection of the production of oxygencentered free radicals by human neutrophils using spin trapping techniques: a critical perspective. J. Leukocyte Biol. 1987, 41 (4), 349-362.

150. Wargon, J. A.; Williams, E., Electron spin resonance studies of radical trapping in the radiolysis of organic liquids. I. Evidence for the primary formation of the methoxy radical in methanol. J. Amer. Chem. Soc. 1972, 94 (22), 7917-7918.

151. Iwamura, M.; Inamoto, N., Novel formation of nitroxide radicals by radical addition to nitrones. Bull. Chem. Soc. Jpn. 1967, 40 (3), 703.

152. Janzen, E. G.; Blackburn, B. J., Detection and identification of short-lived free radicals by electron spin resonance trapping techniques (spin trapping). Photolysis of organolead, -tin, and -mercury compounds. J. Amer. Chem. Soc. 1969, 91 (16), 4481-4490.

153. Janzen, E. G., Spin trapping. Accounts Chem. Res. 1971, 4 (1), 31-40.

154. Harbour, J. R.; Bolton, J. R., Superoxide formation in spinach chloroplasts. Electron spin resonance detection by spin trapping. Biochem. Biophys. Res. Commun. 1975, 64 (3), 803-807.

155. Floyd, R. A.; Kopke, R. D.; Choi, C.-H.; Foster, S. B.; Doblas, S.; Towner, R. A., Nitrones as therapeutics. Free Radical Biol. Med. 2008, 45 (10), 1361-1374.

156. Frejaville, C.; Karoui, H.; Tuccio, B.; Moigne, F. L.; Culcasi, M.; Pietri, S.; Lauricella, R.; Tordo, P., 5-(Diethoxyphosphoryl)-5-methyl-1-pyrroline N-oxide: A New Efficient Phosphorylated Nitrone for the in Vitro and in Vivo Spin Trapping of OxygenCentered Radicals. J. Med. Chem. 1995, 38 (2), 258-265.

157. Bacic, G.; Mojovic, M., EPR spin trapping of oxygen radicals in plants: a methodological overview. Ann. N. Y. Acad. Sci. 2005, 1048 (Biophysics from Molecules to Brain), 230-243.

158. Kourounakis, A. P.; Rekka, E. A.; Kourounakis, P. N., Effect of guaiazulene on some cytochrome $\mathrm{P} 450$ activities. Implication in the metabolic activation and hepatotoxicity of paracetamol. Arch. Pharm. (Weinheim, Ger.) 1997, 330 (1/2), 7-11.

159. Becker, D. A., Highly Sensitive Colorimetric Detection and Facile Isolation of Diamagnetic Free Radical Adducts of Novel Chromotropic Nitrone Spin Trapping Agents Readily Derived from Guaiazulene. J. Am. Chem. Soc. 1996, 118 (4), 905-906.

160. Liu, R.; Althaus, J. S.; Ellerbrock, B. R.; Becker, D. A.; Gurney, M. E., Enhanced oxygen radical production in a transgenic mouse model of familial amyotrophic lateral sclerosis. Ann. Neurol. 1998, 44 (5), 763-770. 
161. Becker, D. A., Diagnostic and therapeutic applications of azulenyl nitrone spin traps. Cell. Mol. Life Sci. 1999, 56 (7/8), 626-633.

162. Klivenyi, P.; Matthews, R. T.; Wermer, M.; Yang, L.; MacGarvey, U.; Becker, D. A.; Natero, R.; Beal, M. F., Azulenyl nitrone spin traps protect against MPTP neurotoxicity. Exp. Neurol. 1998, 152 (1), 163-166.

163. Buettner, G. R., The pecking order of free radicals and antioxidants: Lipid peroxidation, $\alpha$-tocopherol, and ascorbate. Arch. Biochem. Biophys. 1993, 300 (2), 535543.

164. Becker, D. A.; Ley, J. J.; Echegoyen, L.; Alvarado, R., Stilbazulenyl Nitrone (STAZN): A Nitronyl-Substituted Hydrocarbon with the Potency of Classical Phenolic Chain-Breaking Antioxidants. J. Am. Chem. Soc. 2002, 124 (17), 4678-4684.

165. Lapchak, P. A.; Schubert, D. R.; Maher, P. A., De-Risking of Stilbazulenyl Nitrone (STAZN), a Lipophilic Nitrone to Treat Stroke Using a Unique Panel of In Vitro Assays. Transl. Stroke Res. 2011, 2 (2), 209-217.

166. Ley, J. J.; Prado, R.; Wei, J. Q.; Bishopric, N. H.; Becker, D. A.; Ginsberg, M. D., Neuroprotective antioxidant STAZN protects against myocardial ischemia/reperfusion injury. Biochem. Pharmacol. 2008, 75 (2), 448-456.

167. Tawadros, P. S.; Powers, K. A.; Yang, I.; Becker, D. A.; Ginsberg, M. D.; Szaszi, K.; Kapus, A.; Rotstein, O. D., Stilbazulenyl nitrone decreases oxidative stress and reduces lung injury after hemorrhagic shock/resuscitation and LPS. Antioxid Redox Signal 2007, 9 (11), 1971-1977.

168. Belayev, L.; Becker, D. A.; Alonso, O. F.; Liu, Y.; Busto, R.; Ley, J. J.; Ginsberg, M. D., Stilbazulenyl nitrone, a novel azulenyl nitrone antioxidant: improved neurological deficit and reduced contusion size after traumatic brain injury in rats. J. Neurosurg. 2002, 96 (6), 1077-1083.

169. Ley, J. J.; Vigdorchik, A.; Belayev, L.; Zhao, W.; Busto, R.; Khoutorova, L.; Becker, D. A.; Ginsberg, M. D., Stilbazulenyl nitrone, a second-generation azulenyl nitrone antioxidant, confers enduring neuroprotection in experimental focal cerebral ischemia in the rat: Neurobehavior, histopathology, and pharmacokinetics. J. Pharmacol. Exp. Ther. 2005, 313 (3), 1090-1100.

170. Ohashi, H.; Tsurushima, T.; Ueno, T.; Fukami, H., Cerbinal, a pseudoazulene iridoid, as a potent antifungal compound isolated from Gardenia jasminoides Ellis. Agric. Biol. Chem. 1986, 50 (10), 2655-2657.

171. Frantz, M.-C.; Wipf, P., Mitochondria as a target in treatment. Environ. Mol. Mutagen. 2010, 51 (5), 462-475. 
172. Murphy, M. P.; Smith, R. A. J., Targeting antioxidants to mitochondria by conjugation to lipophilic cations. Annu. Rev. Pharmacol. Toxicol. 2007, 47, 629-656.

173. Hoye, A. T.; Davoren, J. E.; Wipf, P.; Fink, M. P.; Kagan, V. E., Targeting mitochondria. Acc. Chem. Res. 2008, 41 (1), 87-97.

174. Jiang, J.; Bakan, A.; Kapralov, A. A.; Ishara Silva, K.; Huang, Z.; Amoscato, A. A.; Peterson, J.; Krishna Garapati, V.; Saxena, S.; Bayir, H.; Atkinson, J.; Bahar, I.; Kagan, V. E., Designing inhibitors of cytochrome c/cardiolipin peroxidase complexes: mitochondria-targeted imidazole-substituted fatty acids. Free Radical Biol. Med. 2014, 71, 221-230.

175. Boyd, G. V., Pseudoazulenes. II. A tricyclic cyclopenta[b]thiapyran and some N analogs. J. Chem. Soc. 1959, 55-61.

176. Seitz, G.; Moddelmog, G.; Hoelzl, J., Cyclopenta[c]pyridines from baldrinal and homobaldrinal by reaction with primary amines. Arch. Pharm. (Weinheim, Ger.) 1985, 318 (10), 946-950.

177. Kanofsky, J. R.; Sima, P. D., Synthetic carotenoid derivatives prevent photosensitised killing of retinal pigment epithelial cells more effectively than lutein. Exp. Eye Res. 2006, 82 (5), 907-914.

178. Jin, H.; Kanthasamy, A.; Ghosh, A.; Anantharam, V.; Kalyanaraman, B.; Kanthasamy, A. G., Mitochondria-targeted antioxidants for treatment of Parkinson's disease: Preclinical and clinical outcomes. Biochim. Biophys. Acta, Mol. Basis Dis. 2014, 1842 (8), 1282-1294.

179. LaMattina, John L.; Suleske, R. T., $\alpha$-Amino acetals: 2,2-diethoxy-2-(4pyridyl)ethylamine. Organic synthesis. 1986, 64, 19-26. 
VITA

\title{
NAGARAJU BIRUDUKOTA
}

\author{
$2003-2006$ \\ B.Sc., Chemistry \\ Andhra University, Visakhapatnam, India \\ $2006-2008$ \\ M.Sc., Chemistry \\ Andhra University, Visakhapatnam, India \\ $2009-2010$ \\ Chemistry Lecturer \\ Sri Bharathi College, Eluru, India \\ $2010-2011$ \\ Lab Technician \\ Bhagavathi Ana Labs, Hyderabad, India \\ $2011-2016$ \\ Teaching Assistant \\ Florida International University \\ Miami, Florida, USA \\ $2011-2017$ \\ Doctoral Candidate \\ Florida International University \\ Miami, Florida, USA
}

\section{PRESENTATIONS}

Birudukota, Nagaraju; Becker, David A., "Synthesis of Pseudoazulenyl dinitrones: ROS radical scavengers", 250 ${ }^{\text {th }}$ ACS National Meeting \& Exposition, Boston, MA, United States, August 16-20, 2015. 